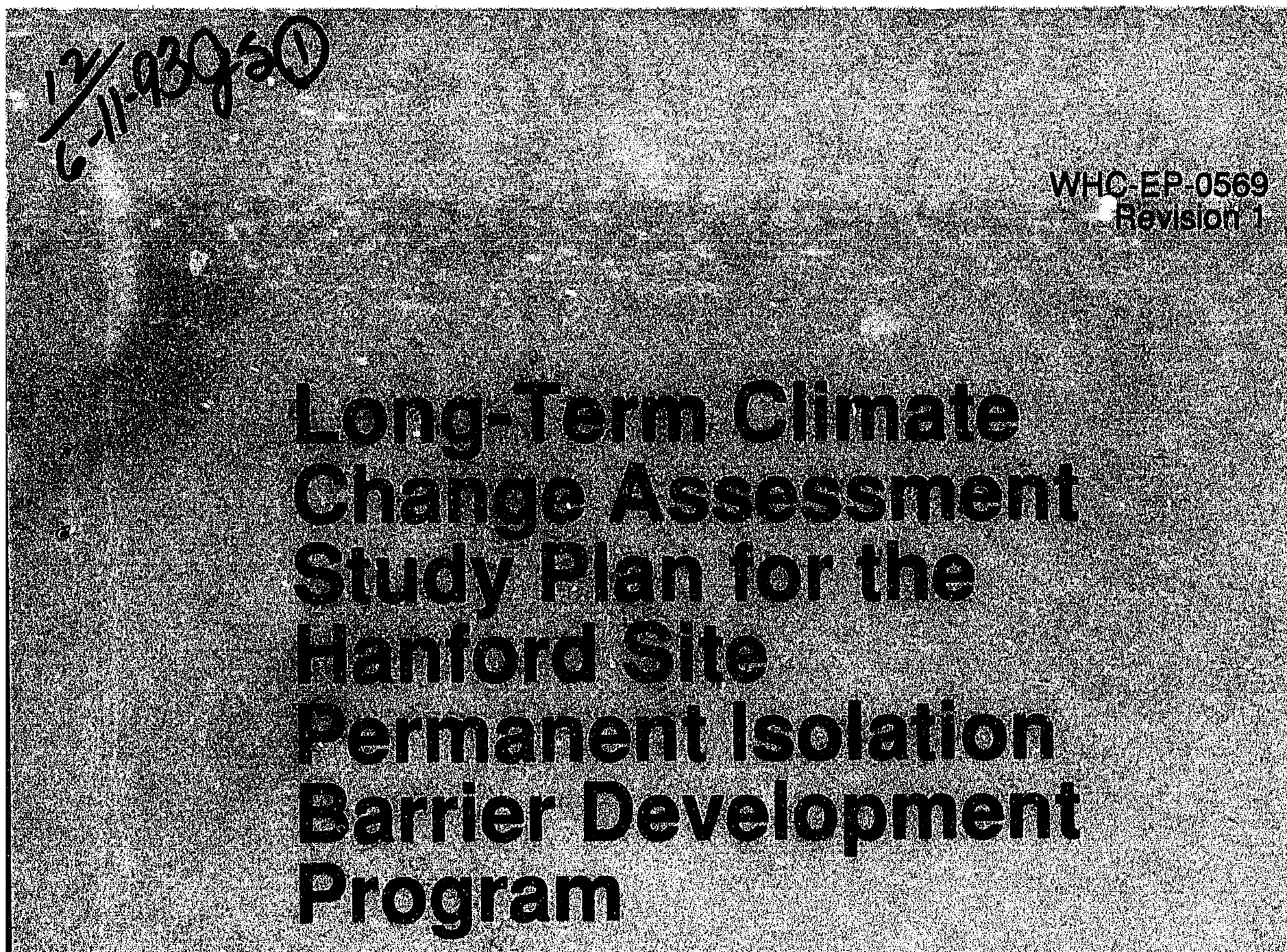

P. pared or the U.S. Daparment of ERergy Ot 0 o or To d hology Dovelempent

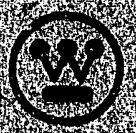

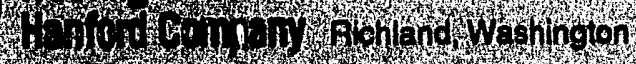

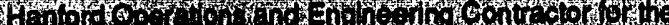

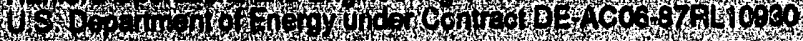




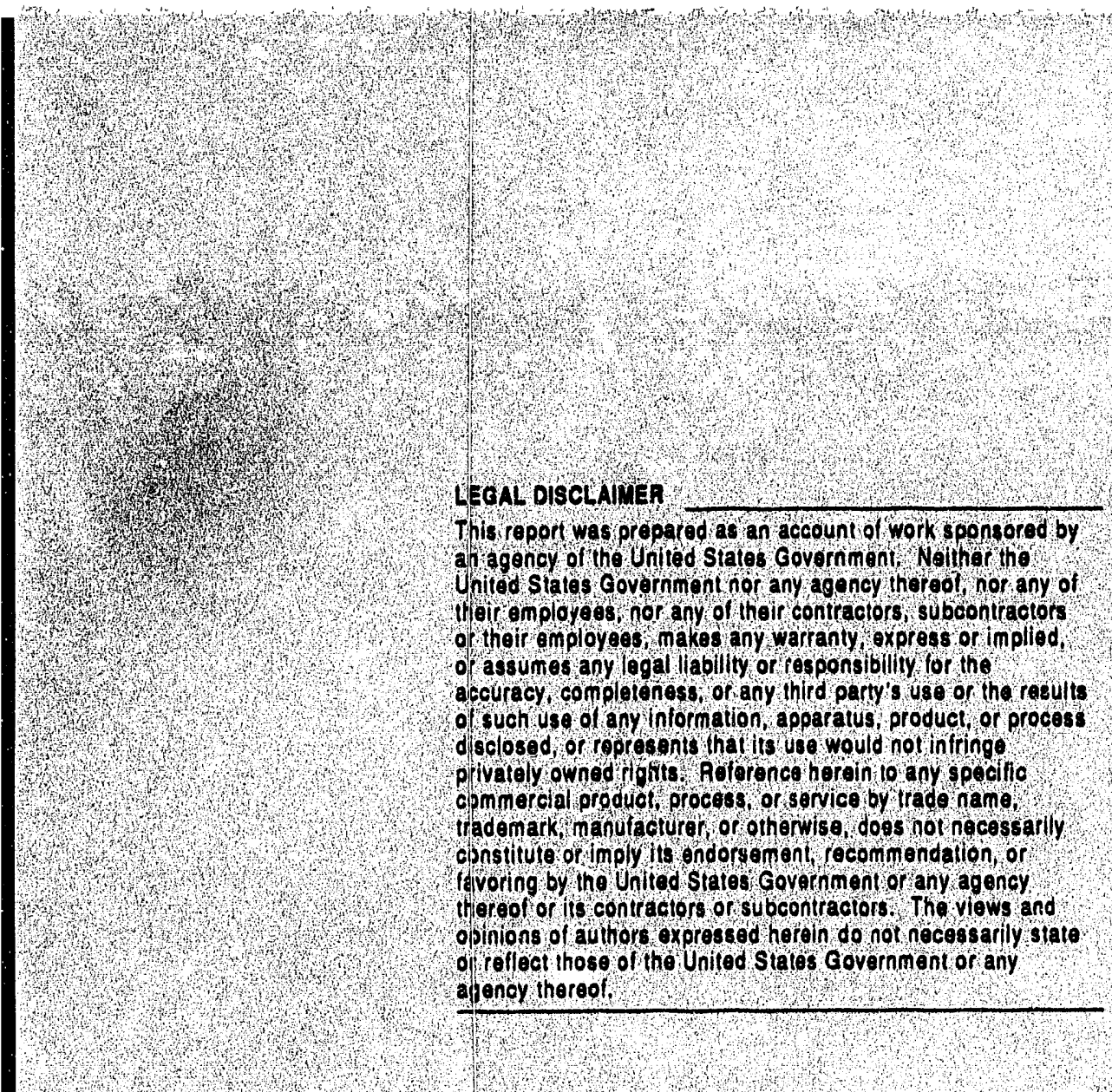

Tils report has been reproduced trom the best available copy. Alrailable in paper copy and microliche.

Aluailabio to the U.S. Depariment of Energy

and its contractors from

Olfice of Scientilic and Technical Inlormation

P. $0.80 \times 62$

Olk Rido TN 37891

(615) 576.840

Available to the oublic from the US. Department of Commerce Nitional Technical Information Service

5 is 5 Port Royal Road

Springfield VA 2216

(703) 487.4650

printod in tho Unitod stato of Amfica

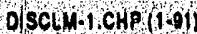


WHC-EP-0569

Revision 1

UC-510, 702

\section{Long-Term Climate Change Assessment Study Plan for the Hanford Site Permanent Isolation Barrier Development Program}

K. L. Petersen

Westinghouse Hanford Company

J. C. Chatters

Pacific Northwest Laboratory

W. J. Waugh

Chem-Nuclear Geotech, Inc.

Grand Junction, Colorado

Date Published

May 1993

Prepared for the U.S. Department of Energy Office of Technology Development

(2) Westinghouse $\begin{aligned} & \text { P.O. Box } 1970 \\ & \text { Hanford Company }\end{aligned}$

Hanford Operations and Engineering Contractor for the

U.S. Department of Energy under Contract DE-AC06-87RL10930 


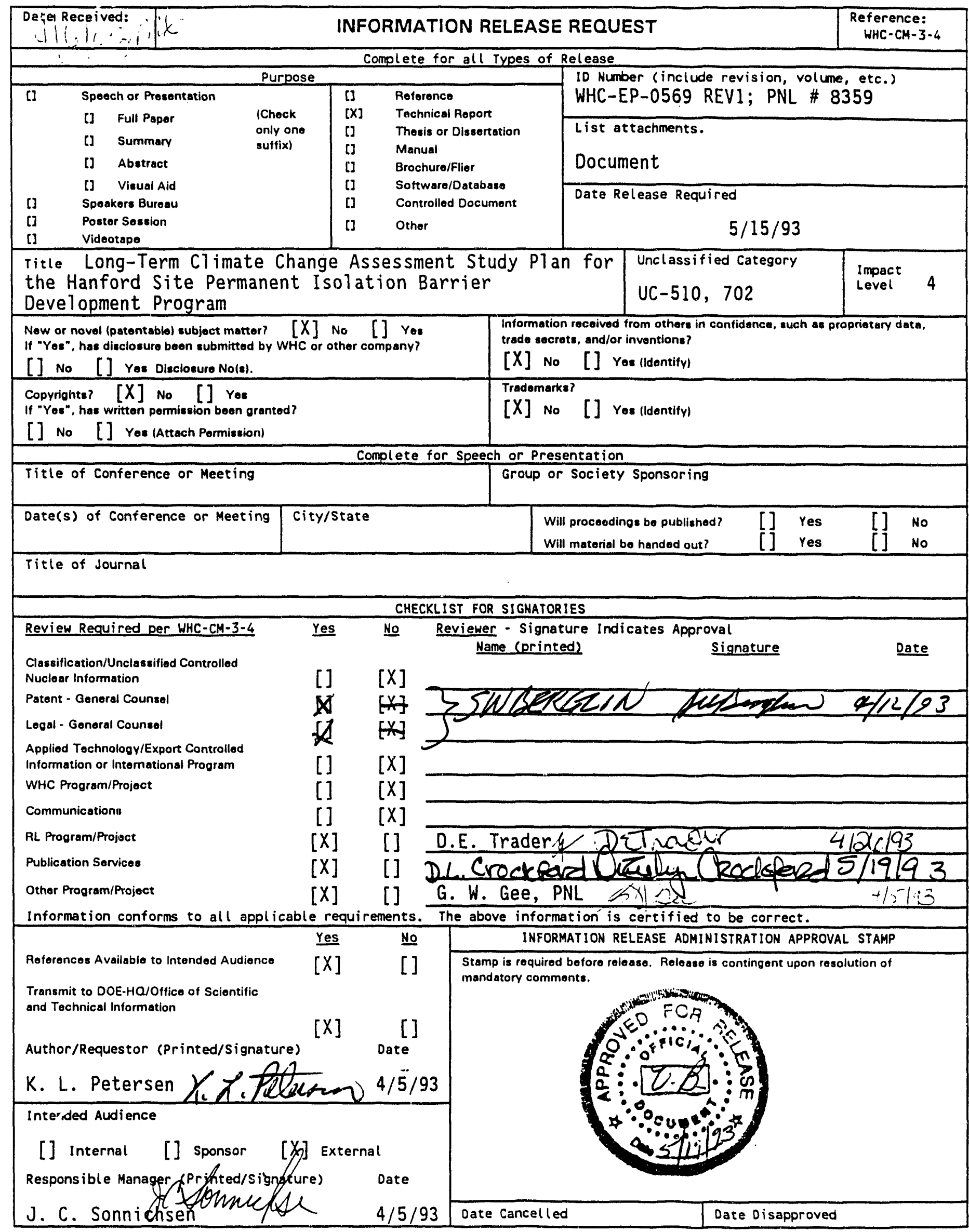


WHC-EP-0569, Rev. 1

\section{EXECUT IVE SUMMARY}

The Hanford Site Permanent Isolation Barrier Development Program (Barrier Development Program) was organized to develop the technology needed to provide an in-place disposal capability for low-level nuclear waste for the U.S. Department of Energy at the Hanford Site in south-central Washington. The goal of the Barrier Development Program is to provide defensible evidence that final barrier design(s) will adequately control water infiltration, plant and animal intrusion, and wind and water erosion for a minimum of 1,000 yr; to isolate wastes from the accessible environment; and to use markers to warn inadvertent human intruders. Evidence for barrier performance will be obtained by conducting laboratory experiments, field tests, computer modeling, and other studies that establish confidence in the barrier's ability to meet its 1,000-yr design life. The performance and stability of natural barrier analogs that have existed for several millennia and the reconstruction of climate changes during the past 10,000 yr and beyond also will provide insight into bounding conditions of possible future changes and increase confidence in the barriers design.

Climate will have a pervasive influence on barrier performance. Soil water movement will be influenced by changes in precipitation, temperature, and vegetation. Climatically induced changes in plant and animal communities will affect the potential for bio-intrusion. Surface stability may be impacted by changes in wind patterns, but also by changes in vegetative cover that may result from climate change. Currently, the potential future climate variation and vegetation change in the Pasco Basin for the millennium is largely unknown. Consequently, the effects of climatic variability on barrier performance have not been evaluated adequately. Efforts are under way to 
WHC-EP-0569, Rev. 1

improve projection of future climatic variability and to measure the uncertainty of those projections. Local climate projections are model-derived estimates based on current climate, past climate, and projected future global climatic controlling factors and bounding conditions.

The Basalt Waste Isolation Project (BWIP) had deveioped plans for characterizing long-term changes in the Pasco Basin climate, some of which the Barrier Development Program proposed to use; however, with the closing of the BWIP, the Barrier Development Program's plans for obtaining much of its climatic information from BWIP changed and this document details a research approach to fill the gap. An early draft of this document benefitted from the comments of a peer review panel made up of internationally recognized experts in climate characterization, paleoclimate reconstruction, and global climate modeling and prediction.

This document describes the Barrier Development Program's new multidisciplinary approach to climatic data acquisition to be taken to obtain defensible projections of climate parameters based on studies of current climate, past climate, and projected future climate. The overall objective of the Long-Term Climate Change Task is to complete the following:

- Obtain defensible probabilistic projections of the long-term climate variability in the Hanford Site and Pasco Basin region at many different time scales into the future

- Develop several test case climate scenarios that bracket the range of potential future climate 
WHC-EP-0569, Rev. 1

- Use the climate scenarios both to test and to model protective barrier performance.

Obtaining defensible climatic information will aid in satisfying (1) design and regulation requirements, (2) barrier performance assessment requirements, and (3) hydrologic and other barrier task input needs. The strategy being applied to accomplish this is a series of proposed task studies to be accomplished during a 5 -yr research program. The proposed program is broken into 13 tasks, titled as follows:

1. Identification of Climatic Data and Sensitivity Requirements

2. Synthesis of Existing Information

3. Pollen and Lake Sediment Studies

4. Fluvial Sediment and Groundwater Studies

5. Terrestrial Sediment Studies

6. Past Climate/Vegetation Variations

7. Future Climate/Vegetation Projections

8. Local Climate Forecast Model

9. Model Calibration and Validation

10. Projection of Future Climates

11. Generation of Weather Statistics

12. Identification of Spatial Analogs of Vegetation Response to Projected Climates

13. Input Climatic Data to Barrier Performance Assessment.

The work performed under this test plan will be a collaborative effort by scientists and engineers from Westinghouse Hanford Company and Pacific 
WHC-EP-0569, Rev. 1

Northwest Laboratory. Total estimated cost for the program is $\$ 608,000$ for Westinghouse Hanford Company and \$1.3 million for Pacific Northwest Laboratory, for a total of $\$ 1.9$ million. A task-by-task schedule is not provided but can be inferred from the yearly cost projections. Milestones are briefly described but not scheduled. A modular approach has been specifically designed to provide an overall research strategy that is flexible so it can be scaled to accommodate future funding uncertainties or to be used for other applications that might have need for climate information. 


\section{CONTENTS}

1.0 INTRODUCTION . . . . . . . . . . . . . . . . . 1

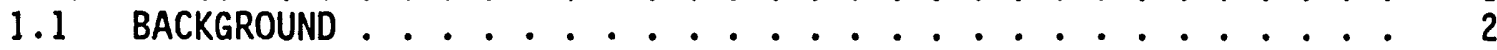

1.1.1 The Hanford Site................ 2

1.1.2 Global Climate Change ............. 2

1.1.3 Engineered Barriers . . . . . . . . . ..... 3

1.1.4 Barrier Development Program ............ 6

1.1.5 Initial Objectives ................. 6

1.1.6 History of the Long-Term Climate Change Effect Task . 7

1.2 DEVELOPMENT OF A RESEARCH STRATEGY ............ 8

1.3 OBJECTIVES ....................... 10

1.4 SCOPE ........................ 11

2.0 TASKS . . . . . . . . . . . . . . . . 12

2.1 TASK 1: IDENTIFICATION OF CLIMATIC DATA AND SENSITIVITY

REQUIREMENTS ...................... 15

2.1.1 Purpose . . . . . . . . . . . . . . . . . . . . . . . 15

2.1.2 Requirements for Assessing Hydrologic Performance . . 15

2.1.3 Requirements for Assessing Barrier Stability and

Erosion Control ..... $\cdot \cdot \cdot \cdot \cdot \cdot \cdot \cdot \cdot \cdot \cdot \cdot 24$

Requirements for Assessing Biointrusion Control... 30

2.1.5 Climate Sensitivity Analyses . . . . . . . . . . 31

2.2 TASK 2: SYNTHESIS OF EXISTING INFORMATION .......... 32

2.2.1 Purpose ................... 32

2.2.2 Methods ................ 32

2.2.3 Required Inputs and Expected Outputs ........ 35

2.3 TASK 3: POLLEN AND LAKE SEDIMENT STUDIES . . . . . . . . . 35

2.3.1 Purpose .................. 36

2.3.2 Methods ..................... 36

2.3.3 Required Inputs and Expected Outputs ........ . . 37

2.4 TASK 4: FLUVIAL SEDIMENT AND GROUNDWATER STUDIES . . . . . . 38

2.4.1 Fluvial Indicators . . . . . . . . . . . . . . . . 38

2.4.2 Feasibility Study for Episodic Groundwater Recharge . 39

2.5 TASK 5: TERRESTRIAL SEDIMENT STUDIES ........... 41

2.5.1 Studies of Eolian Processes ............ 41

2.5.2 Faunal Indicators . . . . . . . . . . . . . . 42

2.6 TASK 6: PAST CLIMATE/VEGETATION VARIATIONS . . . . . . . . 43

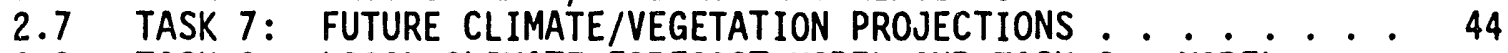

2.8 TASK 8: LOCAL CLIMATE FORECAST MODEL AND TASK $9:$ MODEL

2.8.1 Purpose ..................... 44

2.8.2 Methods ................... . 45

2.8.3 Required Inputs and Expected Outputs . . . . . . . . 46

2.9 TASK 10: PROJECTION OF FUTURE CLIMATES ............. 46

2.9.1 Purpose ................... 46

2.9.2 Methods ........................ 46

2.9.3 Required Inputs and Expected Outputs ......... . 46

2.10 TASK 11: GENERATION OF WEATHER STATISTICS . . . . . . . . . . 47

2.10.1 Purpose ...................... 47

2.10 .2 Methods . . . . . . . . . . . . . . . . . . . 47

2.10.3 Required Inputs and Expected Outputs........ 47 
WHC-EP-0569, Rev. 1

CONTENTS (cont.)

2.11 TASK 12: IDENTIFICATION OF SPATIAL ANALOGS OF VEGETATION RESPONSE TO PROJECTED CLIMATES .............. 47

2.11.1 Purpose .................... 47

2.11.2 Methods .................. 48

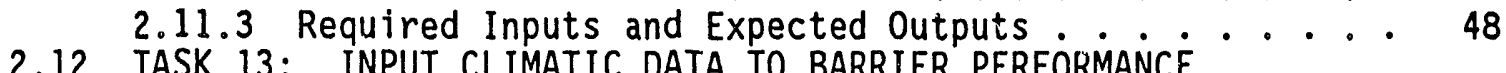

2.12 TASK 13: INPUT CLIMATIC DATA TO BARRIER PERFORMANCE

ASSESSMENT . . . . . . . . . . . . . . . 49

3.0 COST ESTIMATES, SCHEDULE, AND MILESTONES . . . . . . . . . . . . 49

4.0 qualitY ASSURANCE . . . . . . . . . . . . . . . . . . 53

5.0 REFERENCES ......................... 54 
WHC-EP-0569, Rev. 1

\section{LIST OF FIGURES}

1 A Conceptual Permanent Isolation Barrier and Warning Marker System ...................... 4

2 Long-Term Climate Change Assessment Task . . . . . . . . . . 9

3 Decision Matrix for Barrier Development Program Long-Term

Climate Change Assessment Tasks ............. 13

4 Cutaway Drawing Showing Lysimeter Facility Design . . . . . . . 19

5 Small-Tube Lysimeter Facility near the Hanford Meteorological

Station To Test Alternative Surface Configurations . . . . . . . 25

6 Design Structure for the Gravel Admix Field Experiment . . . . . . . 29

\section{LIST OF TABLES}

1 Summary of Environmental Parameters Needed by Barrier Development Studies to Assess Long-Term Performance . . . . . . . . 16

2 Westinghouse Hanford Company Programmatic Cost Estimates $(\$ 1,000 \mathrm{~s})$............... . . 50

3 Pacific Northwest Laboratory Programmatic Cost Estimates $(\$ 1,000 \mathrm{~s})$................. 51

4 Total Programmatic Cost Estimates $(\$ 1,000 \mathrm{~s})$. . . . . . . . 52 
WHC-EP-0569, Rev. 1

\section{ACRONYMS AND ABBREVIATIONS}

Barrier Development The Hanford Site Permanent Isolation Barrier Program

BWIP

CIRES

DOE

FLTF

GCM

GISS

NASA

PET

PNL

RL

STLF

Westinghouse

Hanford
Development Program

Basalt Waste I solation Project

Cooperative Institute for Research in Environmental

Sciences

U.S. Department of Energy

Field Lysimeter Test Facility

General Circulation Mode 1

Goddard Institute for Space Studies

National Aeronautics and Space Administration

potential evapotranspiration

Pacific Northwest Laboratory

DOE, Richland Operations Office

Small-Tube Lysimeter Facility

Westinghouse Hanford Company 
WHC-EP-0569, Rev. 1

\section{LONG-TERM CLIMATE CHANGE ASSESSMENT STUDY PLAN FOR THE HANFORD SITE PERMANENT ISOLATION BARRIER DEVELOPMENT PROGRAM}

\subsection{INTRODUCTION}

The Hanford Site Permanent Isolation Barrier Development Program (Barrier Development Program) was organized to develop the technology needed to provide an in-place disposal capability for the Hanford Site (Adams and Wing 1986; Wing and Gee 1990). The goal of the Barrier Development Program is to provide defensible evidence that final barrier design(s) will adequately control water infiltration; plant and animal intrusion; and wind and water erosion for a minimum of 1,000 yr and isolate wastes from the accessible environment and warm inadvertent human intruders using markers. Evidence for barrier performance will be obtained by conducting laboratory experiments, field tests, computer modeling, and other studies that establish confidence in the barrier's ability to meet its 1,000-yr design life. The performance and stability of natural barrier analogs that have existed for millennia and the reconstruction of climate changes over the past 10,000 yr to $125,000 \mathrm{yr}$ aiso provide insight into bounding conditions of possible future changes and increase confidence in the barriers design.

The Barrier Development Program system uses engineered layers of natural material to create an integrated structure with redundant protective features. The natural construction materials (e.g., fine soil, sand, gravel, riprap, clay, asphalt) have been selected to optimize barrier performance and longevity. The objective of the current designs is to use natural materials to develop a maintenance-free permanent isolation barrier and warning marker system that isolates the wastes for hundreds to thousands of years by limiting water drainage to near-zero amounts; reducing the likelihood of plant, animal and human intrusion; controlling the exhalation of noxious gases; and minimizing erosion-related problems. Once developed, it is anticipated that the permanent isolation barrier could be used at arid to semiarid sites other than the Hanford Site.

This document describes the long-term climate change studies planned to support the Barrier Development Program. The plan outlines a multiyear and multidiscipline approach to assess long-term climate change issues and to help optimize the design of the permanent isolation barriers. A multidisciplinary approach to climatic data acquisition will be responsible for obtaining needed information for concurrent barrier tasks and for developing a local climata forecast model. This model will couple past climate patterns with models of regional and global climate drivers to provide bounding conditions for barrier performance assessment analyses.

The work performed under this test plan for the U.S. Department of Energy (DOE) will be a collaborative effort by scientists and engineers from Westinghouse Hanford Company (Westinghouse Hanford) and Pacific Northwest Laboratory (PNL). The plan provides an overall research strategy that has been designed to be modular to be scaled to accommodate future funding uncertainties or to be used for other applications that might need climate information, such as the Grouted Double-Shell Tank Waste Disposal at the 
WHC-EP-0569, Rev. 1

Hanford Site or the implementation of DOE, Richland Operations office (RL) Order 5820.2A, which specifies that climate changes should be considered in Site-specific radiological performance assessment.

\subsection{BACKGROUND}

\subsubsection{The Hanford Site}

At the DOE's Hanford Site in south-central Washington, efforts are under way to remediate radioactive and hazardous chemical waste sites that have accumulated from defense-related activities. The Hanford Waste Management Plan (DOE-RL 1987) and the Final Environmental Impact Statement, Disposal of Hanford Defense High-Level, Transuranic, and Tank Wastes, Hanford Site, Richland, Washington (DOE 1987) present several options for final disposal of the Hanford Site's radioactive defense wastes. Implementation of these alternatives could include the construction of a permanent isolation barrier and warning marker system over waste that may be disposed of near surface. The barriers would be designed to protect the accessible environment for a minimum of 1,000 yr by limiting the transport of contaminants from the wastes caused by the following circumstances:

- Animal and plant intrusion

- Wind and water erosion/deposition

- Water infiltration/percolation

- Inadvertent human intrusion.

Because of the time desired for waste isolation, long-term changes in the local climate will have a pervasive influence. Therefore, before the formulation of final design criteria and the engineering of permanent isolation barriers for waste sites, projections of climatic variability will be required for the Hanford Site and surrounding regions. The reconstruction of climate changes over the past 10,000 yr to 125,000 yr will provide insight into bounding conditions of possible future changes and increase confidence in the barrier design. The lessons being learned during this study also may be useful for other studies needing climate change information.

\subsubsection{Global Climate Change}

Climatologists universally accept that global climates have undergone significant variation in the past, and such natural variations are expected to continue into the future (Houghton et a1. 1990). For instance, according to the Milankovitch theory (Milankovitch 1969), the Pleistocene ice ages were caused primarily by changes in the seasonal distribution of incoming radiation associated with orbit variations. During the last 700,000 yr, and possibly for as long as 2,000,000 $\mathrm{yr}$, the Earth has experienced a number of glacial cycles, each about $10 \mathrm{yr}$ long with a 10,000-yr-long interglacial (Hays et a1. 1976; Kukla 1981; Berger et a1. 1984). The 1ast interglacial/glacial cycle started with a 10,000-yr-long interglacial cycle about $125 \mathrm{ka}$, which was immediately followed by a rapid growth of global ice sheets beginning $115 \mathrm{ka}$. Glacial climate dominated the Earth until about $12 \mathrm{ka}$ when continental ice 
WHC-EP-0569, Rev. 1

retreated from its most southern extent into what is now the state of Washington. No vegetation escaped the repeated stress of these 61 imates and interglacial adjustments, and the Pasco Basin of south-central Washington is no exception. With each glacial cycle, the species displaced by climate, ice, water, and competition responded through growth form, migration, or selection, or faced local extinction. Based on the geophysical evidence of the past, there is a strong suggestion that the earth is cycling into the next glacial period (Imbrie and Imbrie 1980; Berger 1981; Berger et a1. 1984). Important questions include when and to what magnitude natural climate change will occur and which other confounding effects can be expected.

Although there are large uncertainties in the knowledge of climate, many climatologists now believe that future natural climates will differ significantly from those of today (Houghton et al. 1990; Berger et a1. 1984). However, human activity apparently is rivaling nature's ability to produce climatic change as judged by the potential impact of increasing carbon dioxide and other trace gases in the atmosphere (Hansen et al. 1981; Schneider 1989). The cycle into the next $i$. ye may be confounded by the steady contribution to the atmospheric burder. \& carbon dioxide and other trace gases, produced largely through fossil fu: use and possibly through deforestation. There is a growing world concern that this "greenhouse effect" will lead to unprecedented global warming in as little as $50 \mathrm{yr}$. The potential greenhouse effect, which is possibly the most important consideration for the next $1,000 \mathrm{yr}$, as well as the next glacial period, suggests that the Pasco Basin could have climate extremes that may affect the performance of the permanent isolation barrier. Identification of those potential extremes is important for the proper barrier design to provide assurance that the barriers will function for their design life, without maintenance.

\subsubsection{Engineered Barriers}

Westinghouse Hanford and PNL are jointly developing engineered barriers for hazardous waste site remediation (Adams and Wing 1986). The Barrier Development Program has a research team consisting of experts in soil physics, hydrology, geology and erosion, zoology, botany and range management, plant physiology, quaternary climates, computer modeling, civil engineering, and project management. Various barrier designs have been evaluated with simulation models and natural analogs, and are being or will be demonstrated in the field. The preliminary results from these and other studies suggest that barriers designed of layered earthen materials may be effective in limiting water infiltration and intrusion by plants and burrowing animals on a thousands-of-years time scale. A definitive permanent isolation barrier design is planned for completion by the mid-1990's.

A drawing of a conceptual barrier and warning marker system is shown in Figure 1. The barrier and warning marker system consists of a variety of different materials (fine soils, sands, gravels, asphalts, and geosynthetics) placed in layers to form an abovegrade mound directly above the waste zone. Throughout the multilayer barrier, subsurface markers may be placed to warn any inadvertent human intruders of the danger of the wastes below. In addition, surface markers would be placed around the periphery of the waste sites to inform future generations of the nature and hazards of the buried wastes. 
WHC-EP-0569, Rev. 1

Figure 1. A Conceptual Permanent Isolation Barrier and Warning Marker System.
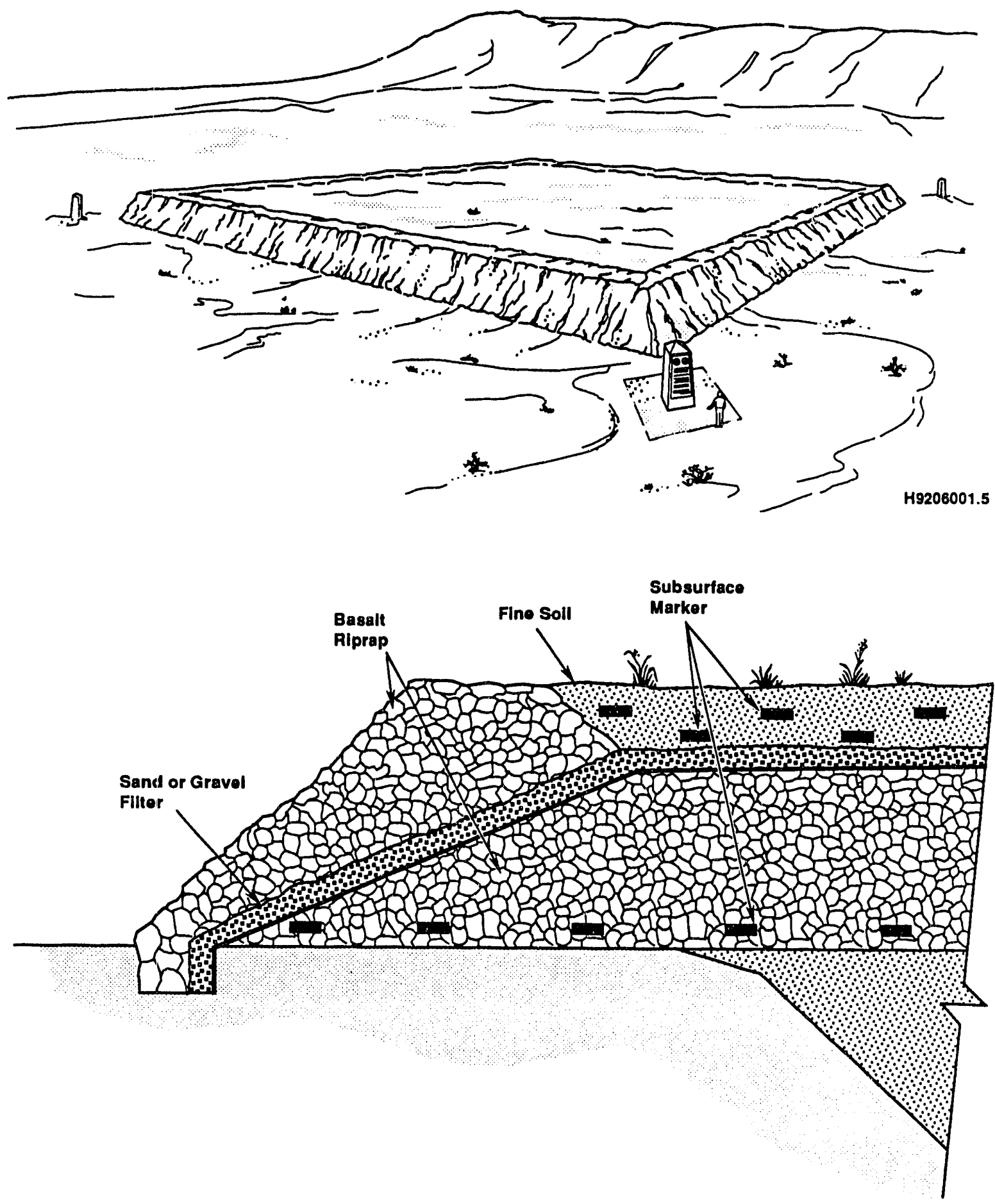

H9206001.6 
A critical design feature of barriers is the layering sequence. A conceptual design is shown in Figure 1. The protective barrier design consists of a fine-soil layer overlying other layers of coarser materials such as sands, gravels, or basalt riprap. Each of these layers serves a distinct purpose. The fine-soil layer acts as a medium for moisture storage until the processes of evaporation and transpiration can recycle any excess water back to the atmosphere. The fine-soil layer also provides the medium for establishing plants necessary for transpiration. The coarser materials placed directly below the fine-soil layer create a capillary break that inhibits the downward percolation of water through the barrier (Richards 1950). This functions because in an unsaturated system, the capillary pressures are much less than atmospheric pressure. For significant quantities of water to flow into and through the coarser sublayers, the water pressure must be raised to nearly equal atmospheric pressure. The overlying fine-textured soils must become nearly saturated for the water pressure to approach atmospheric and allow water to flow into the sublayers. This resistance to drainage explains the large storage capacity of the overlying fine-textured soil. Keeping the water in the fine-textured layer provides time for the processes of evaporation and transpiration to remove it.

The results of preliminary computer simulation model runs suggest using a $4.92-\mathrm{ft}(1.5-\mathrm{m})$ layer of suitable fine soils in the design of the barrier (Fayer 1987). Al so, the capillary barrier concept has been tested for several years at the Field Lysimeter Test Facility (FLTF). Results from these tests indicate that the capillary barrier functions as designed (Campbell and Gee 1990). During a 3-yr test period, water losses in the lysimeters by evaporation and transpiration have exceeded water gains by precipitation and irrigation for conditions representative of two times the annual average precipitation. (Soil water storage decreased in the lysimeters during the 3-yr test period and no drainage occurred.) Annual water losses by evapotranspiration create a soil storage capacity adequate to accommodate estimated 1,000-yr storm events at the Hanford Site $[1.11$ in. $(2.82 \mathrm{~cm})$ of water in $60 \mathrm{~min}]$. In two of the drainage 1ysimeters at the FLTF, enough water was added to force water to break through the capillary barrier. As expected, it was determined that water does not pass through the capillary barrier in the liquid phase until the soil approaches saturation and pore pressure becomes positive. Once breached, the capillary barriers in the lysimeters drained only slowly until they reached a stable water content almost twice as high as that normally held by that soil against gravity.

The coarser materials below the fine soil also act as deterrents for burrowing animals and deep-rooting plants. Low-permeability layers, placed in the barrier profile below the capillary break, are now being considered for use in the protective barriers. The low-permeability layers would be used (1) to divert any percolating water that gets through the capillary break away from the waste zone, and (2) to limit the upward movement of noxious gases from the waste zone. Solution grouts also are being evaluated for use as a construction aid and to provide additional structural stability to the barrier. 
WHC-EP-0569, Rev. 1

\subsubsection{Parrier Development Program}

The Barrier Development Program (Adams and Wing 1986) outlines several studies that address specific issues related to the design and long-term behavior of barriers. Twelve groups of tasks have been identified to resolve the technical concerns and complete the development of barriers and markers. These groups are as follows:

- Project management

- Biointrusion control development

- Water infiltration control development

- Erosion/deposition control development

- Physical stability testing

- Human interference control

- Barrier construction materials procurement

- Prototype barrier designs and testing

- Model development and validation

- Natural analogs studies

- Long-term climate change effects

- Final design.

This process of designing and testing barriers requires an understanding of the interaction among design components and environmental and climatic factors.

Water movement within layered soil systems connects closely to changes in surface soils, precipitation, temperature, and the water extraction characteristics of plants. Changes in climate also may alter the structure of plant and animal communities inhabiting the area and, thus, the potential for biointrusion. Biointrusion studies may need to account for the influence of climate on plant-rooting depths and the regional distribution and behavior of burrowing animals. The stability of the barrier surface may be influenced by changes in the plant cover, burrowing animal behavior, precipitation, temperature, and wind regimes.

\subsubsection{Initial Objectives}

In the Protective Barrier and Warning Marker System Development Plan, Adams and Wing (1986) describe the objective of the long-term climate change assessment tasks as follows.

At present, the possible 10,000-yr variation in the climate and ecology of the Pasco Basin are largely unknown. The object of this task is to obtain probabilistic projections of long-term variability in the Pasco Basin climate that can be input to analyses of water balance, biointrusion, and erosion of barriers. 
WHC-EP-0569, Rev. 1

Adams and Wing (1986) also describe objectives for the activity, including the following:

- The evaluation of climate informational needs (CLIM-1) by using the following operations:

- Identify specific parameters of long-term climate that will be required for water infiltration, erosion, and biointrusion analyses

- Evaluate the adequacy of existing information

- Coordinate Barrier Development Program involvement in a climate characterization project funded by the Basalt Waste Isolation Project (BWIP).

- The prediction of local climate and vegetational changes (CLIM-2) incorporating the following actions:

- Employ different types of models to predict variability in the climate and vegetation of the Pasco Basin during the next 10,000 yr

- Use statistical models (called transfer functions) to reconstruct past climate from geologic and paleobiotic indicators, such as glacier fluctuations, fossil pollen records, and tree rings

- Using the geologic and paleobiotic information, calibrate a local climate forecast model

- Model the relationships between local climate variables and regional controlling factors (such as atmospheric oceanic circulation patterns) and input the information to the local climate forecasts

- Estimate future variability in the vegetation and wind regime of the Pasco Basin in addition to variability in precipitation and temperature; this information will be input to water infiltration, biointrusion, and erosion control tasks.

\subsubsection{History of the Long-Term Climate Change Effect Task}

In the early stages of the Barrier Development Program, the BWIP was in the process of developing study plans for characterizing long-term climate variability in the Hanford Site region in support of high-level waste disposal. Of particular concern to BWIP was the potential effect of climate on the isolation of waste in a geologic repository. The BWIP's multimilitiondollar work requirements were developed in consultation with a panel of recognized leaders in climate modeling and paleoclimate research.

To avoid duplication, PNL and Westinghouse Hanford convened a Barrier Development Program workshop in January 1987 to define key issues regarding 
WHC-EP-0569, Rev. 1

the impacts of climatic variability on the performance of layered soil and rock barriers proposed for possible use at the Hanford Site (Waugh and Foley 1988). Workshop participants concluded that the sensitivity of vegetation and evapotranspiration to potential future climatic changes was a key issue that must be understood better before climatic change impacts on drainage through the barrier and groundwater recharge could be adequately modeled. Based on the workshop findings, Waugh and Foley (1988) proposed several technical tasks to obtain needed information. The BWIP climate program was to be the source of much of the climatic information needed by the Barrier Development Program. By tying into BWIP, the Barrier Development Program would be able to acquire needed climatically related information without incurring the significant costs associated with generating the data for BWIP. The Barrier Development Program would provide funding for and perform any additional climatic work that was needed but not conducted by BWIP.

A decision was made late in 1987 to discontinue investigating the Hanford Site as a possible location for a commercial nuclear waste repository for high-level waste. So BWIP was closed out and the Barrier Development Program was forced to reevaluate its strategy for obtaining needed climate information. The current proposal is presented in this document.

\subsection{DEVELOPMENT OF A RESEARCH STRATEGY}

Figure 2 shows the long-term climate change assessment needs, tasks, and objectives. Before initiating a new climate task, key climate parameters needed by various other Barrier Development Program tasks must be identified. Once identified, the key climate parameters must be priority rated so that an orderly and cost-effective approach can be taken to obtain the needed climate data. In addition, identification must be made of the regulatory requirements and performance standards (as they currently exist or as they evolve) that pertain to the effects of climate change on the disposal of wastes at the Hanford Site.

At a minimum, the ability to predict and defend the performance of barriers over the next 1,000 yr depends on the following two conditions:

- An understanding of present environmental conditions that could compromise long-term barrier integrity and performance to facilitate proper barrier design

- An ability to predict climate changes and climate-induced changes in environmental processes that might adversely affect the barrier in the future, so that appropriate design considerations can be formulated, tested, and implemented.

To accomplish the objectives of the long-term climate change assessment task, paleoclimatic studies and future climatic projections must be closely linked. Local climatic projections will be model-derived estimates based on current climate, past climate, and projected global climatic controlling factors and bounding conditions. 
Figure 2. Long-Term Climate Change Assessment Task.

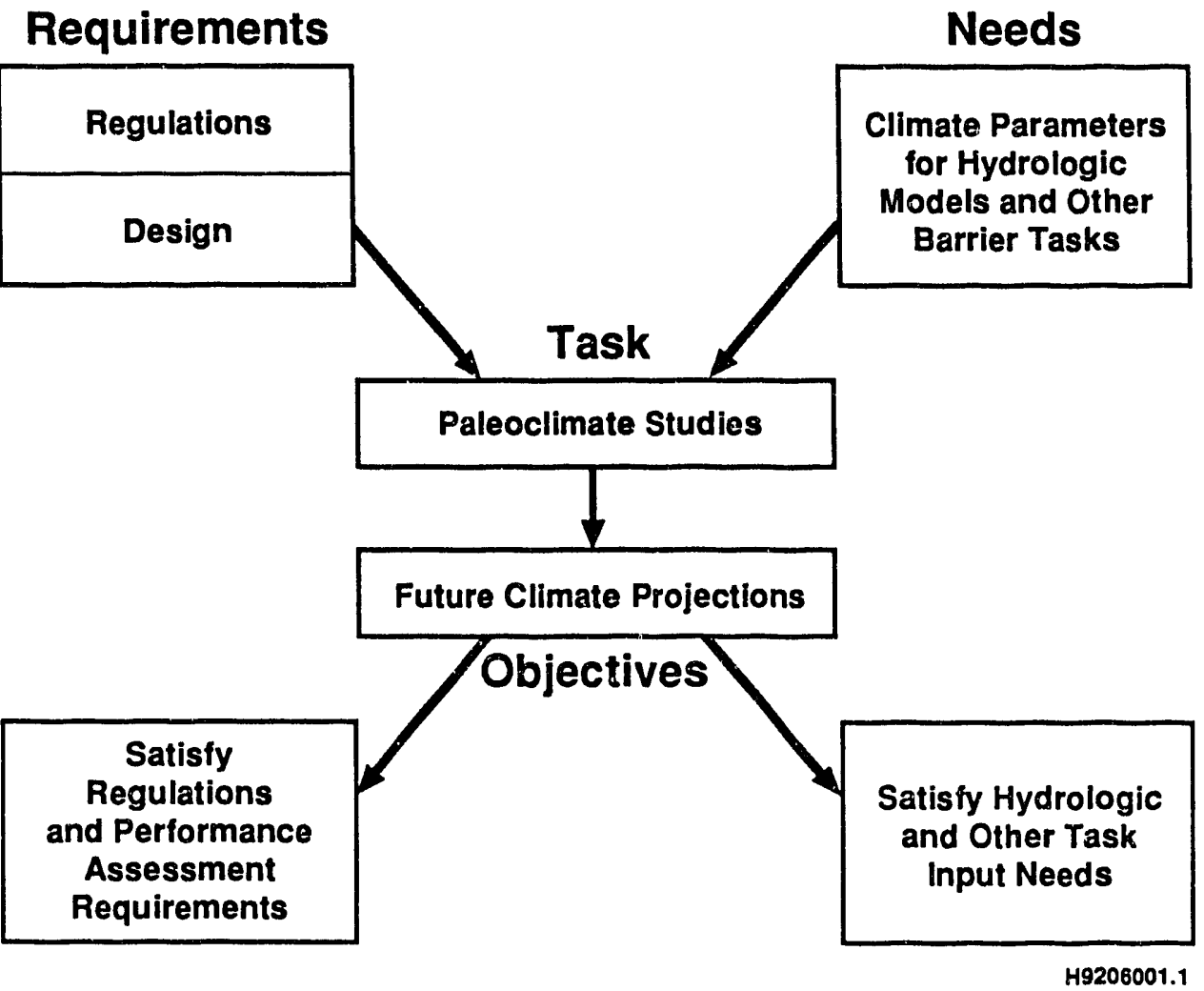

The climate study $\mathrm{plans}$ that were prepared for BWIP were reviewed for applicability to the Barrier Development Program. In 1989, a draft version of the Barrier Development Program's climate study plan was completed. In contrast to the BWIP approach, this plan proposed a focused, stepwise approach to data acquisition whereby the complexity (and cost) would increase with successive tasks. Decisions to progress were to be based on assessments of the expected returns in improved confidence relative to the required sensitivity and cost. The Barrier Development Program's approach accounts for potential future impact of greenhouse gases, something the BWIP approach did not address. In August 1989, the draft was submitted to a peer review panel consisting of a number of experts in paleoclimatic reconstruction and future climate projection. The review of the plan was undertaken at the draft stage so that an early interchange of ideas regarding the document could assist in focusing the proposed investigation. The panel concluded that the program could be focused usefully on several critical issues to eliminate some unnecessary paleoclimate studies, thereby reducing costs and focusing the climate change assessment efforts. The panel noted that detecting extremes that could make a difference in performance of the barrier for up to $10,000 \mathrm{yr}$ should be emphasized. These climatic extremes include changes in temperature, precipitation, and vegetation related to greenhouse warming and the cycling of the climate into the next ice age. 
The review panelists were Dr. Cathy Whitlock (Barnosky), Museum of Natural History, Pittsburgh, Pennsylvania (palynology); Dr. Brian Atwater, U.G. Geological Survey at the University of Washington, Seattle, Washington (glaciation and other nonbiotic studies); Dr. David Rind, National Aeronautics and Space Administration's (NASA) Goddard Institute for Space Studies (GISS), New York (climatic modeling); and Dr. Roger Barry, Cooperative Institute for Research in Environmental Sciences (CIRES), University of Colorado, Boulder, Colorado (general climatology).

\subsection{OBJECTIVES}

Figure 2 indicates the relationship between the various components of the long-term climate change assessment task. The overall objective, as illustrated in Figure 2, is to provide defensible climatic information that will aid in satisfying regulations, barrier performance assessment requirements, and hydrologic and other barrier task input needs. More specific objectives include the following:

- To use the past climate, current meteorological conditions, and modeled future global changes to project likely climatic variability in the Pasco Basin for the next 1,000 yr

- To provide information that pertains to the effects of climatic change on the disposal of wastes at the Hanford Site to the other components of the Protective Barrier Development Program so that the final design meets regulatory requirements and performance standards

- To provide information that will be used to test the long-term performance of the barrier to confirm its effectiveness in minimizing drainage that could lead ultimately to movement of radionuclides to the accessible environment.

The strategy being selected to accomplish these general objectives is a series of studies that provide for an understanding of the range and probability of recurrence of past climate change and for a projection of potential climate at the Hanford Site.

As mentioned in Section 1.1.3, there is strong geophysical evidence from earth history that the Earth is cycling into the next glacial period (Hays et a1. 1976; Berger et al. 1984). This cycling into the next ice age may be influenced by global warming by the steady increase of anthropogenic carbon dioxide and other trace gases. Thus, an ice age climate and greenhouse warming can provide tivo contrasting extreme climate scenarios. The technical review panel suggested that the long-term climate change assessment task could be usefully focused on a series of discrete severe climate scenarios that could provide the bounding condition used to test the performance of barriers. Once selected, efforts would be made to characterize the climatic nature of these extremes in the Hanford region.

Based partly on the recommendations of the technical review panel and partly on the experience of the authors, the following have been selected as potential climatic extremes that could have impact on the barriers performance if such extremes were to occur in the future: the last interglacial/glacial 
WHC-EP-0569, Rev. 1

transition (deep sea oxygen isotope stage 5 to 2 ); the last glacial maximum (nominally $18 \mathrm{ka}$ ); the early Holocene $(9 \mathrm{ka})$; and the middle to late Holocene $(6 \mathrm{ka}$ and $3.5 \mathrm{ka})$. Many questions can be posed to help structure the research strategy to address these other climatic extremes.

- What are the specific climatic parameters that need to be obtained through study (i.e., annual precipitation, daily temperature range)?

- If the needed climatic parameters are unobtainable, are there ways to approximate them?

- How soon will the next ice age begin?

- How rapid will the transition be?

- How rapidly did the last interglacial/glacial transition occur (nominally $115 \mathrm{ka}$ )?

- What is the nature of a glacial climate at the Hanford Site?

- Could a glacial climate impact the effectiveness and performance of a permanent isolation barrier?

- What is the nature of a warmer greenhouse climate at the Hanford Site?

- Could a warmer greenhouse climate impact the effectiveness and performance of a permanent isolation barrier?

- Based on paleoclimate studies, are there other periods of potential climatic extremes that should be considered?

- What is the nature of these other climate extremes at the Hanford Site?

- Could these other climate extremes impact the effectiveness and performance of a permanent isolation barrier?

\subsection{SCOPE}

The current approach for accomplishing the objectives and obtaining needed climatic information for the Barrier Development Program is presented in this study plan. The work described in this plan is consistent with the Protective Barrier and Warning Marker System Development P1 an (Adams and Wing 1986), which was prepared as a guide for resolving the technical issues associated with protective barrier and warning marker systems.

This document will describe the climatically related activities to be undertaken to support development and performance assessment of barrier designs. This document provides a preliminary estimate of climate information needs and describes a series of tasks designed to obtain information about the range of past climatic variation and efforts to predict potential climate conditions. Task interactions, schedules, and preliminary cost estimates also 
WHC-EP-0569, Rev. 1

are provided. Because this is a multiyear plan, initial tasks are described more comprehensively than later tasks. When individual tasks are undertaken, they probably also will be guided by approved technical work plans that will be more comprehensive than this study.

\subsection{TASKS}

Although the design 1 ife of the permanent isolation barrier is a minimum of a 1,000 yr, future climate projections will be assessed to $10,000 \mathrm{yr}$. This additional margin is being added so that the confidence in the 1,000-yr projections can be improved. Based on the recommendations of the independent, third-party technical review panel, a simplified figure was developed depicting various tasks and key decision points to be addressed in the revised climate study plan (Figure 3). In the proposed climatic assessment of the barriers, a stepwise approach to data acquisition will be undertaken. The flow of information among tasks is illustrated in Figure 3 and outlined as follows.

- Tasks:

- Identification of Climatic Data and Sensitivity Requirements

- Synthesis of Existing Information.

- Decision point 1: Does Existing Information Satisfy Data Needs?

- Pollen and Lake Sediment Studies

- Fluvial Sediment and Groundwater Studies

- Terrestrial Sediment Studies

- Past Climate/Vegetation Variation

- Future Climate/Vegetation Projections.

- Decision point 2: Do Reconstructions Bound Long-Term Astronomical Forcing and Projected Greenhouse Effects?

- Local Climate Forecast Model

- Model Calibration and Validation

- Projections of Future Climates.

- Decision point 3: Do Projections Satisfy Climate/Vegetation Data Needs?

- Generation of Weather Statistics

- Spatial Analogs of Vegetation Response

- Input Climatic Data to Barrier Performance Assessment.

The first box in Figure 3 indicates the identification of climate data needs. The next activity in the sequence shown in Figure 3 is the synthesis of existing information. This task is comprehensive, covering the evolving field of global climate modeling. Additionally, the relationship between 
Figure 3. Decision Matrix for Barrier Development Program Long-Term Climate Change Assessment Tasks.

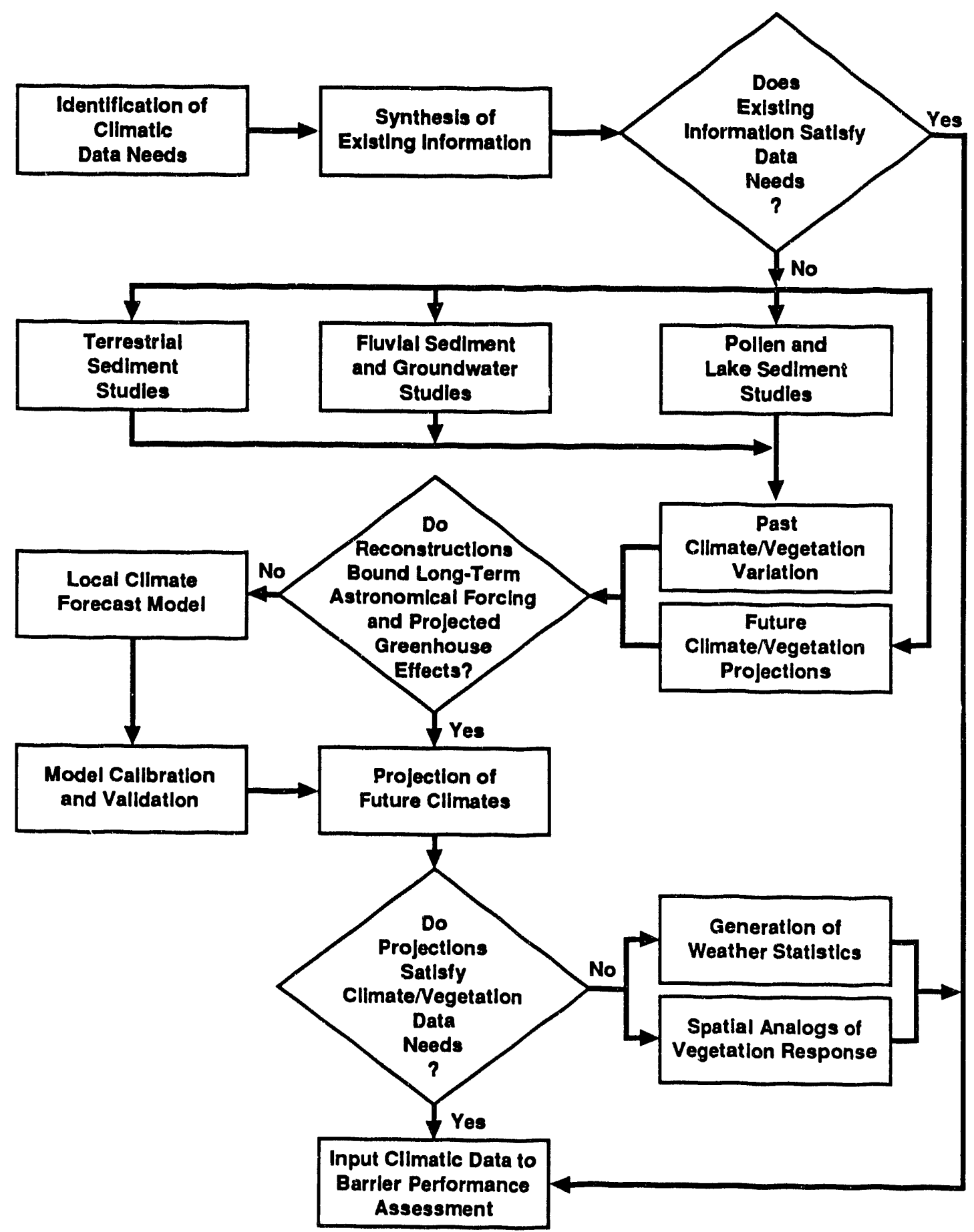


WHC-EP-0569, Rev. 1

local climate variables and regional climatic controlling factors, such as atmospheric and oceanic circulation patterns, must be understood.

The task of synthesizing information also will focus on gathering information on selected paleoclimatic extremes experienced in the Pacific Northwest and the world as a whole. Such information is availabile from studies of fossil pollen and stable isotope ratios from lake and ocean sediment cores; fossilized limbic organisms with narrow tolerances for $H$, temperature, and solutes; isotopic, mineralogic, and sedimentological indicators of lake-level or climatic fluctuation; glacial and eolian depositional histories; and dendroclimatic reconstructions using tree rings. Because some Barrier Development Program studies will need information on specific parameters (i.e., the magnitude and frequency of extreme rainfall events or the seasonality of precipitation), an attempt will be made to identify the range of such parameters historically and for selected prehistoric periods of climatic extremes, and projection of these also will be provided.

New field studies to be undertaken include paleoclimate reconstruction based on interpretations of paleobiotic and geologic records. Because of the paucity and incompleteness of various kinds of evidence, a range of different types of data and analytical tools will be investigated to characterize best the selected times of extreme climatic conditions. These studies are grouped into three types: Pollen and Lake Sediments Studies, Fluvial Sediment and Groundwater Studies, and Terrestrial Sediment Studies. Reconstructions of past climate in the Hanford Site region will be based primarily on interpretations of variability in the composition of fossil pollen from lake sediment cores. Additional index climate data are planned to be used to help characterize extreme climatic conditions and events such as past aridity through the study of past sand dune activity and the evidence for paleofloods. These studies will aid in the development of bounding conditions for the local climate forecasts.

The problem of forecasting future climatic variations is challenging. Modeling projections of future climate at the Hanford Site region will be accomplished by developing a local climate model. Initial bounding conditions for the local climate model will be obtained from general circulation models to be reviewed during the synthesis of information task. In turn, the local climate model will need to be calibrated and verified against present climatic conditions and reconstructions of past local climate. The ability of the local climate model to reproduce past climatic conditions will give some measure of the model's sensitivity to changing bounding conditions. After calibration and validation, the future variability in the precipitation and temperature (and the potential vegetation) and wind regime of the Hanford Site region will be estimated. If additional data needs remain, the generation of weather statistics and development of spatial analogs of vegetation response will be undertaken.

The objective of climate studies is to obtain defensible projections of climate parameters that satisfy the climate-input data needs of various Barrier Development Program tasks (manipulative experiments, barrier analog studies, modeling studies) that in turn will used in the performance assessment of the barriers as shown by the last box in Figure 3 . 
WHC-EP-0569, Rev. 1

\subsection{TASK 1: IDENTIFICATION OF CLIMATIC DATA AND SENSITIVITY REQUIREMENTS}

The Protective Barrier and Warning Marker System Development Plan (Adams and Wing 1986) outlines several studies that address specific issues related to the design and long-term behavior of permaneit isolation barriers (Section 1.1.4). Inciuded in the $\mathrm{plan}$ are studies of hydrologic performance, erosion control, biointrusion control, construction material requirements, physical stability, human intrusion control, and climatic change effects. Predictions of future changes in local climate will be required by almost all of the studies. Tests of snil water movement and storage in the barrier will be sensitive to changes in precipitation, cemperature, plant cover and type, and the water extraction characteristics of plants. Biointrusion studies may need to account for the influence of climatic change on plant type and rooting depths and the regional distribution and behavior of burrowing animals.

Changes in plant cover, burrowing animal behavior, precipitation, temperature, and the wind regime may influence the stability of the barrier surface.

\subsubsection{Purpose}

Task 1 is an essential first step in assessing the effects of climatic change on the long-term performance of permanent isolation barriers. The objectives of this task are the following:

- To identify specific climatic parameters that will be required by the various studies of long-term barrier performance

- To identify the temporal resolution and precision required for each climatic parameter

- To conduct climatic sensitivity analyses to assess the re?ative inportance of climatic parameters

- To deveïop a task hierarchy, task priority ranking, and task sequence for the timely acquisition of needed climatic cata.

The following sections are a preliminary survey of the climatic parameters required by the various barrier development studies. Table 1 is a summary of the findings of the survey. The requirements likely will be modificd in the future as work on the various studies progresses and the results of climatic sensitivity analyses become available. Currently data needs cannot be organized into task sequences, hierarchies, or priority rankings. This will require additional input from project managers.

\subsubsection{Requirements for Assessing Hydrologic Performance}

Precipitation infiltrating the soil overlying buried waste, not extracted by evapotranspiration, will be available to move toward the waste zone. The interface of the fine-textured topsoil layer and the underlying coarse sand and gravel layers will act as a barrier to downward flow, as long as water storage at the interface does not approach saturation. If saturation occurs (i.e., if the storage capacity of the topsoil is exceeded), water could drain 
Table 1. Summary of Environmental Parameters Needed by Barrier Development Studies to Assess Long-Term Performance. (sheet 1 of 2)

Issues and studies

Parameters

Issue: Hydrologic Performance

1. Field Lysimeter Test Facility

2. Soil Water Balance Modeling

3. Evapotranspiration Modeling

4. Alternative Barrier Tests

Issue: Erosion, Deposition, and Structural Stability

1. Wind Erosion and Deposition Tests

Precipitation: Annual mean, monthly means, storm frequency, storm intensity

Vegetation: Species composition, abundance, and phenology

Input parameters: Hourly, daily, or monthly precipitation, surface soil temperature, atmospheric relative humidity; mean annual solar radiation

Parameters controlling stomatal conductance: Light intensity, 1ight quality, carbon dioxide concentrations, precipitation, temperature, atmospheric relative humidity, wind speed

Plant communities: Species composition, relative abundance, leaf area, biomass

Precipitation: Annual mean, monthiy means, storm frequency, storm intensity

Vegetation: Species composition and abundance

Wind: Annual or monthly mean velocity and direction; velocity, frequency, and duration of peak gust events

Other: Annual and monthly mean precipitation; monthly means and ranges of temperature; plant cover as a soil stability factor 
Table 1. Summary of Environmental Parameters Needed by Barrier Development Studies to Assess Long-Term Performance. (sheet 2 of 2)

\begin{tabular}{|c|c|}
\hline Issues and Studies & Parameters \\
\hline \multirow[t]{2}{*}{$\begin{array}{l}\text { 2. Water Erosion and Sideslope } \\
\text { Stability }\end{array}$} & $\begin{array}{l}\text { Precipitation: Rainfall amount; } \\
\text { duration and return frequency of } \\
\text { high-intensity storms }\end{array}$ \\
\hline & $\begin{array}{l}\text { Vegetation: Plant cover } \\
\text { characteristics influencing soil } \\
\text { stability }\end{array}$ \\
\hline \multirow[t]{2}{*}{$\begin{array}{l}\text { 3. Gravel Mulch Effects on } \\
\text { Hydrologic Performance }\end{array}$} & $\begin{array}{l}\text { Precipitation: Annual and monthly } \\
\text { means, storm frequency, storm } \\
\text { intensity }\end{array}$ \\
\hline & $\begin{array}{l}\text { Vegetation: Species composition and } \\
\text { abundance }\end{array}$ \\
\hline \multicolumn{2}{|l|}{ Issue: Biological Intrusion } \\
\hline \multirow[t]{4}{*}{ 1. Biointrusion Control Tests } & $\begin{array}{l}\text { Vegetation: Species composition, } \\
\text { abundance, spatial distribution }\end{array}$ \\
\hline & $\begin{array}{l}\text { Precipitation: Annual and monthly } \\
\text { means, snow accumulation, drought } \\
\text { frequency and duration, atmospheric } \\
\text { relative humidity }\end{array}$ \\
\hline & $\begin{array}{l}\text { Temperature: Seasonality, diurnal } \\
\text { fluctuation, frequency and duration } \\
\text { of extreme warm and cold periods }\end{array}$ \\
\hline & $\begin{array}{l}\text { Other: Wind speed, carbon dioxide } \\
\text { concentrations, atmospheric } \\
\text { pollutants }\end{array}$ \\
\hline
\end{tabular}


through the gravel layer and into the underlying waste zone. Calculations in the Hanford Defense Waste-Environmental Impact Statement (HDW-EIS) (DOE 1987) indicate that a minimum of $0.04 \mathrm{in.} / \mathrm{yr}(0.1 \mathrm{~cm} / \mathrm{yr})$ drainage through the waste zone potentially could carry radionuclides to the groundwater. Based on these calculations, stringent hydrologic performance standards with respect to water movement into the waste zone (e.g., near-zero drainage from the barrier for extended periods of time) will be imposed on the barrier design.

Four studies of hydrologic performance will require climatic data: (1) field lysimeter tests of the HDW-EIS barrier, (2) unsaturated water flow model development, (3) plant transpiration modeling, and (4) lysimeter tests of alternate barrier designs.

2.1.2.1 Field Lysimeter Test Facility. The FLTF was constructed at the Hanford Site in 1987 to measure water balance in various barrier configurations (Gee et al. 1989). The facility contains 14 drainage lysimeters and 4 weighing lysimeters (Figure 4 ). The drainage lysimeters consist of closed-bottom steel tanks buried in the soil at grade. They contain barrier designs with a fixed volume $[6.56 \mathrm{ft}$ in diameter by $9.84 \mathrm{ft}$ deep ( $2 \mathrm{~m}$ in diameter by $3 \mathrm{~m}$ deep)] in which water storage is measured with neutron and gamma attenuation probes. Drainage water is collected from a drain port at the bottom of the lysimeter. The weighing lysimeters isolate a soil volume [ $4.92 \mathrm{ft}$ by $4.92 \mathrm{ft}$ by $4.92 \mathrm{ft}(1.5 \mathrm{~m}$ by $1.5 \mathrm{~m}$ by $1.5 \mathrm{~m})$ ] resting on a platform scale so that a continual record of weight changes can be generated, which, when supplemented with physical measurements, can be used to estimate precipitation, evapotranspiration, and storage changes. The weighing lysimeters also are equipped with bottom ports for direct collection of drainage.

The inputs and outputs of the lysimeter water storage (S) are the water added to the barrier [rain or snow $(P)$ ] and the water extracted at the barrier surface [evapotranspiration (ET)], respectively. When ET exceeds $P$, $S$ decreases. Conversely, when $P$ exceeds ET, $S$ increases, which can lead to drainage (D) at the bottom of the lysimeter. Physical soil characteristics, such as particle size, abruptness of layer boundaries, and soil development (long-term natural changes), determine the amount of water that can be stored in the soil before $D$ occurs.

The treatment structure of the FLTF was selected (1) to demonstrate the effectiveness of a layered soil and gravel barrier with abrupt pore-size discontinuities (textural breaks) in limiting unsaturated flow, (2) to demonstrate the water balance response of a layered barrier to a wetter climate, and (3) to demonstrate the sensitivity of water balance to changes in vegetation. Lysimeters with bare soil and others transplanted with native species are compared to examine the influence of vegetation on water balance. Simulation of a wetter climate at the FLTF is limited to the addition of water (greater precipitation). Currently, water is added to selected lysimeters biweekly to bring the total received during the month up to double the average monthly precipitation. In addition, two lysimeters received even greater amounts of precipitation [0.79 in./week $(2 \mathrm{~cm} /$ week)] until a breakthrough occurred and water drained to the bottom of the lysimeter. 
WHC-EP-0569, Rev. 1

ఖ

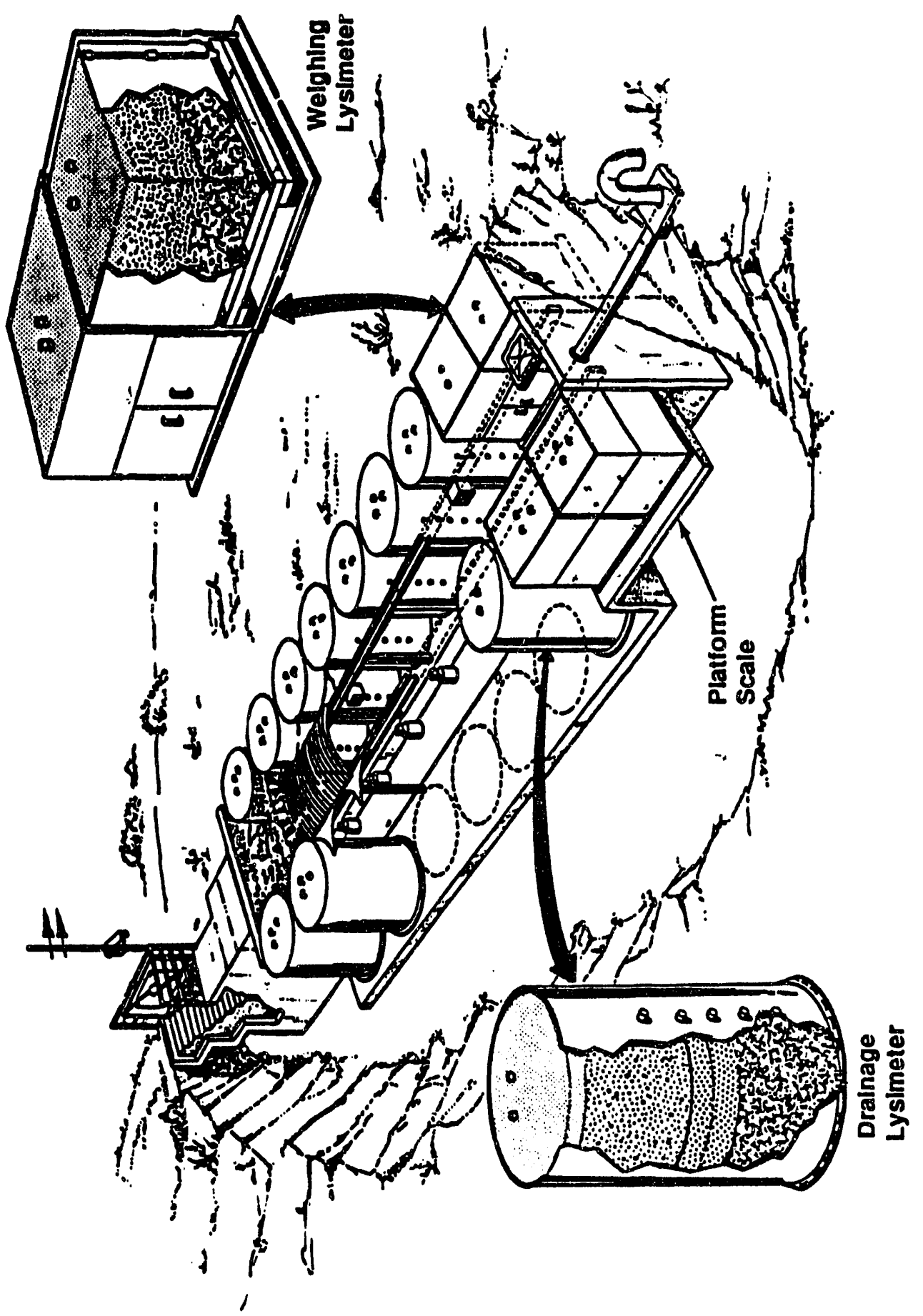

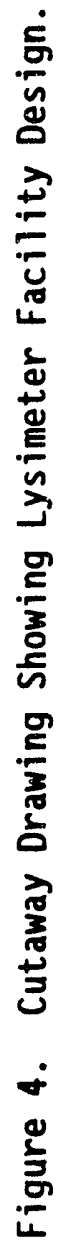


Climatic change data are needed to reduce uncertainties associated with the precipitation and vegetation treatments at the FLTF and, if appropriate, to refine these treatments. Aspects of the precipitation treatment that could be modified include the average annual amount, the seasonal distribution (monthly amount), and the application frequency (daily, twice weekly, biweekly, monthly, etc.). Also, a better understanding of the potential response of the plant community to climatic change is needed to evaluate FLTF vegetation resemblance to expected changes in plant species composition, abundance, and water extraction behavior.

Although climatic change estimates will help to quantify uncertainty in FLTF treatments and to improve treatments, other constraints remain. Currently, precipitation is the only climatic parameter that can be manipulated at the FLTF. However, increased precipitation is only one of several attributes of a wetter climate. Cloud cover, for example, plays an important role in energy exchange at the Earth's surface. Clouds absorb and reflect solar radiation, reducing the amount received and, consequantly, the evaporative demand at the surface. Conversely, clouds reradiate infrared radiation emitted from the earth's surface that otherwise would escape through the atmosphere into space. Also, in wetter climates, more energy is removed from or added to the surface environment as latent heat of evaporation and condensation, respectively. The overall result is a moderation of temperature extremes both diurnally and seasonally.

Other constraints include the water application frequency, application rate, application lag time, and inclement weather. Ideally, the application frequency and rate would change seasonally, proportional to meteorological statistics. However, the interval is dictated by labor costs, and the rate is constrained by the output of the rainulator. The rate must be less than the saturated conductivity of the soil but fast enough to complete each session in a reasonable time. Water cannot be applied when the soil is frozen or snow covered. Applications that 1 ag too far behind may force a seasonally artificial delay in plant growth (and ET) responses, thus confounding interpretations of the influence of a wetter climate on barrier performance.

2.1.2.2 Unsaturated Water Flow Model. Because of the complex and dynamic nature of the waste disposal environment, computer simulation models will serve as the principal tools for predicting long-term barrier behavior. Models also are needed because of the limitations in physically simulating climatic changes in lysimeters (Section 2.1.2.1) and the uncertainties and impracticality of attempting to test multiple combinations of barrier prototypes and climatic scenarios in lysimeters. Manipulative experiments (1ysimeters, field plots, etc.) inadequately depict long-term changes in some key parameters. It may be possible, using computer models, to simulate efficiently the interaction of many different combinations of barrier designs and environmental scenarios. Limitations in modeling involve the acquisition of adequate input parameter data and validation data, and in particular a lack of knowledge regarding the change (over time and space) of input parameters describing the climate, vegetation, and the physical structure of the barrier.

The computer model developed to predict the long-term hydrologic performance of barriers [UNSAT-H (Fayer et al. 1986)] is a one-dimensional flow code. The UNSAT-H simulates the dynamic processes of infiltration, drainage, redistribution, surface evaporation, and uptake of water from the 
WHC-EP-0569, Rev. 1

soil by plants (Fayer et a1. 1986). The mathematical basis for the model is Darcy's Law as extended by Richards (1931). The numerical implementation of UNSAT-H is based on the UNSAT model of Gupta et al. (1978). The UNSAT-H uses a fully implicit, finite difference method for solving the water transport equation. Plant water uptake is introduced as a sink term at each of a vertical string of nodes in the barrier profile and is calculated as a function of root density, soil moisture content, and potential evapotranspiration. The barrier profile can be simulated as either homogeneous or layered. The boundary conditions can be controlled either as a constant head or as a flux to reflect actual conditions.

Input requirements for UNSAT-H include soil hydraulic properties, plant transpiration parameters, system boundary conditions that drive infiltration anu drainage, and simulation time steps (Fayer et al. 1986). The output parameter of greatest interest is drainage (water movement out of the cover and into the waste zone). Other output parameters may include water content distribution throughout the barrier profile, evaporation, and plant transpiration, all of which are directly coupled to drainage.

Water flow in UNSAT-H is driven by meteorological input parameters that are a function of the climate. The surface soil boundary during a simulation is described either as a precipitation/evapotranspiration flux or as a constant head (ponding or evaporation), depending on whether the suction head at the soil surface is above or below prescribed thresholds. Precipitation is normally described as an amount per hour, but also can be input as daily precipitation if hourly precipitation is not available. Also, UNSAT-H presently does not consider snow cover. Precipitation in the form of snow is treated as an equivalent rainfall. The potential water loss from the soil profiles by evaporation and plant transpiration [potential evapotranspiration (PET) ] is calculated with the Penman Equation (Doorenbos and Pruitt 1977) using either hourly or daily meteorological parameters, the nean annual solar radiation, and a uniform nighttime PET loss.

Two suction-head thresholds determine whether the boundary is in a constant head condition or a flux condition. The maximum suction-head threshold, which switches the soil boundary back and forth from a constant head evaporation to a flux condition, and the minimum suction-head threshold, which switches the soil boundary from a flux to a constant infiltration head condition, are based, in part, on meteorological inputs of atmospheric relative humidity, soil temperature at the $0.5-i n .(1.27-\mathrm{cm})$ depth, and precipitation intensity.

Although these meteorological input parameters are known for the present climate, they are not known for any future climate. If UNSAT-H predictions are to have any reliable confidence limits, meteorological subsets will be required for possible future climates. It may be possible to project parameters such as mean monthly precipitation, mean monthly temperature, and coefficients of variation for solar radiation. However, weather statistics generation models, such as WGEN (Richardson and Wright 1984), will have to be applied to create much of the time series input data that will be required by UNSAT-H to simulate the hydrologic performance of the barrier for future climates. 
WHC-EP-0569, Rev. 1

As with other types of performance assessment models, the credibility of UNSAT-H must be established before it can be used confidently to predict the long-term behavior of barriers. The model must be validated to measure uncertainty in its predictive power. Simmons and Cole (1985) indicated that, "A validation should be performed to test a code's ability to simulate specific processes as observed in an actual system under controlled experimental conditions." Model validation involves a comparison of one or more model outputs with experimental data from the system being simulated. The FLTF data will be used to validate UNSAT-H.

In lysimeters, model input requirements (i.e., soil hydraulic properties and system boundary conditions) and output parameters (i.e., soil water content and drainage) can be measured with relatively high-level precision. The greatest uncertainty in such a validation exercise is the comparison of the lysimeter treatments to the water balance conditions of an actual waste disposal environment. Treatments in the FLTF may inadequately represent long-term changes in climate and climatically driven changes in soil hydraulic properties, plant species, and plant water extraction (evapotranspiration). Studies of natural analogs of soil development and plant succession will supply the data for measuring the adequacy of lysimeter treatments, and for judging the sensitivity of models to long-term changes in these parameters.

2.1.2.3 Evapotranspiration Data Collection and Modeling. A study is under way to improve the measurement and modeling of evapotranspiration (Link and Waugh 1989). The plan:-water relation component of the UNSAT-H code, currently based on 2 months of cheatgrass growth, limits the credibility of the model for predicting long-term drainage. The goal of the evapotranspiration study is to develop a plant model that simulates root and shoot growth throughout the growing season. For this model, growth and resulting transpiration will depend on conditions of the simulation rather than being preordained by the code user. Two variables constrain the development and use of a new plant transpiration model: (1) the key input parameters and (2) vegetation changes over time. Key parameters will be evaluated by constructing multidimensional response surfaces at points throughout the growing season. The response-surface models will be the product of controlled experiments that employ whole-plant gas exchange chambers. It is hoped that the climatic change studies will predict possible changes in vegetation.

Transpiration is a function of the supply of water to roots, plant liquid water conductance, stomatal conductance, and leaf area. If a plant is able to acquire adequate water by root exploration, it will transpire at rates controlled by liquid water conductance, stomatal conductance, and leaf area. As the supply of water is reduced, transpiration will be reduced. Abiotic and biotic parameters that drive these components of transpiration will be measured in the field. The most important meteorological parameters controlling stomatal conductance are light intensity, light quality, $\mathrm{CO}_{2}$ concentration, temperature, humidity, and wind speed. Some of these parameters will contribute greatly to variation in transpiration while others will contribute little. The greatest contributors will become input parameters for the UNSAT-H upgrade. 
The transpiration model also will be dependent on the species composition of the barrier plant community. Plants growing on waste sites probably will change significantly. The plant community may change in response to climate, or to disturbances such as fire and inadvertent cultivation. Changes in the types and diversity of species may be accompanied by changes in rates of water extraction. Even under the present climate conditions and without disturbances, the relative abundance of species, biomass production, and transpiration rates will vary seasonally and from year to year in response to variations in precipitation and temperature.

It may be difficult or impossible to predict changes in plant water extraction because of the complex ecological interactions that control plant community development using computer simulation models. One approach to estimating the influences of climatic change on evapotranspiration would be to predict possible future climates, infer what types of plant communities would be present for these climates (based on paleo-ecological data), locate present-day analogs of these climate/vegetation states, and measure evapotranspiration at the analog sites.

Limitations associated with this approach must be recognized. Because agriculture has introduced many non-native plant species, the paleo-ecology of a waste disposal site may be an imperfect representation of possible future changes in vegetation. Much of the Hanford Site vegetation currently is dominated by Asian plants such as cheatgrass and Russian thistle, plants that were found only in the eastern hemisphere $150 \mathrm{yr}$ ago. These species dominate not only cultivated and overgrazed lands, but are supplanting native species on undisturbed lands (Mack 1986). The dominance of such species appears to alter functional ecological processes, such as evapotranspiration, as well as the general appearance of the vegetation.

Increased atmospheric $\mathrm{CO}_{2}$ presents a unique situation for which analogs may not exist. Much has been published recently theorizing about the global rise in atmospheric $\mathrm{CO}_{2}$ and other greenhouse gases, which have thrown the global climate off balance. According to greenhouse theory, the global climate will be restored to equilibrium by a warming of the lower atmosphere to a point that far exceeds climatic changes in historical times (Ramanathan 1988). However, a reduction in plant growth associated with higher global temperatures may be balanced partly by an increase in growth attributable to the higher $\mathrm{CO}_{2}$ concentrations. A doubling of atmospheric $\mathrm{CO}_{2}$, for example, could lead to a greater than $80 \%$ increase in biomass yield and, simultaneous $7 y$, as much as a $10 \%$ decrease in the per-unit-leaf-area transpiration rate (Idso et a) 1987).

\subsubsection{Alternate Barrier Lysimeter Tests. Several experiments using} lysimeters considerably smaller than those at the FLTF (Section 2.1.2.1) were started in 1988 to test the hydrologic performance of alternate designs of the HDW-EIS conceptual barrier (Freeman et a1. 1989; Waugh and Link 1988). The alternate designs include placement of low-permeability layers at the interface of fine-textured topsoil and underlying coarse-textured layers, and replacement of the graded sand-gravel-riprap layers with a mixed sand and gravel layer (pitrun gravel). The low-permeability materials include asphalt, bentonite clay, and sodium silicate grout. 
These alternate barrier designs are being tested in a small-tube lysimeter facility (STLF) constructed adjacent to the FLTF (Sackschewsky et a1. 1991). The STLF contains an array of 100 lysimeters (Figure 5). The lysimeters consist of 66.54-in.-long-by-11.81-in.-I.D. (169-cm-1 ong-by-30-cm-I.D.) sections of flush-threaded plastic well casing, sealed at one end with a recessed cap. The sealed tube serves as a combined drainage and weighing lysimeter. Drainage is measured by collecting water from a clear, flexible polymer tube fitted to a threaded drain hole at the low end of the end cap. Water storage is estimated from a record of weight changes measured by suspending the lysimeters from a load cell attached to a gantry crane. The lysimeters are placed in buried racks of PVC sleeves with the lysimeter surface slightly above the grade of the surrounding terrain. The lysimeters also are designed to be coupled to an acrylic plant gas-exchange chamber, which will be used to conduct controlled experiments on evapotranspiration (Section 2.1.2.3).

Like the FLTF studies, the precipitation-enhancement treatment in the STLF experiments consists of monthly water additions to achieve a total (irrigation plus ambient rainfall) of twice the Hanford Site monthly average. The parameters of long-term climatic change needed to improve this treatment are average annual precipitation, seasonality of precipitation (i.e., shifts in the wet season), and storm frequency. The constraints and uncertainties associated with lysimeter simulations of a wetter climate were discussed in Section 2.1.2.2.

\subsubsection{Requirements for Assessing Barrier Stability and Erosion Control}

The long-term performance of the permanent isolation barrier depends, in part, on a design that controls soil loss. The fine-textured topsoil is intended to store rainwater until surface evaporation and plant transpiration cycle it back into the atmosphere. Erosion of the soil layer could lead to drainage through underlying coarse-textured layers and into the waste zone. The deposition of wind-blown sand on the barrier surface also could have a deleterious effect on barrier performance, permitting rapid infiltration and deeper percolation, which would result in reduced evapotranspiration. Protection of the embankment slope of the mounded barrier from erosion and prevention of slope failure is also critical for long-term performance.

Gravel mulches or admixtures have been proposed for topsoil erosion control, much like pavements and lag gravel veneers that have protected mineral soils in deserts for thousands of years. Well-graded gravel and rock riprap covers have been proposed to control sideslope failure. However, before these concepts can be transformed into defensible designs, the following issues must be resolved:

- Optimal gravel and rock sizes, shapes, layer depths, and concentrations for controlling wind and runoff erosion

- Effect of a surface gravel on soil water balance, plant growth, and evapotranspiration 
Figure 5. Small-Tube Lysimeter Facility near the Hanford Meteorological Station To Test Alternative Surface Configurations.

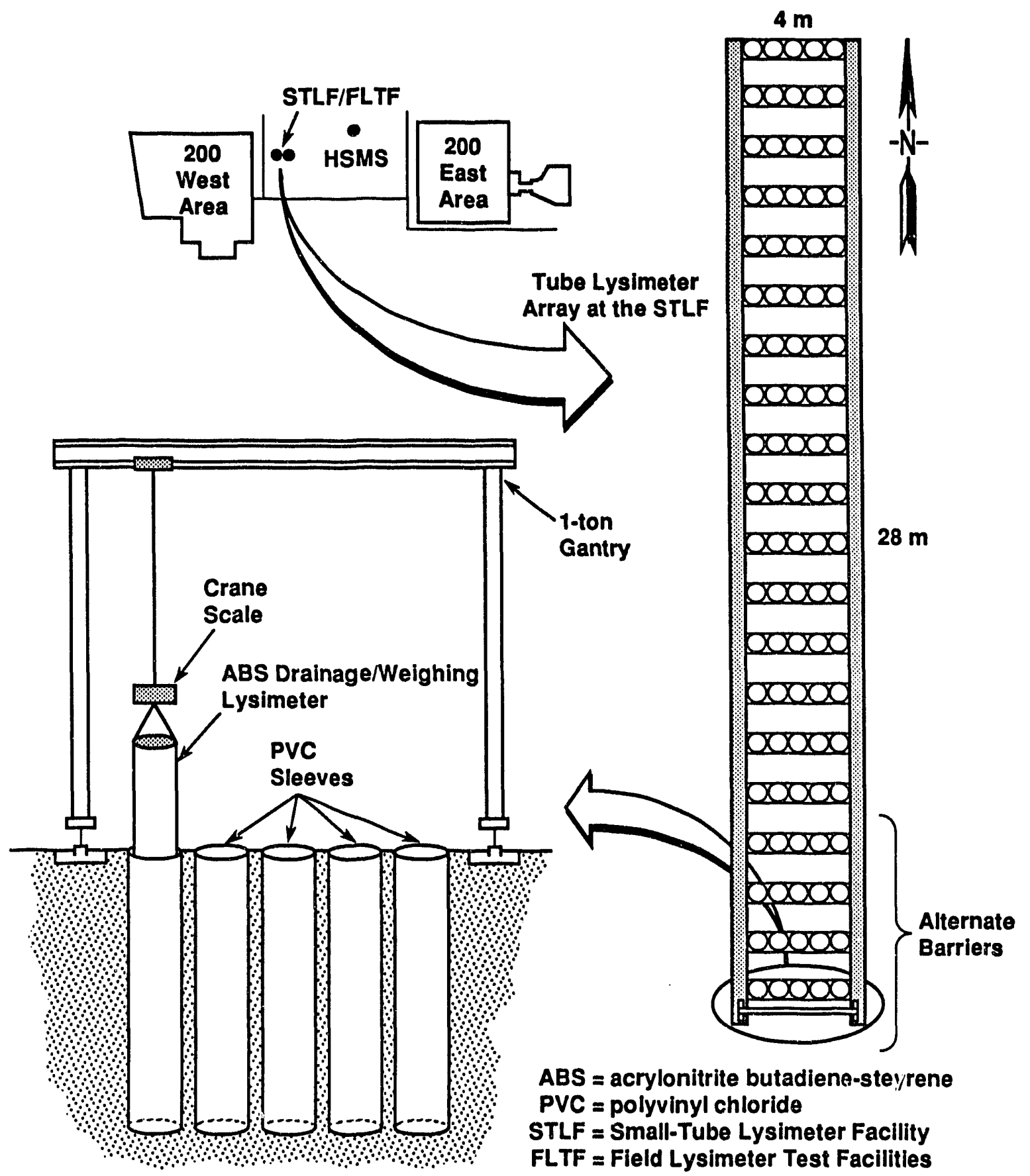

H9206001.3 
WHC-EP-0569, Rev. 1

- Effect of pedoturbation (natural processes of soll mixing) on the morphology of the surface gravel layer

- Effect of riprap on sideslope water balance and on the potential for slope failure

- Sensitivity of the system to climatic change.

2.1.3.1 Wind Erosion Control Requirements. The effects of eolian processes on the performance of the permanent isolation barrier can be grouped in two categories: deflation and deposition. Deflation is the loss of surface soil, especially during extreme wind events, resulting in a gradual lowering of the surface elevation. Rapid deflation can result in depressions, such as blowouts, which form when high winds are directed toward the ground leeward of topographic highs or following a severe disturbance of vegetation on soils high in sand. The following two conditions could lead to sand deposition and dune formation on permanent isolation barriers:

- Unstable surfaces on sandy soils upwind of the barrier

- Influences of the elevated barrier surface and the surrounding topography on wind-flow patterns.

The Barrier Development Program includes several tasks to accomplish the following:

- Testing the resistance of soil and gravel surfaces to wind erosion

- Estimating the probability of sand deposition and sand dune formation on barriers

- Modeling air flow patterns and boundary layers to identify potential edge effects and the possible need for windbreaks (Ligotke 1989).

The deflation tests are being conducted at the Aerosol Wind Tunnel Research Facility, which is at the Hanford Site, which is operated by PNL, (Ligotke 1989). Several experiments were designed to measure the resistance to deflation of various gravel designs in combination with treatments for vegetation, soil moisture content, and surface crusts (Ligotke 1989).

Air-flow profiles, boundary layers, wind speed, relative humidity, temperature, and lighting can be closely controlled and monitored in the wind tunnel. Field studies have also been initiated to estimate sand transport potentials and to measure wind boundary layers and patterns upwind of at the edges of, and over the surface of full-scale barrier prototypes. Included are studies of natural analogs to better understand the likelihood and causes of sand transport and dune formation on barriers. These data will be used to aid in calibration and validation of simulation models of eolian processes on barriers. Simulation models are required because of differences between laboratory and field conditions, and the impossibility of physically testing myriad combinations of surface and environmental conditions.

The wind erosion and sand deposition tests will require climatic data for an adequate assessment of the long-term stability of the barrier surface. 
WHC-EP-0569, Rev. 1

Testing currently is based on Hanford Site meteorological data. However, possible future changes in the magnitude, direction, and duration of Hanford Site winds (such as the possibility of enhanced future aridity and that could least to increased tornadic/dust devil type wind erosion) will be important for the selection of wind tunnel treatments and for developing predictive models of soil transport, surface deflation, and sand deposition. An understanding of possible changes in the frequencies, speeds, and durations of peak gust events also will be needed. Changes in wind direction will be less important for the erosion studies, but will be of primary importance for the studies of sand transport and deposition on barrier surfaces. Other climatic parameters needed for testing and modeling include amount and seasonality of precipitation (in relation to soil water content and the development of surface crusts); temperature ranges, extremes, and seasonality (freeze-thaw cycles); and changes in plant cover as a soil stability factor.

2.1.3.2 Water Erosion Control and Sideslope Stability Requirements. The conceniual barrier design includes two components that could fail as a result of runoff erosion (Cadwell and Walters 1989): (1) the fine-textured topsoil covering the expansive central portion of the barrier, and (2) the riprap shoulder along the upper perimeter of the barrier. Although a level barrier surface may seem ideally suited for controlling runoff erosion, it may become necessary to design barriers with sloped surfaces, if sloped waste sites exist. Crowned surfaces may be used if an effective design requires the partitioning of precipitation into infiltration and runoff components and diverts the runoff away from the barrier. This partitioning may be necessary if precipitation exceeds evapotranspiration for a future wet climate. In that case, barrier designs may require slopes of sufficient declination to provide adequate runoff without causing excessive erosion. Slopes also may be necessary because barriers with level surfaces probably would develop some micro-relief depressions from natural processes (e.g., burrowing, nonuniform soil deposition around plants, freeze-thaw cycles) and differential settlement of barrier materials and underlying waste structures. Infiltration could exceed evapotranspiration in such depressions.

The following forces could damage a riprap sideslope over thousands of years:

- Overland flow after high-intensity storms

- Rock weathering

- Hydrostatic pressures from excess soil moisture

- Subsidence

- Animal burrowing

- Freeze-thaw cycles.

Flood protection also would be of concern if barriers were constructed within the Columbia River floodplain.

As with the previous barrier performance tasks, field studies and modeling exercises both will be required to adequately design and test surface and sideslope components for runoff erosion control (Cadwell and Walters 1989). Estimates of important physical design and environmental parameters obtained in field-plot studies, natural analog studies, and from long-term climatic change projections will be used to calibrate and validate models that will become the engineering design tools needed to optimize 
WHC-EP-0569, Rev. 1

barrier performance. The key climatic parameters are storm properties, including storm duration, intensity, time distribution of intensity, and antecedent climatic parameters such as soil moisture and plant cover as influenced by fire, disease, grazing, and plant succession.

Rainfall intensity and return frequencies are of primary importance in these studies. The present predictions of rainfall amount, storm intensities, and return frequencies are based on extreme value analysis of relatively short Hanford Site meteorological records. Although there is considerable uncertainty in extrapolating estimates of infrequent extreme events, such as the intensity of a storm with a 1,000-yr return interval, meteorological records suggest that the Hanford Site lies geographically and climatologically in a region of high-intensity rainfall and occasional flash floods (Cadwell and Walters 1989). An objective of the climatic change task should be to reduce the uncertainty associated with estimates of infrequent, high-intensity rainfall events.

\subsubsection{Effects of Surface Gravel and Sand Deposition on Soil Water.}

Surface gravel admixtures and mulches have been proposed for the long-term control of wind and runoff erosion on permanent isolation barriers. A gravel mulch or admixture, however, could reduce surface evaporation and plant. transpiration, thus restricting the return of stored water to the atmosphere. Two studies were designed to measure the influence of coarse-textured surface layers on water movement in the permanent isolation barrier (Waugh and Link 1988; Waugh 1989). Both studies used factorial experimenial designs to measure the interactive effects of gravel, sand deposition, and a wet climate (twice the average monthly precipitation) on soil water storage, plant abundance, plant water extraction, and drainage. Tube lysimeters (Section 2.1.2.4) and large field plots were chosen as the experimental units for these studies.

The field-plot study started in 1986 at McGee Ranch, the site selected as a fine soil borrow area at the Hanford Site for the construction of permanent isolation barriers (Figure 6 ). The silt-loam soil at McGee Ranch has formed on deep flood sediments deposited during Pleistocene cataclysmic flooding of the Columbia Basin. The field-plot experiment was designed to test the combined effects of gravel admixtures and enhanced precipitation on soil water storage and plant cover. In contrast with the lysimeter experiments described in the following paragraph, the field plots, because of their location and greater size, retain a degree of edaphic heterogeneity, and the experimental design provides the means for isolating and testing the variation attributable to it. The first-year results of the experiment show that with vegetation absent, gravel admixtures can elevate soil water content within 17.71 in. $(45 \mathrm{~cm})$ of the surface. Gravel had no effect on soil water content in plots where plants were allowed to grow. The experiment will be continued for several more years to detect the influence of gravel and enhanced precipitation on plant establishment and on the soil water profile below the root zone.

The effects of various combinations of coarse-textured surface layers on drainage and evapotranspiration are being measured in lysimeters installed at the STLF near the Hanford Meteorological Station (Section 2.1.2.4). The treatment structure consists of 5 replications of 12 different combinations of gravel, sand, soil, vegetation, and precipitation. The results of wind 
WHC-EP-0569, Rev. 1

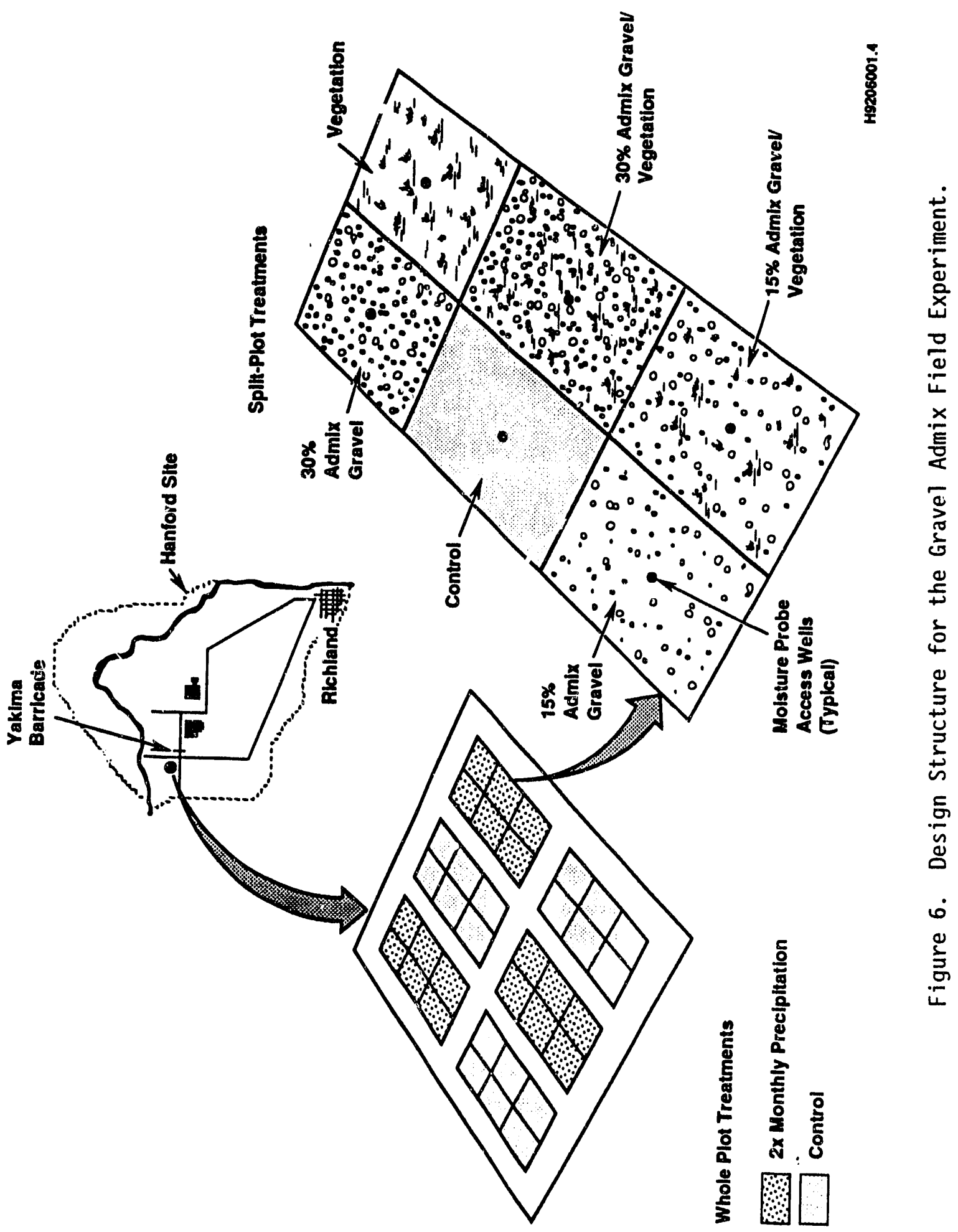


tunnel tests (Section 2.1.3.1) were used as a guide in the selection of gravel treatments. Drainage is measured directly from a valve in the bottom of the lysimeter. Lysimeters are weighed periodically from a hoist-mounted load cell, and water sturage changes are estimated as the difference between the current weight of the drained lysimeter and its drained weight from the previous session. Evapotranspiration is estimated by subtracting the drainage value from the sum of precipita:ion and storage changes.

As in the FLT' and alternate barrier demonstrations (Sections 2.1.2.1 and 2.1.2.4), simulation of a wetter climate in these erosion control tests is 1 imited to pe:-iodic irrigation and comparisons of plots with and without vegetation. To improve these treatments, predictions of possible changes in the average annual amount of precipitation, seasonal distribution (monthly amount), and storm intensities and frequencies are needed.

\subsubsection{Requirements for Assessing Biointrusion Control}

The scope of the bio-intrusion control tasks includes field studies and modeling to assess the influence of burrowing animals in relation to surface water movement through barriers, sirface soil erosion, and the direct physical transport of contaminants to the surface (Landeen et al. 1989;

Cadwell et al. 1989). Burrowing may influence infiltration by creating conduits for water movement through the barrier topsoil. Accelerated erosion may result as burrowing animals cast loose soil to the surface where it is susceptible to wind and water erosion. The field work planned to address these issues includes studies of climatic change on burrowing animal habitat, measurements of animal burrow characteristics (depth, soil volume excavated, density, survival, etc.), tests of burrowing effects on water infiltration, and tests of various construction materials for controlling bio-intrusion. Data from the field tests will be input to the model BIOPORT

(McKenzie et a1. 1986) to predict cumulative volumes of animal burrows, cumulative volumes of soil displaced by burrowing activities, and the cumulative amount of radioactive material brought to the surface of a permanent isolation barrier by burrowing animals.

To predict changes in burrowing animal habitat on barriers, a better understanding of the probable response of the barrier plant community to climatic change is needed. Plant species composition, abundance, and distribution determine the availability and quality of food and cover for burrowing animals. Burrowing animal habitat also is influenced by the following climatic parameters:

- Rainfall--amount and seasonality, snow accumulations, frequency and duration of droughts, humidity

- Temperature--seasonality, diurnal fluctuation, frequency and duration of extreme warm and cold periods, soil frost depth

- Wind speed

- Atmospheric gas composition $\left(\mathrm{CO}_{2}\right.$, pollutants). 
A rotating-boom rainfall simulator is used to test the effects of burrowing on water infiltration. Tests of small-mammal burrowing (pocket mice and pocket gophers) are conducted in large steel and wooden enclosures containing barrier materials. Rainfall, equivalent to a 100-yr storm event $(6.4 \mathrm{~cm} / \mathrm{h}$ for $13 \mathrm{~min})$, is applied on these small-mammal lysimeters on a monthly basis. The extent of rainfall penetration below large-mammal burrows (badgers and coyotes) is determined in the field. The effects of high-intensity storms $(6.4 \mathrm{~cm} / \mathrm{h}$ for $20 \mathrm{~min})$ have been simulated on the large-mammal burrows. Climatic change predictions are needed to justify the selection of these treatments.

\subsubsection{Climate Sensitivity Analyses}

Sensitivity analyses will be conducted to quantify the relative importance of climatic input parameters required by the various tasks to predict the long-term behavior of the permanent isolation barrier. The previous sections specify the many input parameters that will be required. In some cases, levels of temporal resolution and precision are indicated. The information in these sections should be viewed as a preliminary discussion of climatic data needs. Many more parameters may be required for future studies of barrier performance assessment.

Analyses of the sensitivity of the barrier to climate are a critical early phase in Task 1. Sensitivity analyses should dictate the scope and progression of the program. If the methods adopted to predict the long-term performance of the permanent isolation barrier indicate that, within prescribed levels of uncertainty, measures of performance are insensitive to climatic change, then the Long-Term Climate Change Effects Task would become more qualitative and less complex. Conversely (and more likely), if analyses indicate that barrier performance is highly sensitive to changes in certain climatic parameters, then the task would be expected to produce more quantitative estimates of bounding conditions for those parameters. Reasonable margins of uncertainty, which are needed to guide the sensitivity analyses, will hopefully emerge from regulatory guidelines and performance standards. Regardless, uncertainty will be constrained by the technology available for performance assessment.

The relative importance of climatic parameters will be determined by monitoring the sensitivity of one or more outputs of interest, such as drainage or evapotranspiration, to variation in one or more climatic inputs, such as precipitation or wind speed. For most tasks, an expedient approach will be to first examine the sensitivity of the performance assessment tool (e.g., model, lysimeter, or field plot) to climatic parameters within a range bounding the values expected for a series of worst-case scenarios. Refinement of a sensitivity analysis for a particular climatic parameter would be pursued only if warranted by the results of the worst-case situations. Refinement would consist of additional analyses for successively less severe scenarios. 
WHC-EP-0569, Rev. 1

\subsection{TASK 2: SYNTHESIS OF EXISTING INFORMATION}

\subsubsection{Purpose}

The available published literature will form the basis for developing a systematic understanding of the nature, magnitude, and rate of past and potential future climatic change in the Pacific Northwest. This information then will help to answer the first decision point question: "Does existing information satisfy data needs of the various Barrier Development Program Tasks?" In general, the answer to this question is "no," and additional studies must be undertaken to gain the needed resolution and detail. However, most of the studies associated with the other Barrier Development Tasks are already underway. In designing the treatments for many of these studies, some assumptions were made about possible future climatic conditions (precipitation amount, storm intensity, wind speed, etc.). These preliminary estimates of potential climate are actually an early product of Task 7: Future Climate/ Vegetation Projections and are shown logically in Figure 3 as the arrow that by-passes the field studies and goes directly to the box titled Future climate/Vegetation Projections. Because the final results of the climate tasks may not be available until near the conclusion of these other barrier development task studies (when changes in treatments would be impractical), it will be necessary to make the best projections possible when they are needed based on the results of Task 2, the synthes is of information. For those tasks for which climate projections have been provided early, the remainder of the climate program may actually serve more of a confirmatory role and be an effort to improve our confidence of the estimates that were made relatively early in the program. If new information is discovered too late for inclusion in experiment treatment design, the impact of these new considerations will have to be modeled.

\subsubsection{Methods}

Based partly on the recommendation of the technical review panel, this task is divided into five subtasks: Modern Climatic Patterns, Holocene Paleoclimatic Literature, Late Quaternary Paleoclimate Literature, Flood History, and Global Climate Modeling. These five divisions make some intuitive sense because of the differing expertise that is required to deal with each one. This task will compile, analyze, and synthesize extant literature on the five parts. It will help identify areas that are sufficiently covered by extant literature and areas in need of further study. Literature and records will be reviewed and analyzed and the results integrated into climatically or hydrologically meaningful synopses. A useful starting place is provided by Houghton et a1. (1990), Crowley and North (1990), and Goodess and Palutikof (1991).

Based on the recommendations of the technical review panel, the synthesis of paleoclimatic/paleo-environmental information will focus on characterizing periods of selected climatic extremes as contrasted with the present that could impact the barriers if such extremes were to occur. These include the last interglacial/glacial transition (deep sea oxygen isotope stage 5 to $2 \mathrm{ka}$ ); the last glacial maximum (nominally $18 \mathrm{ka}$ ); and the early Holocene $(9 \mathrm{ka})$. Based on the results of some literature surveys and the experience of 
the authors, it may be appropriate to analyze other periods of times. For instance, the COHMAP model simulations include characterization for $18 \mathrm{ka}$ and $9 \mathrm{ka}$, but also for $6 \mathrm{ka}$ and $3 \mathrm{ka}$ (COHMAP Members 1988). If these two later time periods were also examined, it would allow for an assessment of the applicability of the COHMAP simulation to the central Columbia Basin. Based on the experience of Chatters and Hoover (1992), the period $3.5 \mathrm{ka}$ appears to have the greatest relative wetness locally and thus potentially provides an analog for an extreme climatic condition that could affect water infiltration potential into the barriers. The local and regional paleoclimatic reconstructions for $125 \mathrm{ka}, 18 \mathrm{ka}, 9 \mathrm{ka}, 6 \mathrm{ka}$, and $3.5 \mathrm{ka}$ will be compared with other available global climate modeling simulations for these intervals.

\subsubsection{Modern Climatic Patterns. Understanding modern climatic patterns} gives a better basis for evaluating past changes and potential changes. In addition, historic characteristics of extreme events and changes of seasonality ultimately may give insight to important controlling variables to be considered in assessing climatic impacts to permanent isolation barrier performance. A number of regional dendroclimatic reconstructions using tree rings provide additional insight into recent climatic trends. These modern trends can be used to compare and contrast with the five discrete time periods that have been identified for further characterization.

\subsubsection{Holocene Paleoclimate Literature. The available paleoclimatic} i iterature is divided into the two groups indicated because of the paucity of records covering the Pleistocene (about the last 1,500,000 yr) in the Pacific Northwest, contrasted with abundance of those records for the Holocene (the last $10,000 \mathrm{yr}$ ). The Holocene Paleoclimate Literature study will analyze alpine glacier histories of the mountain ranges surrounding the Columbia Basin, physical stratigraphy in caves and rockshelters of the region, fluvial geomorphology and riparian archaeofaunas from the Columbia and Snake Rivers (as indicators of climatic change), evidence for elevational changes in regional timber lines, palynology of lake basins and terrestrial sediments of the region, and terrestrial archaeofaunas. All will be integrated into a record of temperature and precipitation patterns on a seasonal and mean annual scale to the extent that the data permits such conclusions. Because the magnitude and frequency of extreme rainfall events and/or the seasonality of precipitation may prove important, a special effort will be made to identify the range of such parameters for the selected periods of past climatic extremes.

The 9,000-yr period has been identified by the technical review panel as a period of climatic extreme to receive particular study. There is considerable paleo-ecologic evidence from the Pacific Northwest that the period from 6 to $10 \mathrm{ka}$ was a time of greater summer drought than today. The COHMAP model results for the 9-ka condition point to the amplification of the seasonal cycle of radiation and the consequent expansion of the subtropical high as the cause of drier hotter summers at the time (COHMAP Members 1988). Another period selected for study is the period centered on $3.5 \mathrm{ka}$ because preliminary indications are that it was locally a period of increased recharge.

2.2.2.3 Late Quaternary Paleocl imate Literature. The focus of this study will be on climatic records primarily for the last $200 \mathrm{ka}$ because of the paucity of records older than that and because the five periods of climatic 
WHC-EP-0569, Rev. 1

extreme that have been identified to be the focus of study fall with in that time period. A useful starting place is provided by Houghton et al. (1990), Crowley and North (1990), and Goodess and Palutikof (1991); Chapter 5 of the BWIP SCP (DOE-RW 1988) will also be consulted. Synthesis of data on full glacial and interglacial climates will use more limited sets of data from a larger geographic area that include ocean sediment and reef records, ice core records, long pollen and lake sediment records, calcic veins and spring deposits, glacial moraines, and geomorphology and paleopedology of loess deposits in the Columbia Basin and el sewhere. These records, when viewed in the context of global climate change, possibiy can give information about the timing and type of climatic change in relation to astronomical forcing (the so-called Milankovitch cycles) that have occurred in the past thus heiping to provide bounding conditions for any potential changes in the future. This paleoclimate synthesis will attempt also to provide a brief but critical comparison among purported index data.

2.2.2.4 Flood Records. The Hanford Site region has been affected by past catastrophic flooding, and a large body of literature has been devoted specifically to that one topic. This task will outline clearly the history of the flooding concerns that have been expressed in the development of the research strategy in support of the Barrier Development Program. The synthesis of the literature on flood histories will compile hydrographs of the historic Columbia River, compile evidence for estimates of the magnitude of Holocene floods, and search information on Scabland Floods and, later, glacial flooding to gain estimates of the magnitude and climatic controls on catastrophic floods that have scoured this region. Using these groupings, floods will be categorized into the following three classes.

- Type I consists of floods resulting from precipitation or snowmelt without drainage from ice-dammed lakes.

- Type II floods are glacial outburst floods from Canada, which occurred in the terminal Pleistocene, after glaciers had receded north of the international boundary. Initiation of a new glacial cycle during the next 10,000 yr may occasion floods of comparable magnitude.

- Type III floods are those from Glacial Lake Missoula, the largest of which formed the gravel plateau on which the 200 Areas are located. This task will explore the possibility that floods of this magnitude could occur during a less-than-full glaciation which could develop during the next 1,000 to $10,000 \mathrm{yr}$. Flood protection for Type III floods is impractical--they would wipe out all Pasco Basin sites.

2.2.2.5 Global Climate Modeling. Because of the recent concern over the potential impact on global climate by increasing $\mathrm{CO}_{2}$, this study encompasses the quickly developing field of global climate modeling (Section 1.1.2). Various general circulation mode1 (GCM) experiments have been run for the doubled $\mathrm{CO}_{2} \mathrm{climate}$ and the ice age climate, which arguably could represent extreme climate scenarios probable during the next 1,000 to $10,000 \mathrm{yr}$. Data available from the models include most of the relevant parameters for many hydrologic models including temperature, precipitation, cloud cover, etc. A review will be conducted of modeling results of the ice age and doubled $\mathrm{CO}_{2}$ climatic conditions focusing on the Pacific Northwest. Useful starting 
WHC-EP-0569, Rev. 1

material is provided by Houghton et al. (1990), Crowley and North (1990), and Goodess and Palutikof (1991). The GCMs also produce changes in soil moisture and ground temperature, which would be of relevance. Additional model results are available for the (approximately) 9,000-yr interval, a time of possible extreme for which paleodata is more readily available. The methodology of Smith and Tirpack (1989) will be used to evaluate model results. An improved approach currently under development is the use of a high-resolution mesoscale model that has a higher grid density nested within a global climate model. The global climate model provides the boundary conditions for the mesoscale model simulation (Dickinson et al. 1989; Giorgi 1991). Anyway, the relationship between local climate variables and regional climatic controlling factors, such as atmospheric and oceanic circulation patterns, must be understood and summarized.

\subsubsection{Required Inputs and Expected Outputs}

The inputs needed by this study are the bodies of literature mentioned in Section 2.2.2, instrumental climatic records, and the critical reviews by other climate and paleoclimate experts. Expected outputs are project reports and journal articles subject to peer review that synthesize data on future climate probabilities, Holocene paleoclimates, glacial and interglacial climates, and flooding histories of the Hanford Site area. Each of these documents will assess the completeness of extant information, and will make recommendations for additional studies needed to make the climate scenarios for extreme conditions detailed enough so that they can be input to the local climate model. These syntheses are shown first in Figure 3 to be input into the three groups of field studies (Terrestrial Sediment Studies/Fluvial Sediment and Groundwater Studies/Pollen and Lake Sediment Studies) or into Task 7: Future Climate/Vegetation Projections (Section 2.7).

\subsection{TASK 3: POLLEN AND LAKE SEDIMENT STUDIES}

Pollen grains and spores of vascular plants are among the most abundant type of fossils preserved in terrestrial quaternary sediments. As a result, extensive use of the techniques of stratigraphic pollen analysis have been applied in attempts to reconstruct past plant distribution and abundance and to estimate the controlling climatic conditions (Berglund 1986). Analysis of dated cores of lake sediments can yield pollen characteristics of the vegetation and climate at the time the sediment was deposited. Specifically, pollen analysis can aid in accomplishing the following activities:

- Detecting differences in past vegetation distribution

- Indicating relative differences in effective moisture through time

- Helping to determine the limits of the extent of climatic variation

- Characterizing the rates of change from one climate regime to another. 
WHC-EP-0569, Rev. 1

\subsubsection{Purpose}

The purpose of this task is to collect, date, and analyze fossil pollen and other lake sediment data obtained from long cores to allow further refinement of the developing climate history of the Pasco Basin region and provide more location-specific climatic information on periods of climatic extreme identified for study in this study plan. Specifically, two subtasks (Sections 2.3.2.1 and 2.3.2.2) have been identified to accomplish this task.

\subsubsection{Methods}

The study of lake sediments cores and their constituents (including the sediments [gross physical and chemical characteristics, organic weight loss on ignition, volcanic ashes, and isotopic content], charcoal, fossil pollen, plant and fungal spores, algae, and plant and animal macrofossils) provide evidence of vegetational and climatic changes for the time period represented by the deposited sediments (Berglund 1986; Birks and Birks 1980; Birks and Gordon 1985; Faegri et a1. 1989). Two subtasks will be undertaken to elucidate specific details of paleoclimate in eastern Washington. The first subtask (Section 2.3.2.1) is a transect of pollen sites across the central Columbia Basin designed to refine estimates of change in past climatic conditions and especially for the 9-ka, 6-ka, and 3.5-ka periods. The second subtask (Section 2.3.2.2) is a recording of a lake near Goldendale, Washington, that already has a pollen record dating $33 \mathrm{ka}$. The specific objectives of this second subtask includes getting more information on the 18-ka period of extreme climate, extending the record as far back in time to document the antecedent climate conditions, and attempting to recover some missing record that occurred during the 9-ka period.

Sediment cores will be taken from each lake in an attempt to obtain unbroken records from modern times back to the time the basins began to accumulate sediment (since the last glacial flood in the case of the first subtask or creation of the volcanic crater in the case of the second task). Coring will be conducted using a modified Livingstone piston sampler (Deevey 1965). Once obtained, cores will be opened, described, and sampled for chronological, compositional, and palynological studies. Chronology will be based on radiocarbon dating of organic sediment and tephrochronology using as many as six volcanic ash layers of known age and mineral composition. Compositional analyses, used to determine the rates of organic and inorganic sediment influx, will rely on weight loss on ignition. Palynological studies (taken here to include analyses of pollen, spores, plant macrofossils, and diatoms) will follow standard, state-of-the-art techniques. Sampling intervals will vary with the site and time period; sediments representing intervals of special interest ( $18 \mathrm{ka}, 9 \mathrm{ka}, 6 \mathrm{ka}$, and $3.5 \mathrm{ka}$ ) may be sampled more closely than others, as will sediments from important floristic transitions. Sediment samples taken for pollen and spore analyses will be of constant volume and be combined with known concentrations of tracer Lycopodium spores as a standard for use in computation of pollen and diatom concentrations. Identification will be done in a standard manner, using type collection for identification of unknowns. Results of palynological analyses will be described as raw counts, pollen percentages, and pollen concentrations/influx rates. 
2.3.2.1 Transect of Pollen Sites Across the Scabland of the Central Columbia Basin. Studies will be conducted of lacustrine sediments from four lake basins. These lakes, Williams (near Cheney, Washington), Wildcat (near Hooper, Washington), Sulphur (near Connel1, Washington), and Badlands (near Benton City, Washington) span the steppe zone of eastern Washington and straddle the Hanford Site, and thus are expected to provide detailed information on the distributions of vegetation types and levels of groundwater in the Pasco Basin and vicinity. Cores already exist for Williams and Wildcat Lakes, and these have been analyzed to varying extents already (Mehringer 1985; Nickmann 1979), but core will need to be taken from Sulphur and Badiands Lakes. The time period covered by these basins is the past 13,000 yr for all basins and may be as much as 20,000 yr for Sulphur Lake. Variations in the occurrence and frequencies of different pollen, algae, and plant macrofossil types across this transect will be interpreted in terms of changing plant community composition, which will in turn be a basis for estimates of changing subannual patterns of temperature and precipitation, and positions and intensities of major storm tracks for the latest Pleistocene and periods of the Holocene centering on $9 \mathrm{ka}, 6 \mathrm{ka}$, and $3.5 \mathrm{ka}$. Sulphur Lake in particular has been chosen for study because of its potential to contain a pollen record dating to the full Glacial (ca. $18 \mathrm{ka}$ ) about which nothing is known for the central Columbia Basin. In addition to vegetation and paleoclimatic reconstruction, lake sediments will be studied for evidence of changing water levels in the lakes, which are believed to reflect groundwater levels in the lakes' vicinities. These data will be used as an adjunct to, and cross-check of, data on groundwater recharge rates obtained from extant wells (see Section 2.4.2, Feasibility Study for Episodic Groundwater Recharge).

2.3.2.2 Full Glacial Pollen Record from Carp Lake, Goldendale, Washington. The second subtask is a recording of Carp Lake, south-central Washington. Carp Lake, $7 \mathrm{mi}(11.27 \mathrm{~km})$ north of Goldendale, is within a volcanic crater of early Pleistocene age, and has been shown (Barnosky 1985) to have a record that extends at least $33 \mathrm{ka}$ and brackets the period of maximum full glacial conditions that date to approximately $18 \mathrm{ka}$. A geophysical survey of the bottom of Carp Lake will be performed to locate within the lake basin the thickest and hopefully the most complete section of lake sediment. This will aid in the attempt to extend the climatic record even farther back in time to provide more information on the antecedent climatic conditions that preceded development of full glacial conditions. This second coring will aid also in the attempt to recover sediment from the 9-ka period that appears as a hiatus in the earlier coring record. A pollen profile will be produced and analysis performed on the data in terms of quantitative estimates of past climate. The location of Carp Lake is such that it will complete the northeast-to-southwest linear transect formed by the four lakes to be studied in the other pollen subtask (Section 2.3.1) and can be compared and contrasted with them for the post 13-ka period. The work at Carp Lake also will utilize response surfaces that are being currently developed for western plant taxa and other regression-based methods to reconstruct paleoclimate.

\subsubsection{Required Inputs and Expected Outputs}

Input requirements for this task include the existing sediment cores from Williams and Wildcat lakes, extant palynological data from previous work at 
WHC-EP-0569, Rev. 1

those two lakes, and that of Carp Lake, and botanical data on the ecological tolerances and climatic controls on plant communities of the Steppe and foothills region. Expected outputs include dated records of pollen, spores, plant macrofossils, diatoms, physical stratigraphy, and deposition rates from the five lake linear transect. These data and those previously reported for a number of pollen sites that surround the central Columbia Basin (Barnosky et a1. 1987; Baker 1983; Huesser 1983; Mehringer 1985) will be used to infer past climatic conditions for the time periods identified for study. These data and those from the other tasks in this study plan also will be used to reconstruct past lake (groundwater) levels for the entire Holocene and the late Pleistocene. This information will be passed to Task 7: Past Climate/ Vegetational Variation, which is shown as a box in Figure 3.

\subsection{TASK 4: FLUVIAL SEDIMENT AND GROUNDWATER STUDIES}

This task focuses on evidence of climatic change from fluvial sediment or groundwater studies. It has two subtasks: one flood history (Section 2.4.1) and a feasibility study (Section 2.4.2) for using groundwater dates to infer climatic change.

\subsubsection{Fluvial Indicators}

2.4.1.1 Purpose. This task will assess the potential that Columbia River and glacial outburst floods might inundate and erode barriers located at lower elevations of the Hanford Site, and can be used in conjunction with paleoclimatic records to assess the effects of climatic conditions on the magnitude of flood hazards. The 100 and 300 Areas of the Hanford Site are located a few meters above the modern Columbia River, and it is possible that under extreme flooding conditions, water might exceed the confines of the river's channel and affect the barriers and waste deposits located there. The 200 Areas of the Hanford Site are located much higher on the landscape, but nonetheless were under water during the maximum glacial floods that swept the region in the late Pleistocene.

Floods will be considered in three classes. Type I consists of floods resulting from precipitation or snowmelt without drainage from ice-dammed lakes. This type of flood may have the potential to affect only the 100 and 300 Areas of the Site; this possibility will be explored by studying the elevations of Holocene floods and historic floods on the Columbia River using geological and historical techniques. Type II floods are Glacial outburst floods from Canada, which occurred in the terminal Pleistocene, after glaciers had receded north of the international boundary. Initiation of a new glacial cycle during the next 1,000 to 10,000 yr may occasion floods of comparable magnitude. Such floods, if repeated, also would affect only the 100 and 300 Areas. Type III floods are those from Glacial Lake Missoula, the largest of which formed the gravel plateau on which the 200 Areas are located. This task will explore the possibility that floods of this magnitude could occur during a less-than-full glaciation, which could develop during the next 1,000 to $10,000 \mathrm{yr}$. Of course protection from floods of this magnitude is not practical because they would wipe out Pasco Basin sites. 
WHC-EP-0569, Rev. 1

2.4.1.2 Methods. We will consider both the record of various flood types and the probability for similar floods to occur in the future. The past record of the largest Type I floods will be explored using geological (e.g., Kochel and Baker 1982; Costa 1978) and historical techniques. Historical records of the largest floods of modern times, the 1894 and 1948 Columbia River floods will be searched for records of flood water elevation. In addition, floodplain sediments, particularly those exposed along the Columbia River near the 300 , 100-D to 100-H, 100-N, and 100-F Areas, will be trenched using a backhoe to identify and document fluvial sediments of Holocene age. Maximum elevations of individual fluvial beds will be measured, and these sediments will be dated using either tephrochronology, radiocarbon, or thermoluminescence. Paleoflood records thus obtained will be compared with paleoclimatic data obtained in other tasks and also will be used to infer the climatic conditions that contribute to major flooding. Risks to the low-elevation waste sites then will be estimated by elevation and climatic scenario. Geologic records also will be used to explore the magnitude of Type II floods, but in this case will include a search for the youngest glacial flood channels on the Hanford Site, using aerial photogrammetry and surface inspection. When sediments are identified, their elevations will be mapped and they will be dated by one or more of the aforementioned means. Dated flood deposits then will be correlated with glacier positions and paleoclimates so that the conditions necessary for the occurrence of Type II floods can be determined. Type III floods, which have been studied extensively by others, will be investigated through a literature review, covered largely under Task 2. The potential for all types of floods found to reach elevations high enough to affect potential waste sites will be estimated using extant models of climatic change and development of glacial cycles.

2.4.1.3 Required Inputs and Expected Outputs. Required data include paleo-ecological and paleoflood summaries for the Columbia Basin prepared in Task 2, data on historical flow characteristics of the Columbia River, and models of future climate and glacial development scenarios. Data produced by the task will be used to produce the following:

- A chronology of severe Type I floods and their maximum elevations

- An estimate of the timing and severity of Type II floods

- Models of the conditions contributing to severe Type I and II floods

- Estimates of the probability for any of the three flood types to occur in the next 1,000 to 10,000 yr and in doing so the possibility that they could adversely affect barrier survival.

\subsubsection{Feasibility Study for Episodic Groundwater Recharge}

2.4.2.1 Purpose. In a study of groundwater in eastern Washington, Silar (1969) obtained 43 radiocarbon dates on dissolved $\mathrm{CO}_{2}$ from confined aquifers that lie between basalt strata. Preliminary reanalysis of these dates and their geographic distributions has shown that, rather than exhibiting the expected inverse exponential frequency distribution with age, the dates exhibit strong modalities that correlate with climatic periods recognized in the Holocene. Although the number of dates is small, it is indicative of the 
potential of water dating for understanding the relationship between climate and groundwater recharge in the region around the Hanford Site. Additionally, because groundwater is likely to percolate from the surface into the vadose zone early in the year--before evaporation becomes a significant influence--isotopic composition of dissolved oxygen in groundwater should reflect the cumposition of the precipitation from which it was derived (Eicher and Siegenthaler 1976; Stuiver 1970). The isotopic composition of this precipitation is directly related to air temperature (Dansgaard 1964). Because the majority of precipitation in this region falls in winter--and the primary source of groundwater is winter precipitation--the oxygen isotope composition of groundwater should be useful as a measure of winter temperature (which is not available from any other data source). This task will explore the feasibility of radiocarbon and oxygen isotope assay of confined groundwaters in and around the Pasco Basin as means for studying recharge in relation to climate and winter temperatures, respectively. If the approach proves feasible for one or both applications, the task will be expanded into a full-scale study that will contribute significantly to the understanding of the impact of climatic scenarios on the infiltration of water into waste forms.

2.4.2.2 Methods. This feasibility study will have two parts. Part I will consist of a literature review, and Part II will consist of field studies. In Part I, review of the theory and techniques of groundwater dating and isotopic analys is will be undertaken and experts will be consulted. If this review demonstrates the theoretical feasibility of the research, then Part II, the field studies, will be initiated. This will consist of analysis of an initial 10 groundwater samples. Samples will be obtained from existing irrigation or drinking water wells that draw from confined aquifers, distributed systematically in geographic space. The exact sampling procedures to be used will depend on results of the literature review. Carbon from carbon dioxide, and oxygen, deuterium, and tritium from water will be extracted and isotopicaliy analyzed by mass spectrometry. Important carbon isotopes are ${ }^{14} \mathrm{C}$ and the ratio of ${ }^{13} \mathrm{C}:{ }^{12} \mathrm{C}$; the former for determines sample age, the latter the contribution of ancient carbonates (e.g., from limestone) to the carbon content of the water. If ancient carbon is absent or occurs in insignificant amounts, then the radiocarbon date may be correct. Deuterium and 0 isotopes will be analyzed together to ascertain the water source. If they are derived from meteoric precipitation, and little recent water has been added to the aquifer, then $D$ and 0 should exhibit a linear relationship. Tritium will also indicate the extent of modern groundwater contamination of deep aquifers. Finally, the ratio of ${ }^{18} 0$ to ${ }^{16} 0$ will be determined and compared with the ratio for standard mean sea water to calculate the air temperature at the time of condensation.

2.4.2.3 Data Input Requirements and Expected Outputs. Data input requirements for this task include literature on dating and isotopic analyses of groundwaters and water samples from 10 wells in the Columbia Basin. Expected outputs are an assessment of task feasibility, and if this result is positive, a demonstration of technical approach used including tables of isotopic contents of the 10 water samples. If the work proves feasible, a final output of this feasibility task will be development of a detailed task plan for further research. 
WHC-EP-0569, Rev. 1

\subsection{TASK 5: TERRESTRIAL SEDIMENT STUDIES}

This task focuses on terrestrial sediment studies. It has two subtasks, studies of eolian sediments (Section 2.5.1) and faunal data (Section 2.5.2).

\subsubsection{Studies of Eolian Processes}

2.5.1.1 Purpose. The influence of climate on surface winds is a variable important for understanding the impact of those climatic states on the performance of permanent isolation barriers. The direction and velocity of surface winds flowing over sediment source areas (also partially controlled by climate) affects patterns of wind erosion and disposition. Collectively these are referred to as eolian processes. Removal from or deposition of fine sediment on barriers may impact soil water balance, thereby affecting the barrier's ability to prevent dissolution and transport of waste materials. This task will study the relationship between eolian processes and climatic conditions during the postglacial period (the last 10,000 to $13,000 \mathrm{yr}$ ) on and around the Hanford Site. This task consists of three phases. Phase I will characterize the eolian systems and eolian sediment chronology on the Hanford Site by collating and analyzing existing meteorological and dune distribution data to clarify the link between climate and eolian processes and by outlining a sequence of dune formation and stabilization intervals on the Hanford Site during the postglacial period (the last 10,000 to 13,000 yr). Phase II will accomplish the following:

- Conduct studies of the regional terrain

- Map and date dune formation episodes on a regional scale

- Reconstruct past wind flow patterns.

Phase III will interpret the link between Holocene climatic conditions and eolian erosion and sedimentation. The results can be used in conjunction with future climate models, past climatic scenarios, and wind tunnel experiments studied by other Barrier Development Program tasks to estimate the future likelihood for extensive dune formation on and wind erosion from the barriers.

2.5.1.2 Methods. One goal of Phase I is to characterize the eolian systems on the Hanford Site by collating and analyzing existing meteorological and dune distribution data to clarify the link between climate and eolian processes. Phase I will begin by characterizing dune formation proiesses on the Hanford Site. Extant data will be compiled on meteorology (especially wind) and sand roses that have been generated by Hanford Site contractors during the past $45 \mathrm{yr}$. Aerial photographs of the Site will be analyzed to allow creation of maps of past dune movement. Results will be used to reconstruct a history of dune migration in relation to short-term climatic variation at the Site. Some measurement of dune migration rates during the contract period may be necessary although this type of activity mostly will be covered in Phase II. Another goal of Phase I is outlining a sequence of dune formation and stabilization intervals on the Hanford Site during the postglacial period (the last 10,000 to $13,000 \mathrm{yr}$ ). Phase I will next establish a chronology of eolian deposition on the Hanford Site by identifying, describing, sampling, and analyzing dune deposits and source areas for eolian sediment. Chronological control will be accomplished by locating dunal sediments that are associated with some datable material such 
WHC-EP-0569, ReV. 1

as soil carbon, archaeological remains, or volcanic ashes. Dates will be obtained by tephrochronology, thermoluminescence, or radiocarbon. Eolian sediments at each site will be described, including sediment structure, texture, mineralogy, and the degree and type of soil development at the surface of each depositional stratum.

Phase II includes objectives to conduct studies of the regional terrain, to map and to date dune formation episodes on a regional scale, and to reconstruct past wind flow patterns. Phase II provides for the collection of data on the morphology and sedimentology of dunes active since 1945 from areas within and beyond the Hanford Site and for analysis of these with meteorological and sand rose data for the same period to clarify the causal relationships of these phenomena. Additional data on the geographic distribution of different-aged dune sediments and sediment source areas also will be studied. Systematic sampling of stabilized and active dunes will be conducted on and around the Hanford Site to generate maps of dune fields for each depositional episode, identify sediment sources for each episode, and obtain data for use in determining wind direction and velocity from the dune field maps, and dune sedimentology and morphology. This will require extensive trenching, core sampling, and textural, mineralogical, sedimentological, and chronological analysis to obtain cross-dating of sampled dunes with the eolian chronology of Phase I and evidence for air flow patterns. The result will be maps of air flow patterns and velocitios for identified periods in the past.

Phase III is for the interpretation of the link between Holocene climatic conditions and eolian erosion and sedimentation. The results can be used in conjunction with future climate models, past climatic scenarios, and wind tunnel experiments studied by other Barrier Development Program tasks to estimate the future likelihood for extensive dune formation on and wind erosion from the barriers. Phase III will compare maps produced in Phase II, with the climatic conditions for the periods they represent. This information, along with data obtained during Task 2 on modern climates and dune formation, will be used to generate a model of the relationship between climate and eolian processes. This model then can be run using climatic conditions expected under extreme climatic states identified and characterized by other components of the Climate Change task of the Barriers Development Program.

2.5.1.3 Required Inputs and Expected Outputs. Required inputs are the paleoclimatic reconstructions from Task 3 and other tasks, historic data on Hanford Site meteorology and sand and wind roses, a dated series of aerial photographs, and literature on eolian processes. Expected outputs are an analysis of the recent history of dune formation and movement on the Hanford Site, maps of dune fields and paleowind patterns in the region, and a model describing the relationship between climate and eolian processes throughout the Late Glacial and Holocene.

\subsubsection{Faunal Indicators}

2.5.2.1 Purpose. In the event that palynological studies fail to obtain a record of vegetation for the full glacial period $(18 \mathrm{ka})$ or the last interglacial period $(125 \mathrm{ka})$, assemblages of small vertebrate fossils will be 
WHC-EP-0569, Rev. 1

obtained from the loess deposits in the vicinity of the Pasco Basin to provide the needed data. The composition of microfaunal communities is relevant to the characterization of past climate at the Hanford Site because animal community composition correlates with modern vegetation distributions and temperature extremes (Hiarris and Maser 1984). Microfauna, including primarily rodents and reptiles, are short-- 7 ived, nonmigratory animals with small home ranges. They are often highly habitat specific, so that individual species are good indicators of vegetation and other environmental characteristics. Their bones are resistent to decay in the neutral to basic soils of arid lands and are readily identifiable to genus and usually to species leve . Based on the ecoiogical amplitudes of the various animals found in paleontological collections, and the relative abundance of different species, past environmental conditions can be inferred. The results of analysis are usually consistent with paleo-envircnmental reconstructions from other sources.

2.5.2.2 Methods. Agronomists from Washington State University have reported oliserving concentrations of small mammal remains while conducting studies of fossi? soils in southeastern Washington. Additional fossil deposits are known to occur in the Horse Heaven Hil?s (Rensberger et a1. 1984). Known sites will be visited and assessed for their potential to provide the needed quantity of remains, then a subset of observed sites will be selected for sampling. Fossils will be excavated and preserved using standard paleontological techniques. Associated sediments will be dated by tephrochronology, thermoluminescence and, if appropriate, radiocarbon. Bone assemblages will be identified using keys (e.g., Maser and Storm 1970) and comparative collections, and they will be quantified by appropriate methods (Grayson 1984). Using modern ecologies of the represented animals, environmental conditions at the time of assemblage deposition will be inferred. These will be used along with any other evidence obtained from outside the area to estimate climatic conditions in the Pasco Basin during the full glacial and last interglacial.

2.5.2.3 Required Inputs and Expected Outputs. Data required will be information on the ecology and identification of microvertebrates, the locations of fossil sites, and records and possibly collections from previous palecitological excavations in the region. The expected output is a tabulation of small mammal and reptile faunas from the loess deposits around the Pasco Basin dating to the full glacial and/or interglacial, an inte:apretation of their meaning in environmental and climatic terms.

\subsection{TASK 6: PAST CLIMATE/VEGETATION VARIATIONS}

The results obtained from Tasks 2 though 5 will be integrated into one comprehensive picture of past climate/vegetation variations in the Hanford Site region for the Late Quaternary and Holocene with special emphasis on the periods $125 \mathrm{ka}, 18 \mathrm{ka}, 9 \mathrm{ka}, 5 \mathrm{ka}$, and $3.5 \mathrm{ka}$. For this task, the gathered data will be used to formally document a defensible answer to part of the question contained in the second decision point in Figure 3: "Do

Reconstructions Bound Long-Term Astronomical Forcing ... ?" At this point it might be possible to learn enough about the bounding ranges of precipitation and temperature and the types of vegetation that have occurred in the past to use these ranges exclusively in the performance assessment of the permanent isolation bariiers. However, the entire question for the second decision 
WHC-EP-0569, Rev. 1

point cannot be answered completely until the timing, character, and uncertainty for greenhouse warming can be projected for the Hanford Site Region. Therefore, the results of this task must be coupled with those of Task 7.

\subsection{TASK 7: FUTURE CLIMATE/VEGETATION PROJECTIONS}

The results obtained from the literature search in Task 2 will be used to make future climate/vegetation projections that take into consideration the potential near-term effect of future greenhouse warming and the longer term effect of cycling into the next ice age. Together with Task 6 , the gathered data for this task will be used to document formally a defensible answer tot the question posed in the second decision point: "Do Reconstructions Bound Long-Term Astronomical Forcing and Projected Greenhouse Effects?" If it were found that the characterization of the past climate change more than bound those anticipated for the future based on the a result of the literature survey, the answer to the question would be "yes" and there possibly would not need to be a development of a local climate model. The results of Task 6 and this task then would be fed directly to Task 10: Projection of Future Climate. However, preliminary indications are that a local climate forecast model is called for because of the uncertainty of the local effect that greenhouse warming could have in the Hanford Site Region. Some of these concerns will be discussed in the following sections.

Further, as discussed in Section 2.2.1, most of the studies associated with the other Barrier Development Program Tasks are already underway. In designing the treatments for many of these studies, some initial estimates were or will be made about possible future climatic conditions (precipitation amount, storm intensity, wind speed, etc.). Because the final results of the long-term climatic assessment task may not be available until near the conclusion of some of these studies (when changes in treatments would most likely be impractical), the remainder of the climate change assessment for these studies may serve as a confirmatory role for the early estimates. If new information is received too late for inclusion in treatment design, the impact of these new considerations will have to be modeled or estimated using professional judgement.

\subsection{TASK 8: LOCAL CLIMATE FORECAST MODEL AND TASK 9: MODEL CALIBRATION AND VALIDATION}

\subsubsection{Purpose}

Conceptually, the projection of future climate variation in the Hanford Site region will be accomplished through the development of a local climate forecast model that will use GCM experiment results to provide initial and lateral bounding conditions. The primary purpose of the local-climatemodeling effort to substantiate estimates of future climate change from the effects of increased $\mathrm{CO}_{2}$ or other anthropogenic gas sources, such as methane or chlorofluorocarbon. Validation and calibration of the local climate model will be accomplished in part by using past climate conditions derived from paleoclimate studies. The output from the local climate model then will be 
WHC-EP-0569, Rev. 1

used to project future variability in the precipitation and temperature of the Hanford Site region, which then will be available to aid in barrier performance assessment analyses.

\subsubsection{Methods}

Assuming general circulation models can provide a reasonable climate forecast for the large-scale atmospheric flow, local climatic changes can be determined by correlating point-specific data with large-scale patterns. This idea will be used to construct a climate model for the Pasco Basin region. The research will be divided into three phases: (1) determining the pattern identification process, (2) building a stochastic or regression model between historical large scale patterns and regional precipitation or temperature, and (3) applying the model to GCM results for altered climate.

Work on the first phase has started as part of a separate project to examine the impact of global change on the Cascade hydrological cycle. Results from this research have identified statistical methods for classification of weather types based on rotated principal components. As part of the first and second phases, a statistical analysis of the variability explained by the pattern classification method will be performed. It is important to understand the predictive ability of pattern classifications for the current climate before undertaking an extensive forecast study. For example, pattern identification schemes should be able to identify short-term (decades) climate variability with reasonable accuracy.

One method for testing the pattern classification is to generate a stochastic model of a parameter using one 10-yr period of data and apply the model to a different $10-y r$ control. By running the model numerous times, a statistical sample can be obtained and used for determining the model variance. The model variance then can be compared to observed variability to ascertain model uncertainty. The stochastic model also will be tested by using GCM control run cases that represent current atmospheric climatic conditions. These tests will determine the bias of $\mathrm{GCM}$ runs compared to actual climate parameters and may be used to adjust altered climate scenarios.

After determining the uncertainty of the stochastic model, tests will be performed to simulate the local climate for the paleoclimate periods. These validation tests will use data simulated using a GCM for times examined in the paleoclimate analysis (Tasks 2 through 6 ). Based on the stochastic model output, simulated parameters (such as average monthly precipitation, monthly average temperature, and extreme events, such as record maximums of rain or temperature) will be determined. Values for these climate measures should be within the values found in the reconstructed paleoclimate record, providing verification.

Simulations of future climates will proceed with the application of $\mathrm{CO}_{2}$ GCM simulation results. This phase of the study will involve the examination of various model runs including cases with doubled $\mathrm{CO}_{2}$ and gradual $\mathrm{CO}_{2}$ increase. From these runs, estimates of precipitation and temperature for the Hanford Site region will be made for long-term changes. 
WHC-EP-0569, Rev. 1

\subsubsection{Required Inputs and Expected Outputs}

The proposed model will require outputs from a GCM model run representing the type of climate of interest. Currently, $5^{\circ}$ lat. by $5^{\circ}$ long. data are being used to determine principal components for the northwest region. A station record for observation sites over the period from 1946 to present also is needed to calibrate the stochastic model.

Output from the stochastic model will consist of daily precipitation totals along with maximum and minimum temperatures for a length of record equal to the GCM output period. More extended records can be artificially constructed using Monte Carlo techniques with the GCM output.

\subsection{TASK 10: PROJECTION OF FUTURE CLIMATES}

\subsubsection{Purpose}

The purpose of this task is to provide the needed information on potential future climates so that the effects of future climatic change can be assessed as they pertain to the disposal of wastes at the Hanford Site. This will aid in development of the barrier design and the demonstration of compliance to regulatory requirements and performance standards. Specifically the information in this task will be used to help answer the question posed in decision point 4 which asks, "Do projections Satisfy Climate/Vegetation Data Needs?" This task also acts as the administrator of and collector for all other tasks and their output, and includes miscellaneous level-of-effort activities.

\subsubsection{Methods}

This task will focus on documenting the use of past climatic reconstructions, current meteorological conditions and historic patterns, and the modeled future global changes related to both the greenhouse effect and the cycling into the next ice age to provide defensible projections of future climatic variability and vegetation in the Pasco Basin for the next 1,000 to $10,000 \mathrm{yr}$. Both paleoclimate indicators and modeling outputs will be examined to identify the bounding ranges of potential future climate change. Any deficiencies will attempt to be rectified by Tasks 11 and 12 .

\subsubsection{Required Inputs and Expected Outputs}

Information is required from Tasks 2 through 9 . The expected deliverables and output include the following:

- Defensible probabilistic projections of the long-term climate variability in the Hanford Site and Pasco Basin region at many different time scales into the future

- Several test case climate scenarios that bracket the range of potential future climate 
WHC-EP-0569, Rev. 1

- Use of the climate scenarios both to test and model protective barrier performance

- Status reports documenting program progress.

\subsection{TASK 11: GENERATION OF WEATHER STATISTICS}

\subsubsection{Purpose}

If data from Task 10 do not project specific parameters in enough detail such as mean monthly precipitation, mean monthly temperature, and coefficients of variation for solar radiation, then specific weather statistics generation models will be used to estimate these parameters.

\subsubsection{Methods}

Weather statistics generation models, such as WGEN (Richardson and Wright 1984), have been used to generate specific climatic parameters such as mean monthly precipitation, mean monthly temperature, and coefficients of variation for solar radiation. One method of applying such a model is to select a representative analog location, obtain the characteristic climatic data for the analog site, and then use it as the basis for generating time-series data of the type required by UNSAT-H to simulate the hydrologic performance of the barrier for a future climate state that matches that of the analog site. These time series data also could supply the needs of other Barrier Development Tasks (Table 1). To ensure confidence limits for the predictions of UNSAT-H, such meteorological subsets will be required.

Also, if data from Task 10 do not project specific parameters such as maximum storm events, a statistical study will have to be undertaken to obtain the needed parameters using techniques such as those described by Nyhan et al. (1989), Ballerini and Waylen (1989), Gumbel (1954), and Kinnison (1985).

\subsubsection{Required Inputs and Expected Outputs}

Input includes the results of Task 10 and the climate data needs from Task 1, Table 1, and the output is the specific parameter needed in the form that can be used by the task requiring them.

\subsection{TASK 12: IDENTIFICATION OF SPATIAL ANALOGS OF VEGETATION RESPONSE TO PROJECTED CLIMATES}

\subsubsection{Purpose}

The Natural Analogs Studies of the Barriers Development Program includes a study of the effects of different vegetation types likely to develop on barriers under the extremes of climate characterized by the this study plan. Task 12 will provide the criteria, in terms of climatic conditions and plant 
WHC-EP-0569, Rev. 1

community composition, that will be used to select vegetation analog sites. Further, as discussed in Section 2.2.1, this is a study that may have to be undertaken before the final projection of climates is made.

\subsubsection{Methods}

Two possible approaches will be used to select spatial analogs of possible future vegetation communities. These sites will be studied intensively, data to be collected include a community description, rooting characteristics, evapotranspiration, and soil water balance on an annual scale. The first approach will use the results from Tasks 7 and 10 to identify, in the greatest possible detail, the vegetation communities and climatic patterns for five past extreme climatic periods identified for study. However, as discussed, these studies may have to be undertaken before the final characterization of these five and the projection of future climate states are made. In this case, there will have to be some initial estimates made using the best available information about possible future climatic conditions. Once this is done, much of the focus of the climates studies will be focused on increasing the confidence concerning the initial estimates. For instance, an analog location that has three times the annual precipitation of the Hanford Site may be selected as one of the sites for intensive study. In this case, the study efforts will be focused on providing a defensible justification for selecting a three-times-annual-precipitation analog site, rather than a four-times-annual-precipitation analog site. The later efforts would serve a confirmatory role for the early estimates. However, if new information indicates that the four-times annual site would have been a better effort, it may have to be modeled using the three-times annual site as a guide.

It is possible that for future climate scenarios based on GCMs, no vegetation community data may be available. For past scenarios including vegetation communities with known modern analog communities, analog sites will be chosen using maps of modern steppe vegetation types in the Northwest (as in Daubenmire 1970) or others farther afield. An effort will be made to select analog sites with climates most closely approximating those that have been reconstructed by paleoclimate tasks. For all other climate scenarios, localities will be sought that have the same or similar climate to those that are reconstructed or modeled. Climate statistics from the U.S. Weather Service will be used in this endeavor. At least four alternative sites will be identified for each climate scenario from which study sites can be selected.

\subsubsection{Required Inputs and Expected Outputs}

Required input will include the climatic and past vegetation scenarios generated by other tasks of this study, plant community maps for the Northwest region, and climate statistics published by the United States Government.

Output will be a selection of analog sites to be studied in greater detail. 
WHC-EP-0569, Rev. 1

\subsection{TASK 13: INPUT CLIMATIC DATA TO BARRIER PERFORMANCE ASSESSMENT}

The purpose of this task is to meet the objectives specified in Section 1.3, which include the following.

- Use the past climate, current meteorological conditions, and modeled future global changes to project that future climatic variability in the Pasco Basin for the next 1,000 to $10,000 \mathrm{yr}$.

- Provide information that pertains to the effects of climatic change on the disposal of wastes at the Hanford Site to the other components of the Protective Barrier Development Program so the final design meets regulatory requirements and performance standards (as they currently exist or as they evolve).

- Provide information that will be used to test the long-term performance of the barrier to confirm its effectiveness in minimizing drainage that ultimately could lead to movement of radionuclides to the accessible environment.

To meet these objectives, close cooperation and coordination is necessary so that the needed information will be provided to all other barrier tasks in a timely manner. In some cases this will include early climatic parameter estimates, with much of the subsequent work serving a confirmatory role for those estimates.

\subsection{COST ESTIMATES, SCHEDULE, AND MILESTONES}

The schedule for this study plan is designed to cover $5 \mathrm{yr}$. The estimated dollar figures are programmatic doliars (shown in thousands of dollars) and do not include escalation and contingency (see Tables 2, 3, and 4). The estimated budget is provided as a strawman that shows the first cut at a schedule and cost estimates. The budget is based partly on the estimates developed with the BWIP climate program. The level of funding with the years of funding provide a rough timel ine for the schedule and sequencing of tasks. One new task not discussed previously is listed in the following tables: "0. Task Administration." This category is included to cover the expenses and time associated with such items as completing the peer review, writing the Statements of Work, writing and updating the study plan, preparing for and attending Barrier Team meetings, and any a number of other miscellaneous activities that do not fit in the other categories.

The milestones listed below could apply to any one of the tasks. The date associated with any one milestone as it is applied to a specific task still must be worked out either in a specific technical work plan or work order. In addition, an overall timeline that coordinates the points of integration between tasks needs to be developed. 
WHC-EP-0569, Rev. 1

Table 2. Westinghouse Hanford Company Programmatic Cost Estimates $(\$ 1,000 s)$.

\begin{tabular}{|c|c|c|c|c|c|c|c|}
\hline & Task Name & Year 1 & Year 2 & Year 3 & Year 4 & Year 5 & Total \\
\hline 0. & Task Administration & 10.0 & 10.0 & 5.0 & 5.0 & 5.0 & 35.0 \\
\hline 1. & $\begin{array}{l}\text { Identification of Climatic } \\
\text { Data Needs }\end{array}$ & 5.4 & & & & & 5.4 \\
\hline 2.1 & Modern Climatic Patterns & 32.4 & & & & & 32.4 \\
\hline 2.2 & $\begin{array}{l}\text { Holocene Paleoclimate } \\
\text { Literature }\end{array}$ & & & & & & 0.0 \\
\hline 2.3 & Late Quaternary Literature & 16.2 & 32.4 & & & & 48.6 \\
\hline 2.4 & Flood Records & & & & & & 0.0 \\
\hline 2.5 & Global Climate Modeling & 10.8 & 10.8 & 32.4 & & & 54.0 \\
\hline 3.1 & Scablands Pollen site Transect & & & & & & 0.0 \\
\hline 3.2 & Full Glacial Pollen Study & 51.8 & 82.7 & & & & 134.5 \\
\hline 4.1 & Fluvial Indicators & & & & & & 0.0 \\
\hline 4.2 & Episodic Groundwater Recharge & & & & & & 0.0 \\
\hline 5.1 & Studies of Eolian Processes & & & & & & 0.0 \\
\hline 5.2 & Faunal Indicators & & & & & & 0.0 \\
\hline 6. & $\begin{array}{l}\text { Past } \mathrm{Cl} \text { imate/Vegetation } \\
\text { Variations }\end{array}$ & 5.4 & 10.8 & & & & 16.2 \\
\hline 7. & $\begin{array}{l}\text { Future } \mathrm{Cl} \text { imate/Vegetation } \\
\text { Projections }\end{array}$ & 5.4 & 10.8 & & & & 16.2 \\
\hline 8. & Local Climate Forecast Model & & & & & & 0.0 \\
\hline 9. & $\begin{array}{l}\text { Model Cal ibration and } \\
\text { Validation }\end{array}$ & & & & & & 0.0 \\
\hline 10. & Projection of Future $\mathrm{Climates}$ & 43.6 & 43.6 & 43.4 & 59.6 & 43.4 & 233.6 \\
\hline 11. & $\begin{array}{l}\text { Generation of Weather } \\
\text { statistics }\end{array}$ & & & & & & 0.0 \\
\hline 12. & $\begin{array}{l}\text { Identification of future } \\
\text { Spatial Analogs }\end{array}$ & & & & & & 0.0 \\
\hline 13. & $\begin{array}{l}\text { Input to Barrier Performance } \\
\text { Assessment }\end{array}$ & & & & 16.2 & 16.2 & 32.4 \\
\hline & Total & 181.0 & 201.1 & 80.8 & 80.8 & 64.6 & 608.3 \\
\hline
\end{tabular}


WHC-EP-0569, Rev. 1

Table 3. Pacific Northwest Laboratory Programmatic Cost Estimates $(\$ 1,000 s)$.

\begin{tabular}{|c|c|c|c|c|c|c|c|}
\hline & Task Name & Year 1 & Year 2 & Year 3 & Year 4 & Year 5 & Total \\
\hline 0. & Task Administration & 26.9 & 26.9 & 20.2 & 13.5 & 6.7 & 94.2 \\
\hline 1. & $\begin{array}{l}\text { Identification of } \mathrm{Cl} \text { imatic } \\
\text { Data Needs }\end{array}$ & 13.5 & & & & & 13.5 \\
\hline 2.1 & Modern Climatic Patterns & & & & & & 0.0 \\
\hline 2.2 & $\begin{array}{l}\text { Holocene Paleocl imate } \\
\text { Literature }\end{array}$ & 13.5 & & & & & 13.5 \\
\hline 2.3 & Late Quaternary Literature & 16.1 & 16.1 & & & & 32.2 \\
\hline 2.4 & Flood Records & & 33.6 & 40.4 & 20.2 & & 94.2 \\
\hline 2.5 & Global Climate Modeling & 2.7 & 2.7 & 10.8 & & & 16.2 \\
\hline 3.1 & Scablands Pollen site Iransect & 46.5 & 51.8 & & & & 98.3 \\
\hline 3.2 & Full Glacial Pollen Study & & & & & & 0.0 \\
\hline 4.1 & Fluvial Indicators & 74.0 & 20.2 & & & & 94.2 \\
\hline 4.2 & Episodic Groundwater Recharge & 53.8 & 87.4 & 87.4 & & & 228.6 \\
\hline 5.1 & Studies of Eolian Processes & 51.8 & 51.8 & & & & 103.6 \\
\hline 5.2 & Faunal Indicators & & 33.6 & 74.0 & 40.4 & & 148.0 \\
\hline 6. & $\begin{array}{l}\text { Past } C l \text { imate/Vegetation } \\
\text { Variations }\end{array}$ & 6.7 & 13.5 & & & & 20.2 \\
\hline 7. & $\begin{array}{l}\text { Future } \mathrm{Cl} \text { imate/Vegetation } \\
\text { Projections }\end{array}$ & 6.7 & 6.7 & 13.5 & & & 26.9 \\
\hline 8. & Local Climate Forecast Model & 40.4 & 26.9 & & & & 67.3 \\
\hline 9. & $\begin{array}{l}\text { Model Calibration and } \\
\text { Validation }\end{array}$ & 6.7 & 20.2 & & & & 26.9 \\
\hline 10. & Projection of Future Climates & & & 47.1 & 20.2 & & 67.3 \\
\hline 11. & $\begin{array}{l}\text { Generation of Weather } \\
\text { Statistics }\end{array}$ & & & 40.4 & & & 40.4 \\
\hline 12. & $\begin{array}{l}\text { Identification of Future } \\
\text { Spatial Analogs }\end{array}$ & & & 40.4 & & & 40.4 \\
\hline \multirow[t]{2}{*}{13.} & $\begin{array}{l}\text { Input to Barrier Performance } \\
\text { Assessment }\end{array}$ & & & & 40.4 & 40.4 & 80.8 \\
\hline & Total & 359.3 & 391.4 & 374.2 & 134.7 & 47.1 & $1,306.7$ \\
\hline
\end{tabular}


WHC-EP-0569, Rev. 1

Table 4. Total Programmatic Cost Estimates $(\$ 1,000 \mathrm{~s})$.

\begin{tabular}{|c|c|c|c|c|c|c|c|}
\hline & Task Name & Year 1 & Year 2 & Year 3 & Year 4 & Year 5 & Total \\
\hline 0. & Task Administration & 80.5 & 80.5 & 68.6 & 61.9 & 55.1 & 346.6 \\
\hline 1. & $\begin{array}{l}\text { Identification of Climatic } \\
\text { Data Needs }\end{array}$ & 18.9 & & & & & 18.9 \\
\hline 2.1 & Modern Climatic Patterns & 32.4 & & & & & 32.4 \\
\hline 2.2 & $\begin{array}{l}\text { Holocene Paleoclimate } \\
\text { Literature }\end{array}$ & 13.5 & & & & & 13.5 \\
\hline 2.3 & Late Quaternary Literature & 32.4 & 48.5 & & & & 80.9 \\
\hline 2.4 & Flood Records & & 33.6 & 40.4 & 20.2 & & 94.2 \\
\hline 2.5 & Global Climate Modeling & 13.5 & 13.5 & 43.2 & & & 70.2 \\
\hline 3.1 & $\begin{array}{l}\text { Scablands Pollen site } \\
\text { Transect }\end{array}$ & 46.5 & 51.8 & & & & 98.3 \\
\hline 3.2 & Full Glacial Pollen study & 51.8 & 82.7 & & & & 134.5 \\
\hline 4.1 & Fluvial Indicators & 74.0 & 20.2 & & & & 94.2 \\
\hline 4.2 & Episodic Groundwater Recharge & 53.8 & 87.4 & 87.4 & & & 228.6 \\
\hline 5.1 & Studies of Eolian Processes & 51.8 & 51.8 & & & & 103.6 \\
\hline 5.2 & Faunal Indicators & & 33.6 & 74.0 & 40.4 & & 148.0 \\
\hline 6. & $\begin{array}{l}\text { Past Climate/Vegetation } \\
\text { Variations }\end{array}$ & 12.1 & 24.3 & & & & 36.4 \\
\hline 7. & $\begin{array}{l}\text { Future Climate/Vegetation } \\
\text { Projections }\end{array}$ & 12.1 & 17.5 & 13.5 & & & 43.1 \\
\hline 8. & Local Climate Forecast Model & 40.4 & 26.9 & & & & 67.3 \\
\hline 9. & $\begin{array}{l}\text { Model Calibration and } \\
\text { Validation }\end{array}$ & 6.7 & 20.2 & & & & 26.9 \\
\hline 10. & Projection of Future $\mathrm{Climates}$ & & & 47.1 & 36.4 & & 83.5 \\
\hline 11. & $\begin{array}{l}\text { Generation of Weather } \\
\text { Statistics }\end{array}$ & & & 40.4 & & & 40.4 \\
\hline 12. & $\begin{array}{l}\text { Identification of future } \\
\text { Spatial Analogs }\end{array}$ & & & 40.4 & & & 40.4 \\
\hline 13. & $\begin{array}{l}\text { Input to Barrier Performance } \\
\text { Assessment }\end{array}$ & & & & 56.6 & 56.6 & 113.2 \\
\hline & Total & 540.4 & 592.5 & 455.0 & 215.5 & 111.7 & $1,915.1$ \\
\hline
\end{tabular}




\author{
WHC-EP-0569, Rev. 1
}

This document also has been designed to be modular to allow scaling to meet specific needs. Like Adams and Wing (1986), this document is expected to be supplement as the needs for climate tasks evolve or future funding levels become more concrete. It also can provide the basis for developing climate studies for other applications that might have need such as the Grouted Double-She11 Tank Waste Disposal at the Hanford Site or the implementation of DOE-RL Order 5820.2A (DOE-RL 1990) that specifies climate changes should be considered ("Site Specific Radiological Performance Assessment").

\title{
MILESTONES
}

The following are milestones for the project:

1. Work Plans/Cost Plans/Statements of Work for contracts, completed as appropriate

2. Initiation of studies

3. Annual status reports

4. Data for climatic model verification

5. Field studies and sample collection completion

6. Data analysis completion; availability of data to test climatic models

7. Draft Reports submittal

8. Final Reports submittal.

\subsection{QUALITY ASSURANCE}

All work and deliverables to be performed under this study plan must comply with the following requirements for the documentation and traceability of project records.

- Project Files must contain a Technical Work Plan that outlines the specific work to be accomplished, the methods and procedures to be used, and the identity and qualification of all major participants.

- A11 project work must be documented to produce complete and traceable data or information. Original data or information must be treated as evidence to provide QA-defensible work.

- Final project data or information must be complete, clearly legibie, and readily traceable through intermediary information to the original data. 
- The identity, qualifications, and contribution of all researchers must be traceable through project records.

- If the original data or information are entered into a computer, a printout may serve as the original record.

- Original data or information generated by the project must be retained and accounted for in a systematic manner.

- All sources of information must be identified and complete references maintained.

- All verifiable items will be verified through the use of one or a combination of the six following verification methods:

- Alternate calculations

- Alternate tests

- Controlled notebook review

- Data evaluation report review

- Peer review

- Technical document review.

\subsection{REFERENCES}

Adams, M. R. and N. R. Wing, 1986, Protective Barrier and Warning Marker System Development PIan, RHO-RE-PL-35P, Rockwell Hanford Operations, Richland, Washington.

Baker, R. G., 1983, "Holocene Vegetational History of the Western United States," in H. E. Wright (editor), The Holocene, University of Minnesota Press, Minneapolis, pp. 109-127.

Ballerini, R. and P. Waylen, 1989, "Extreme Precipitation Events Generated by Periodic Processes," Water Resources Research, Vol. 25, pp. 1403-1412.

Barnosky, C. W., 1985, "Late-Quaternary Vegetation in the Southwestern Columbia Basin, Washington," Quaternary Research, Vol. 23, pp. 109-122.

Barnosky, C. W., P. M. Anderson, and P. J. Bartlein, 1987, "The Northwestern U.S. During Deglaciation; Vegetational History and Paleoclimatic Implications," in W. F. Ruddiman, and H. E. Wright, Jr. (editors), North America and Adjacent Oceans During the Last Deglaciation. The Geology of North America, Vol. K-3, Geological Society of America, Boulder, Colorado, pp. 289-321.

Berger, A. L., 1981, "The Astronomical Theory of Paleoclimates," in A. Berger, (editor), Climatic Variations and Variability: Facts and Theories, D. Reidel Publishing Company, Dordrecht, Holland, pp. 501-525.

Berger, A., J. Imbrie, J. Hays, G. Kukla, and B. Saltzman (editors), 1984, Milankovitch and Climate, D. Reidel, Publishing Company, Dordrecht, Holland. 
Berglund, B. E. (editor), 1986, Handbook of Holocene Paleoecology and Paleohydrology, John Wiley and Sons, Chichester, England.

Birks, H. J. H. and H. H. Birks, 1980, Quaternary Paleoecology, University Park Press, Baltimore, Maryland.

Birks, H. J. H. and A. D. Gordon, 1985, Numerical Methods in Quaternary Pollen Analysis, Academic Press, London.

Cadwel1, L. L., L. E. Eberhardt, and M. A. Simmons, 1989, Animal Intrusion Studies for Protective Barriers: Status Report for 1988, PNL-6869, Pacific Northwest Laboratory, Richland, Washington.

Cadwel1, L. L. and W. H. Walters, 1989, Project Test Plan: Runoff and Erosion on Fine-Soil Barrier Surfaces and Rock-Covered Side Slopes, PNL-6791, Pacific Northwest Laboratory, Richland, Washington.

Campbel1, G. W. and G. W. Gee, 1990, Field Lysimeter Test Facility: Protective Barrier Test Results (FY 1990, the Third Year), PNL-7558, Pacific Northwest Laboratory, Richland, Washington.

Chatters, J. C. and K. A. Hoover, 1992, "Response of the Columbia River Fluvial System to Holocene Climatic Change," Quaternary Research, Vol. 37, pp. 42-59.

COHMAP Members, 1988, "Climatic Changes of the Last 18,000 Years: Observations and Model Simulations," Science, Vol. 241, pp. 1043-1052.

Costa, J. E., 1978, "Holocene Stratigraphy in Flood Frequency Analysis," Water Resources Research, Vol. 14, pp. 626-632.

Crowley, T. J. and G. R. North, 1990, Paleoclimatology, Oxford Monographs on Geology and Geophysics, No. 16, Oxford University Press, New York, New York.

Dansgaard, W., 1964, "Stable Isotopes in Precipitation," Tellus, Vol. 16, pp. 436-468.

Daubenmire, R., 1970, Steppe Vegetation of Washington, Washington Agricultural Experiment Station Technical Bulletin 62, Washington State University, Pullman, Washington.

Deevey, E. W., 1965, "Sampling Lake Sediments by the Use of a Livingstone Sampler," in B. Kunnel and D. Raup (editors), Handbook of Paleontological Techniques, Freeman and Company, San Francisco, California, pp. 521-529.

Dickinson, R. E., R. M. Errico, F. Giorgi, and G. T. Bates, 1989, "A Regional Climate Model for the Western United States," Climatic Change, Vol. 15, pp. 383-422.

DOE, 1987, Final Environmental Impact Statement for the Disposal of Hanford Defense High-Level, Transuranic, and Tank Waste, DOE/EIS-0113, U.S. Department of Energy, Washington, D.C. 
DOE, 1988, Nuclear Waste Policy Act Site Characterization Plan Reference Repository Location, Hanford Site, Washington, DOE-RW-0164, Vols. 3 and 8, U.S. Department of Energy, Office of Civilian Radioactive Waste Management, Washington, D.C.

DOE-RL, 1987, Hanford Waste Management Plan, DOE-RL-87-13, U.S. Department of Energy, Richland Operations Office, Richland, Washington.

DOE-RL, 1990, Site Specific Radiological Performance Assessment, DOE-RL Order 5820.2A, U.S. Department of Energy, Richland Operations Office, Richland, Washington.

Doorenbos, J. and W. 0. Pruitt, 1977, Guidelines for Predicting Crop Water Requirements, FAO Irrigation Paper No. 24, 2nd ed., Food and Agricultural Organization of the United Nations, Rome, Italy.

Eicher, U. and U. Siegenthaler, 1976, "Palynological and Oxygen Isotope Investigations on Late-Glacial Sediment Cores from Swiss Lakes," Boreas, Vol. 5, pp. 109-117.

Faegri, K., P. E. Kaland, and K. Krzywinski, 1989, Textbook of Pollen Analysis, 4 th edition, John Wiley and Sons, New Jersey.

Fayer, M. J., G. W. Gee, and T. L. Jones, 1986, UNSAT-H Version 1.0: Unsaturated Flow Code Documentation and Applications for the Hanford Site, PNL-5899, Pacific Northwest Laboratory, Richland, Washington.

Fayer, M. J., 1987, Model Assessments of Protective Barriers: Part II, PNL-6297, Pacific Northwest Laboratory, Richland, Washington.

Freeman, H. D., G. W. Gee, and J. F. Relyea, 1989, Field Study Plan for Alternate Barriers, PNL-6840, Pacific Northwest Laboratory, Richland, Washington.

Gee, G. W., R. R. Kirkham, J. L. Downs, and M. D. Campbe11, 1989, The Field Lysimeter Test Facility (FLTF) at the Hanford Site: Installation and Initial Tests, PNL-6810, Pacific Northwest Laboratory, Richland, Washington.

Giorgi, F., 1991, "Sensitivity of Simulated Summertime Precipitation over the Western United States to Different Physics Parameterizations, "Monthly Weather Review, Vol. 119, pp. 2870-2888.

Goodess, G. M. and J. P. Palutikof (editors), 1991, Future Climate Change and Radioactive Waste Disposal: Proceedings of the International Workshop held at UEA, Norwich, 1-3 November 1989, NSS/R257, Climatic Research Unit, School of Environmental Sciences, University of East Anglia, Norwich, England.

Grayson, D. K., 1984, Quantitative Zooarchaeology, Academic Press, New York, New York.

Gumbel, E. J., 1954, Statistical Theory of Extreme Values and Some Practical Applications, U.S. Department of Commerce, National Bureau of Standards, 
WHC-EP-0569, Rev. 1

Applied Mathematics Series 33, U.S. Government Printing Office, Washington, D.C.

Gupta, S. K., K. K. Tanja, D. R. Nielsen, J. W. Biggar, C. S. Simmons, and J. L. MacIntyre, 1978, Field Simulation of Soil-Water Movement with Crop Water Extraction, Water Science and Engineering Paper No. 4013, Department of Land, Air, and Water Resources, University of California, Davis.

Hansen, J., D. Johnson, A. Lacis, S. Lebedeff, P. Lee, D. Rind, and G. Russe11, 1981, "Climate Impact of" Increasing Atmospheric Carbon Dioxide," Science, Vol. 213, pp. 95\%-966.

Harris, L. D. and C. Maser, 1984, "Animal Community Characteristics," in L. D. Harris (editor!, The Fragmented Forest: Island Biogeography Theory and the Preservation of Biotic Diversity, University of Chicago Press, Chicago, Illinois, pp. 44-70.

Hays, J. D., J. Imbrie, and N. J. Shackleton, 1976, "Variations in the Earth's Orbit: Pacemakers of the Ice Ages," Science, Vol. 194, pp. 1121-1132.

Heusser, C. J., 1983, "Vegetational History of the Northwestern United States Including Alaska," in S. C. Porter (efitor.), Late Quaternary Environments of the United States: The Late Pleistocene, Vol. 1, University of Minnesota Press, Minneapolis, pp. 239-258.

Houghton, J. T., G. J. Jenkins, and J. J. Epıraums, editors, 1990, Climate Change: The IPCC Scientific Assessment, Intergovernmental Panel on Climate Change, Cambridge University Press, Cambridge, United Kingdom.

Idso, S. B., B. A. Kimball, and J. R. Mauney, 1987, "Atmospheric Carbon Dioxide Enrichment Effects on Cotton Midday Foliage Temperature: Implications ior Plant Water Use and Crop Yield," Agronomy, Vol. 79, pp. 667-672.

Imbrie, J. and J. Z. Imbrie, 1980, "Modeling the Climatic Response to Orbital Variations," Science, Vol. 207, pp. 943-953.

Kinnison, R. R., 1985, Applied Extreme Value Statistics, Battelle Press, Mcmillian, New York.

Kochel, R. C. and V. R. Baker, 1982, "Palenflood Hydrology," Science, Vol. 215, pp. 353-361.

Kuk1a, G. J., 1981, "Pleistocene Climates on Land," in A. Berger (editor), Climate Variations and Variability: Facts and Theories, D. Reidel Publishing Company, Dordrecht, Holland, pp. 207-232.

Landeen, D. S., L. L. Cadwel1, L. L. Eberhardt, R. E. Fitzner, and M. A. Simmons, 1989, Animal Intrusion Field Test Plan, WHC-EP-0253, Westinghouse Hanford Company, Richland, Washington.

Ligotke, M. W., 1989, Surface Stability Test Plan for Protective Barriers, PNL-6722, Pacific Northwest Laboratory, Richland, Washington. 
Link, S. 0. and W. J. Waugh, 1989, Evapotranspiration Studies for Protective Barriers: Experimental Plans, PNL-6899, Pacific Northwest Laboratory, Richland, Washington.

Mack, R. N., 1986, "Alien Plant Invasion into the Intermountain West: A Case History," in H. A. Mooney and J. A. Drake (editors), Ecology of Biological Invasions of North America and Hawai, [cological Studies, Vo1. 58, Sprirger-Verlag, New York.

Maser, C. and R. M. Storm, 1970, A Key to the Microtinae of the Pacific Northwest, 0.S.U. Book Stores, Inc., Corvallis, Oregon.

McKenzie, D. H., L. L. Cadwe11, W. E. Kennedy, Jr., L. A. Prohammer, and M. A. Simmons, 1986, Relevance of Biotic Pathways to the Long-Term Regulation of Nuclear Waste Disposal: Phase II Final Report, Vol. 6, PNL-4241, Pacific Northwest Laboratory, Richland, Washington.

Mehringer, P. J., Jr., 1985, "Late Quaternary Pollen Records from the Interior Pacific Northwest and Northern Great Basin of the United States," in V. M. Bryant, Jr. and R. G. Holloway (editors), Pollen Records of Late-Quaternary North American Sediments, American Association of Stratigraphic Association, Dallas, Texas, pp. 167-189.

Milankovitch, 1969, Canon of Insolation and the Ice-Age Problem, TT 67-51410/1 and 2, U.S. Department of Commerce, Springfield, Virginia.

Nickmann, R., 1979, The Palynology of Williams Lake Fen Spokane County, Washington, Unpublished Master's Thesis, Department of Geology, Eastern Washington University, Cheney, Washington.

Nyhan, J., R. Beckman, and B. Bowen, 1989, An Analysis of Precipitation Occurrences in Los Alamos, New Mexico, for Long-Term Prediction of Waste Repository Behavior, LA-11459-MS, Los Alamos National Laboratory, Los Alamos, New Mexico.

Ramanathan, V., 1988, "The Greenhouse Theory of Climate Change: A Test by an Inadvertent Global Experiment," Science, Vol. 240, pp. 293-299.

Rensberger, J. M., A. D. Barnosky, and P. Spencer, 1984, Geology and Paleontology of a Pleistocene-to-Holocene Loess Succession, Benton County, Washington, Eastern Washington University Reports in Archaeology and History 100-39, Cheney, Washington.

Richards, L. A., 1931, "Capillary Conduction of Liquids in Porous Mediums," Physics, Vol. 1, pp. 318-333.

Richards, L. A., 1950, "Laws of Soil Moisture," Transactions of the American Geophysical Union, Vol. 31, pp. 750-756.

Richardson, C. W. and D. A. Wright, 1984, WGEN: A Model for Generating Daily Weather Variables, ARS-8, U.S. Department of Agriculture, Agricultural Experiment Service. 
Sackschewsky, M. R., C. J. Kemp, L. L. Cadwell, M. E. Thiede, and W. J. Waugh, 1991, Status Report for the Small-Tube Lysimeter Facility

Fiscal Year 1990, WHC-EP-0381, Westinghouse Hanford Company, Richland, Washington.

Schneider, S. H., 1989, Global Warming, Sierra Club Books, San Francisco, California.

Silar, J., 1969, Groundwater Structures and Ages in the Eastern Columbia Basin, Washington, College of Engineering Research Division Bulletin 315, Washington State University, Pullman, Washington.

Simmons, C. S. and C. R. Cole, 1985, Guidelines for Selecting Codes for Groundwater Transport Modeling of Low-Level Waste Burial Sites, PNL-4980, Vol. 1, Pacific Northwest Laboratory, Richland, Washington.

Smith, J. B. and D. Tirpak, 1989, The Potential Effects of Global Climate Change on the United States, EPA-230-05-89-050, U.S. Environmental Protection Agency, Policy, Planning, and Evaluation (PM-221), Washington, D.C.

Stuiver, M., 1970, "Oxygen and Carbon Isotope Ratios of Fresh Water Carbonates as Climatic Indicators," Journal of Geophysical Research, Vol. 75, pp. 5247-5257.

Waugh, W. J., 1989, Gravel Admix, Vegetation, and Soil Water Interactions in Protective Barriers: Experimental Design, Construction, and Initial conditions, PNL-6616, Pacific Northwest Laboratory, Richland, Washington.

Waugh, W. J. and M. G. Foley, 1988, Protective Barrier Climate-Change Impacts: Technical Workshop Findings and Recommendations, PNL-6615, Pacific Northwest Laboratory, Richland, Washington.

Waugh, W. J. and S. 0. Link, 1988, Barrier Erosion Control Test Plan: Gravel Mulch, Vegetation, and Soil Water Interactions, WHC-EP-0067, Westinghouse Hanford Company, Richland, Washington.

Wing, N. R. and G. W. Gee (editors), 1990, Hanford Protective Barrier Development Program: Fiscal Year 1989 Highlights, WHC-EP-0318, Westinghouse Hanford Company, Richland, Washington. 
WHC-EP-0569, Rev. 1

\section{DISTRIBUTION}

Number of copies

FOREIGN

1 BRGM - Departement

"Environment"

BP 6009

45060 ORLEANS CEDEX, FRANCE

M. Barres

1 Department of Geography

University of Western Ontario

London, Ontario

N6A 5 C2

Canada

Dr. B. H. Luckman

1 Waste Management Unit

British Nuclear Fuels plc Sellafield

Seascale, Cumbria CA201PG

ENGLAND

P. Grimwood

1 Institut für Bodenkunde der

Universität Hamburg

Allende-Platz 2, D-2000

Hamburg 13

Federal Republic of Germany

S. Melchior

1 Intera Information

Technologies

Chiltern House

45 Station Road

Henley-on-Thames

Oxfordshire RG9 IAT

UNITED KINGDOM

G. M. Smith
Number of copies

OFFSITE

2 Agronomy Department Washington State University

Pullman, Washington 99164

Dr. A. J. Busacca

Dr. G. S. Campbell

1 Anasazi Heritage Center Bureau of Land Management 27501 Hwy 184

Dolores, Colorado 81323

Document Clerk

1 Archaeological Research Services

P.0. Box 701

Virginia City, NV 89440

V. L. Clay

1 Argonne National Laboratory 9700 South Cass Avenue

Argonne, IL 60439

M. J. Steindler

1 Argonne National Laboratory P.0. Box 2528

Idaho Falls, ID 83401

C. S. Abrams

1 Arizona-Sonoran Desert Museum Rt. 9, Box 9 Tucson, Arizona 85743

Dr. T. R. Van Devender

1 Arizona State Museum University of Arizona Tucson, AZ 85721

S. K. Fish 
WHC-EP-0569, Rev. 1

\section{DISTRIBUTION (cont)}

Number of copies

1 Bandelier National Monument HCR 1, Box 1, Suite 15

Los Alamos, New Mexico 875449702

C. Allen

3 Battelle Memorial Institute Project Management Division 505 King Avenue

Columbus, $\mathrm{OH} 43201$

W. A. Carbeiner

W. S. Madia

Technical Library

1 Bureau of Land Management

Moab District

P.0. Box 970

Moab, Utah 84532

B. D. Louthan

1 Bureau of Reclamation MP-750 U.S. Department of Interior 2800 Cottage Way

Sacramento, California 958251898

Dr. G. J. West

3 Bibly Research Center

Northern Arizona University

Box 6013

Flagstaff, Arizona 86011

Dr. L. Agenbroad

Dr. R. S. Anderson

Dr. J. I. Mead

2 Botany and Range Science

Department

Brigham Young University

401 WIDB

Provo, Utah 84602

Dr. W. M. Hess

Dr. K. T. Harper
Number of copies

1 Boulder Laboratory

Geological Survey

U.S. Department of Interior

Box 25046, M.S. 458

Denver Federal Center

Denver, Colorado 80225

Dr. L. Benson

1 Branch of Sedimentary

Processes

U.S. Geological Survey-MS 902

345 Middlefield Road

Menlo Park, California 94025

Dr. G. I. Smith

1 Cascade Earth Sciences, Ltd.

P.0. Box 137

Corbett, OR 97019

S. W. Childs

4 Chem Nuclear Geotech

P.0. Box 14000

Grand Junction, CO 81502

J. Duray

J. Elmer

V. Ponc

W. J. Waugh

2 CIRES

University of Colorado

Campus Box 449

Boulder, Colorado 80309

Dr. R. G. Barry

Dr. M. K. Humfrey

1 Colorado Climate Center Department of Atmospheric Science

Colorado State University

Fort Collins, Colorado 80523

N. J. Doesken 
WHC-EP-0569, Rev. 1

\section{DISTRIBUTION (cont)}

\section{Number of copies}

1 Colorado Department of Health Drinking Water Division

4210 E. 11th Avenue

Denver, CO 80220

\section{W. Wright}

2 Crow Canyon Archaeological Center 23390 County Road $K$ Cortez, C0 81321

R. H. Wilshusen

$K$. Adams

1 Dames and Moore

Suite 108

4220 S. Maryland Park Way

Las Vegas, Nevada 89119

Dr. W. G. Spaulding

1 Department of Anthropology

Arizona State University

Tempe, Arizona 85281

Dr. J. Schoenwetter

5 Department of Anthropology

Washington State University

Pullman, Washington 99164

Dr. J. H. Bodley

Dr. G. L. Gamble

Dr. F. A. Hassan

Dr. W. A. Lipe

Dr. P. J. Mehringer

1 Department of Anthropology

University of Oregon

Eugene, Oregon 97403

Dr. C. M. Aikens
Number of copies

2 Department of Anthropology University of Colorado

Boulder, Colorado 80309-0233

Dr. F. W. Eddy

Dr. P. D. Sheets

1 Department of Atmospheric Science

Creighton University

Omaha, Nebraska 68178-0110

Dr. A. V. Douglas

1 Department of Biology University of New Mexico Albuquerque, New Mexico 87131

Dr. R. G. Holloway

1 Department of Biological Sciences

Northern Arizona University

Flagstaff, Arizona 86001

Dr. R. H. Hevly

1 Department of Civil Engineering University of Texas

Austin, TX 78712

D. E. Daniel

1 Department of Forest Resources

University of Minnesota

115 Green Hall, NPS/CPSU

St. Pau1, Minnesota 55108

Dr. K. L. Cole

1 Department of Geography

Arizona State University

Tempe, Arizona 85287

Dr. P. L. Fall 


\section{DISTRIBUTION (cont)}

Number of copies

2 Department of Geography University of Oregon Eugene, Oregon 97403

Dr. P. J. Bartlein

Dr. C. Whitlock

2 Department of GeographyGeology Geological Survey U.S. Department of Interior Box 25046, M.S. 913 Denver Federal Center Denver, Colorado 80225

Dr. P. E. Carrara

Dr. R. R. Shroba

1 Department of Geology University of New Mexico Albuquerque, New Mexico 87131

Dr. R. Y. Anderson

1 Department of Geology University of Iowa Iowa City, Iowa 52242

Dr. R. G. Baker

2 Department of Health Radiation Protection Division Airdustrial Park

Bldg. 5, M.S. LE-13

OTympia, WA 98504

Alan Rainey

1 Department of Mechanical Engineering New Mexico State University Box 30001

Las Cruces, NM 88003

R. G. Hills
Number of copies

1 Department of Plant and Soil Science 12A Stockbridge $\mathrm{Hall}$ University of Massachusetts Amherst, MA 01003

D. Hillel

2 Department of Range Science Utah State University Logan, Utah 84322

Dr. M. M. Caldwell

Dr. N. E. West

1 Department of Soil and Water Science 429 Shantz Building University of Arizona Tucson, AZ 85721

\section{P. J. Wierenga}

1 Department of Soils University of California at Riverside

Riverside, CA 92502

W. A. Jury

1 Department of Systematic Ecology University of Kansas Lawrence, Kansas 66045

Dr. P. V. Wells

2 Desert Research Institute P.0. Box 60220 Reno, NV 89506

J. T. Ball

S. Tyler 


\section{DISTRIBUTION (cont)}

Number of copies

1 Desert Research Institute Suite 1

2505 Chandler Avenue

Las Vegas, NV 89120

\section{N. Ingraham}

1 Division of Earth Sciences University of Nevada, Las Vegas

100 Washington Street, Suite 201

Reno, Nevada 89503

\section{T. Flynn}

1 Division of Fuel Material

Safety

U.S. Nuclear Regulatory Commission

Washington, D.C. 20555

\section{A. T. Clark}

1 Division of Historic

Preservation and Archaeology

123 W. Nye Lane, Room \#208

Capitol Complex

Carson City, Nevada 89710

Dr. E. M. Hattori

12 DOE/Office of Scientific and Technical Information

2 EBASCO

1201 Jadwin

Richland, WA 99352

W. Riggsbee

R. L. Treat

2 EG\&G Idaho, Inc.

P.0. Box 1625

Idaho Falls, ID $83415-3900$

J. E. Conner

K. M. Kostelnik
Number of copies

1 Electric Power Research Institute 3412 Hillview Avenue Palo Alto, CA 94304

R. Shaw

1 Environmental Research Laboratory

NOAA

325 Broadway

Boulder, Colorado 80303

Dr. H. F. Diaz

2 Environmental Research

Laboratory-Corvalis

Environmental Protection Agency

200 S.W. 35th Street

Corvalis, Oregon 97333

Dr. G. A. King

Dr. R. P. Neilson

1 Environmental Sciences

Division, ER-74

Department of Energy - HQ

Office of Health and Environmental Research Office of Energy Research Washington, D.C. 20585

Dr. C. D. Jorgensen

1 Forestry Department University of Washington Seattle, WA 98195

L. J. Fritschen

1 Geography Department University of Texas at Austin Austin, TX 78712

Dr. S. A. Hall 
WHC-EP-0569, Rev. 1

\section{DISTRIBUTION (cont)}

\section{Number of copies}

1 Geography Department 501 Earth Sciences University of Cal ifornia Berkeley, Cal ifornia 94720

Dr. R. Byrne

1 Geology Department Texas A\&M University College Station, TX 77843

J. A. Gennett

2 Geology Department Washington State University Pullman, Washington 99164

Dr. K. Keller

Dr. D. Gaylord

3 Geosciences Department University of Arizona Bldg. \# 77

Tucson, Arizona 85721

Dr. 0. K. Davis

Dr. P. S. Mart in

P. Van de Water

1 Global Climate Change Program

Building 203, Room J-159 Argonne National Laboratory 9700 South Cass Avenue Argonne, I1linois 60439

\section{R. A. Reck}

1 Goddard Institute for Space Studies 2880 Broadway

New York, New York 10025

Dr. D. H. Rind
Number of copies

1 Hazen and Sawyer 4011 W. Chase BTvd.

Suite 500

Raleigh, NC $2760 \%$

G. N. Richardson

1 High-Level Waste Management Washington State Department of Ecology

Mail Stop PU II

Olympia, WA 98504

J. Rensel

4 Idaho National Engineering $\frac{\text { Laboratory }}{\text { P. Box } 1625}$ Idaho Falls, ID 83415

M. A. Knecht

J. B. Sisson

B. B. Russell

Technical Library

1 Illinois State Water Survey 2204 Griffith Dr. Champaign, Illinois 61820

Dr. W. M. Wendland

1 In-Situ, Inc. P.0. Box 1 Laramie, WY 82070

C. R. McKee

4 INSTAAR

University of Colorado

Box 450

Boulder, Colorado 80309-0450

Dr. S. A. Elias

Dr. V. Markgraf

Dr. H. Nichols

Dr. S. K. Short 


\section{DISTRIBUTION (cont)}

Number of copies

1 Intermountain Forest and Range Experiment Station U.S. Department of Agriculture Forest Service Northern Forest Fire Laboratory

Drawer G

Missoula, Montana 59806

Dr. S. Arno

1 Jacobs Engineering Group Inc. 2530 Arnold Drive Martinez, CA 94553

C. Reith

4 Jacobs Engineering Group. Inc. 5301 Central Avenue NE Suite 1700

Albuquerque, NM 87108
M. Kyllo
N. B. Larson
F. Titus
T. Goering

1 Laboratory of Biomedical and Environmental Sciences University of California at Los Angeles

Los Angeles, CA 90024

E. M. Romney

5 Laboratory of Tree-Ring Research University of Arizona Building \#58

Tucson, Arizona 85721

Dr. J. S. Dean

Dr. H. C. Fritts

Dr. L. J. Grauml ich

Dr. K. K. Hirschboeck

Dr. M. A. Stokes
Number of copies

1 Lawrence Livermore National Laboratory University of California P.0. Box 808

Livermore, CA 94550

L. D. Ramspott

1 Lockheed Environmental

Sciences and Technology Division 870 Kelly Johnson Drive Las Vegas, NV 89119

K. Snyder

5 Los Alamos National

Laboratory

P. 0. Box 1663

Los Alamos, NM 87545

T. E. Hakonson

J. W. Nyhan

F. Barnes

T. D. Oakley

Charles Harrington

1 Low-Level Radioactive Waste Program

Washington State Department of Ecology

Mai1 Stop PV-11

Olympia, WA 98504

E. M. Carlin

3 Low-Leve1 Radioactive Waste Program U.S. Geological Survey Water Resources Division 12201 Sunrise Valley Drive Reston, VA 22092
J. Fisher
P. Stevens
N. Trask 
WHC-EP-0569, Rev. 1

\section{DISTRIBUTION (cont)}

\section{Number of copies}

1 Mesa Verde Regional Research Center

P.0. Box 592

Dove Creek, Colorado 81324

Dr. D. A. Breternitz

1 Metcalf and Eddy Consultants, Inc. P.0. Box 24110

Santa Barbara, CA 93121

L. G. Everett

1 Nature Conservancy

P.0. Box 11486

Salt Lake City, Utah 84147

Dr. N. S. Van Pelt

2 New Mexico State University Agricultural Experiment Station

Box 3BF

Las Cruces, NM 88003

T. L. Jones

D. M. Briggs

1 NPS-Haleakala National Park

P.0. Box 369

Makawao, Maui, Hawaii 96768

Dr. L. L. Loope

3 Oak Ridge National Laboratory P.0. Box Y

Oak Ridge, TN 37830

J. 0. Blomeke

W. D. Burch

R. T. Jubin

1 Oak Ridge National Laboratory

P.0. Box 2008

Oak Ridge, TN 37831

G. Suter II
Number of copies

1 office of High-Level Nuclear Waste Management

Washington State Department

of Ecology

Olympia, WA 98504

\section{W. Brewer}

1 Paleo Reseach Laboratories 1990 South Garrison, Suite 5 Lakewood, CO 80227

Dr. L. S. Cummings

1 Paleontology and Stratigraphy Branch Geological Survey

U.S. Department of Interior

Box 25046, M.S. 919

Denver Federal Center

Denver, Colorado 80225

Dr. R. S. Thompson

4 Sandia National Laboratories P. O. Box 5800

Albuquerque, NM 87185

R. W. Lunch

E. Webb

R. Sandoval

Technical Library

1 Scripps Inst. of Oceanography A-0224, Univ of CA-San Diego La Jolla, California 920930224

\section{Cayan}

3 Social Science Center Desert Research Institute P.0. Box 60220

Reno, Nevada 60220

F. M. Nials

Dr. L. C. Pippin

Dr. P. E. Wigand 
WHC-EP-0569, Rev. 1

DISTRIBUTION (cont)

Number of copies

1 Southern California Edison

P.0. Box 800

Rosemead, CA 91770

A. A. Eiseewi

1 Tech Reps, Inc.

5000 Marbel Avenue NE

Albuquerque, NM 87110

P. N. Swift

1 Tree-Ring Laboratory

Lamont-Doherty Geol. Observ.

Palisades, New York 10964

Dr. G. C. Jacoby

1 University of California

Department of Plant and Soil Biology

Berkeley, CA 94720

R. K. Schulz

1 U.S. Army Engineer Waterways

Experiment Station

3909 Halls Ferry Road

Vicksburg, MS 39180-6199

R. D. Bennett

1 U.S. Bureau of Mines

Spokane Research Center

East Montgomery

Spokane, WA 99207

J. 01 son

2 U.S. Department of Energy

785 D0E P1ace

Idaho Falls, ID 83402

0. D. Markham

T. E. Reynolds
Number of copies

1 U.S. Department of Energy Savannah River Operations Office

P.0. Box A

Aiken, SC 29801

W. J. Brumley

1 U.S. Department of Energy San Francisco Operations

Office

1333 Broadway

Oakland, CA 94612

F. T. Fong

1 U.S. Department of Energy Oak Ridge Operations Office P.0. Box E

Oak Ridge, TN 37830

M. R. Jugan

1 U.S. Department of Energy West Valley Project Office P.0. Box 191 West Valley, NY 14171

E. Maestas

1 U.S. Department of Energy Albuquerque Operations Office P.0. Box 5400

Aibuquerque, NM 87185

M. Matthews

1 U.S. Department of Energy Morgantown Energy Technology Center

P.0. Box 880

Morgantown, WV 26505

R. C. Letcher 
WHC-EP-0569, Rev. 1

\section{DISTRIBUTION (cont)}

Number of copies

1 U.S. Department of Energy 625 Marion Street, N.E. Salem, OR 97310

L. Frank

2 U.S. Ecology

P. 0. Box 7246 9200 Shelbyville Rd

Suite 526

Louisville, KY 40207

\section{R. E. Sauer}

D. Lane

1 U.S. Environmental Protection Agency 1200 Sixth Avenue Seattle, WA 98101

C. Massimino

1 U.S. Environmental Protection Agency Office of Radiation Programs (ANR-458)

401 M Street, S.W.

Washington, D.C. 20460

S. Meyers

1 U.S. Geological Survey 345 Middlefield Road-MS 915 Menlo Park, California 94025

Dr. D. P. Adam

1 U.S. Geological Survey

1675 W. Anklam Road

Tucson, Arizona 85745

Dr. J. L. Betancort

1 U.S. Geological Survey Federal Center Mail Stop 413 Denver, CO 80225

E. P. Weeks
Number of copies

1 U.S. Geological Survey

M.S. 913

P.0. Box 25046

Denver Federal Center

Denver, CO 80225

J. Whiting

2 U.S. Geological Survey

12201 Sunrise Valley Drive Reston, VA 22092

G. A. Dinwiddie

I. J. Winograd

2 U.S. Nuclear Regulatory Commission

Division of Engineering

Safety

MS NL-005

Washington, DC 20555

E. O'Donnel1

T. J. Nicholson

1 Ward Center for Mountain

Research

8297 Overland Road

Ward, Colorado 80481

Dr. J. B. Benedict

2 Washington State Department of Ecology

Mail Stop PV-11

Olympia, WA 98504-8711

C. Cline

R. B. Hibbard

1 Washington State Department of Ecology

7601 W. Clearwater, Suite 102

Kennewick, WA 99336

N. U. Uzimblo 
WHC-EP-0569, Rev. 1

\section{DISTRIBUTION (cont)}

Number of copies

1 Waste Management Branch Office of Nuclear Regulatory Research

U.S. Nuclear Regulatory

Commission

Washington, DC 20555

M. Silberberg

4 West Valley Nuclear Service Company

P.0. Box 191

West Valley, NY 14171

R. R. Borisch

J. Buggy

J. M. Pope

R. A. Thomas

1 Western Regional Climate Center

Desert Research Institute

P.0. Box 60220

Reno, Nevada 89506-0220

Dr. K. Redmond

2 Westinghouse Idaho Nuclear

$\frac{\text { Co. }}{\text { P.0. Box } 4000}$

Idaho Falls, ID 83403

J. R. Berreth

D. A. Knecht

6 Westinghouse Savannah River Company

Aiken, SC 29801

R. G. Baxter

M. D. Boersma

J. G. Glasscock

J. R. Knight

S. McMullen

M. J. Plodinec

C. T. Randall
Number of copies

1 White Mesa Institute 295 N 100 W 19-3

Blanding, Utah 84511

W. Hurst

3 World Data Center - A For Paleoclimatology NOAA Paleoclimatology Program National Geophysical Data Center 325 Broadway E/GC, Boulder, CO 80303
J. Overpeck
D. Anderson
R. Webb

\section{ONSITE}

14 U.S. Department of Energy Richland Field office

G. J. Bracken

J. J. Broderick

A4-02

P. K. Clark

R. D. Freeburg

A7-27

M. J. Furman

R3-80

R. E. Gerton

A5-19

R3-80

J. D. Goodenough

A4-02

A. C. Harris

A5-19

J. M. Hennig

A5-19

R. D. Izatt

R3-80

C. R. Pasternak

A3-42

R. K. Stewart

A7-27

D. E. Trader

A5-19

DOE-RL Public Reading

Room1

A5-90

H2-53

5 Environmental Protection

Agency - Hanford Project Office

P. R. Beaver

B5-01

D. A. Faulk

B5-01

L. E. Gadbo is

B5-01

P. S. Innis

B5-01

D. R. Sherwood 


\section{DISTRIBUTION (cont)}

\section{Number of copies}

35 Pacific Northwest Laboratory

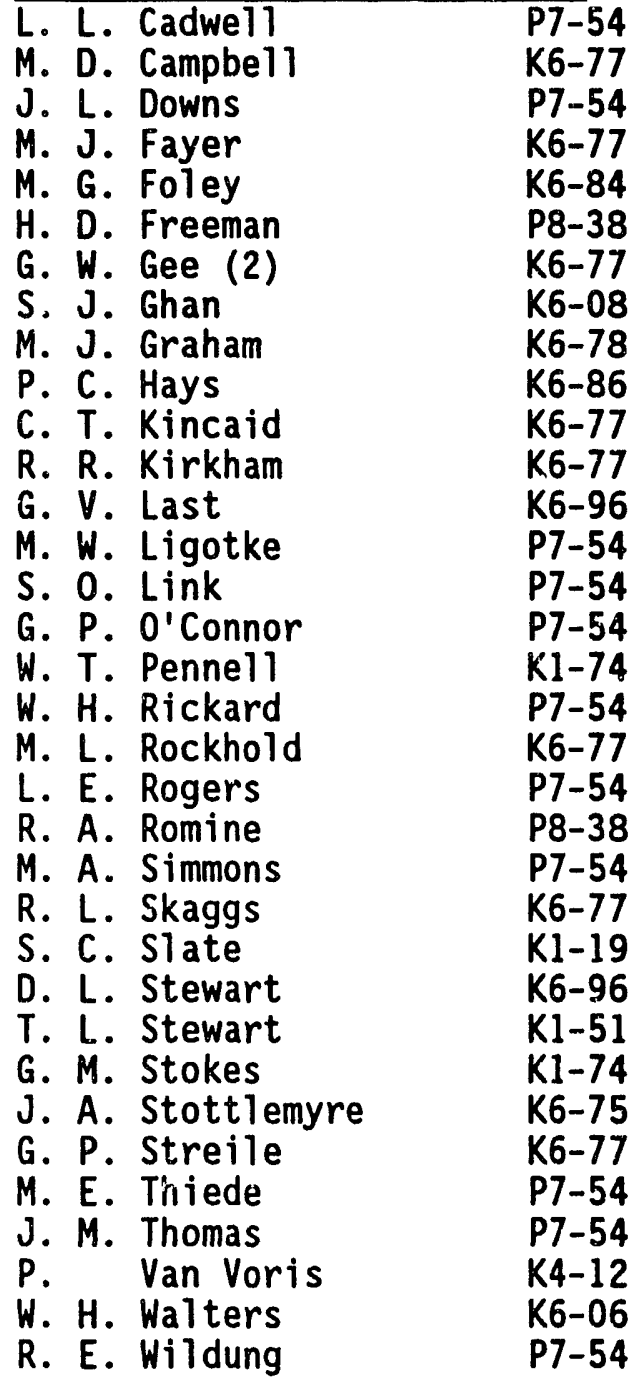

2 U.S. Army Corps of Enqineers

W. L. Greenwald A5-20

J. H. Jacobson

A5-20

74 Westinghouse Hanford Company

M. R. Adams

H6-01

W. C. Alaconis

H6-28

H. Babad

$\mathrm{R} 2-78$

J. D. Berger

R. J. Bliss

LO-18

D. J. Brown

B3-04

J. A. Caggiano

B4-63

H6-06

J. W. Cammann
R. A. Carison

D. L. Crockford

J. I. Dearing

H. D. Downey

K. R. Fecht

C. J. Geier

R. L. Gilchrist

V. W. Hall

W. F. Heine

F. N. Hodges

G. W. Jackson

V. G. Johnson

A. R. Johnson

K. N. Jordan

C. J. Kemp

M. K. Korenko

D. S. Landeen

M. J. Lauterbach

A. G. Law

R. E. Lerch

H. E. McGuire

R. M. Mitchell

D. R. Myers

D. J. Newl and

K. L. Petersen (15)

S. J. Phillips

R. W. Fowell

S. P. Reidel

R. C. Roos

M. R. Sackschewsky

K. R. Simpson

W. A. Skelly

J. C. Sonnichsen

L. C. Stegen

A. M. Tallman

J. A. Voogd

$S$. Weiss

4. R. Wing (2)

. M. Wintczak

D. D. (Don) Wodrich

R. D. Wojtasek

D. E. Wood

J. G. Wool ard

Central Files (3)

Environmental Data

Management Center (2) H6-07

Publishing Services (3) L8-04
H6-03

H4-14

H5-72

H6-27

H6-06

H6-21

L5-63

B1-59

B3-63

H6-06

H6-21

H6-06

H6-30

H6-28

H4- 14

B3-08

H4-14

H6-01

H6-06

B3-63

B3-63

H6-04

H4-14

B1-58

H4- 14

H4- 14

H4- 14

H6-06

H6-04

H4-14

H6-06

H6-03

H4- 14

S4-58

H5-60

R4-03

H6-02

H4-14

H6-27

B1-59

H6-27

HO-33

H6-05

L8-04 

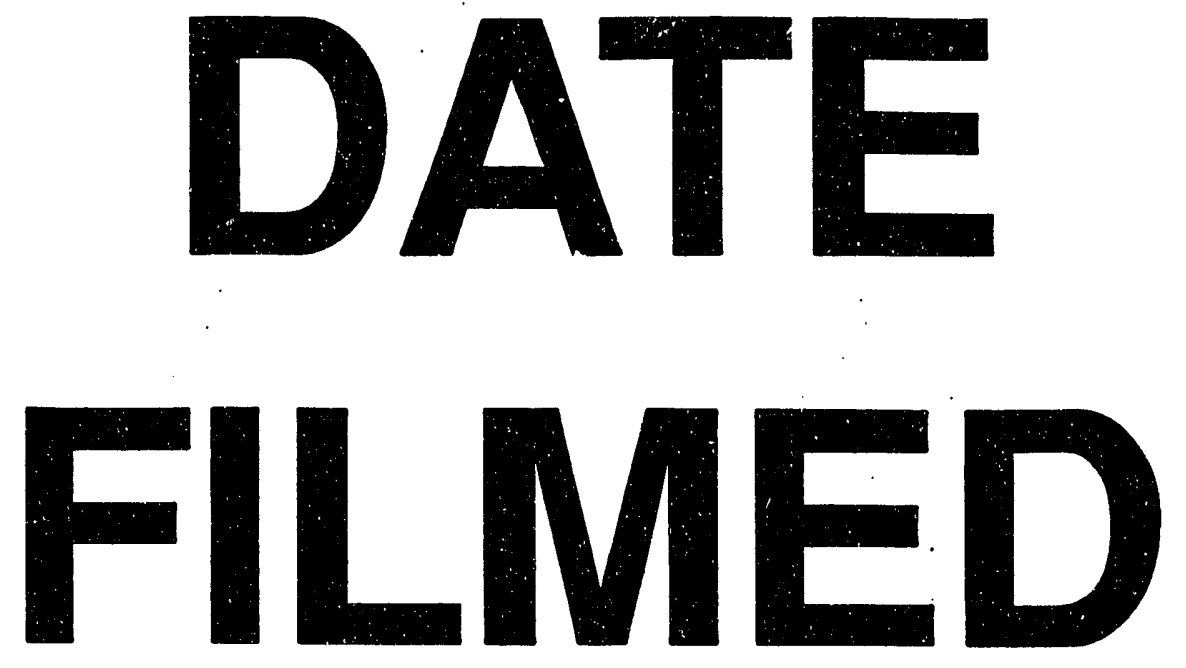

$8 / 17 / 93$
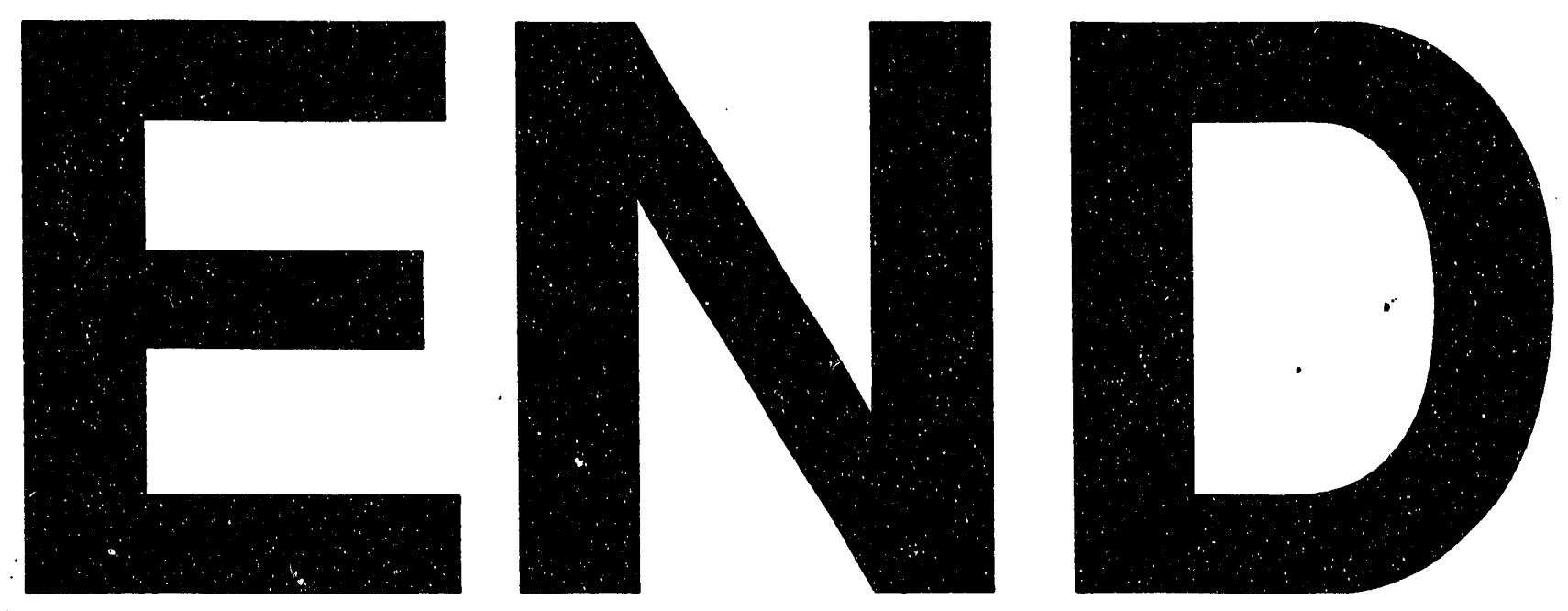


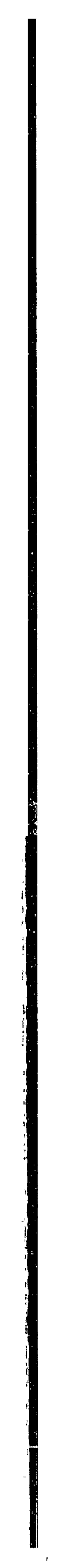

